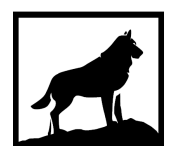

Michigan Technological

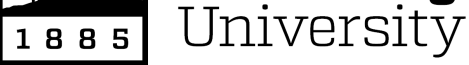

Michigan Technological University Digital Commons @ Michigan Tech

\title{
TOWARDS EFFICIENT WATER TREATMENT: MECHANISM OF COLLOIDAL FOULING OF ULTRAFILTRATION MEMBRANES
}

Ikenna Henry Ozofor

Michigan Technological University, iozofor@mtu.edu

Copyright 2020 Ikenna Henry Ozofor

\section{Recommended Citation}

Ozofor, Ikenna Henry, "TOWARDS EFFICIENT WATER TREATMENT: MECHANISM OF COLLOIDAL FOULING OF ULTRAFILTRATION MEMBRANES", Open Access Master's Thesis, Michigan Technological University, 2020.

https://doi.org/10.37099/mtu.dc.etdr/1019

Follow this and additional works at: https://digitalcommons.mtu.edu/etdr

Part of the Environmental Engineering Commons, Membrane Science Commons, and the Transport Phenomena Commons 
By

Ikenna H. Ozofor

\begin{abstract}
A THESIS
Submitted in partial fulfillment of the requirements for the degree of MASTER OF SCIENCE

In Chemical Engineering
\end{abstract}

MICHIGAN TECHNOLOGICAL UNIVERSITY

2020

(C) 2020 Ikenna H. Ozofor 
This thesis has been approved in partial fulfillment of the requirements for the Degree of MASTER OF SCIENCE in Chemical Engineering.

Department of Chemical Engineering

\author{
Thesis Co-advisor: $\quad$ Dr. Timothy Eisele. \\ Thesis Co-Advisor: $\quad$ Dr. Andre Da Costa \\ Committee Member: Dr. Gerard Caneba. \\ Committee Member: $\quad$ Dr. David Shonnard. \\ Department Chair: Dr. Pradeep Agrawal.
}




\section{Table of Contents}

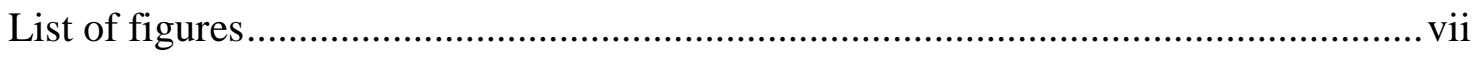

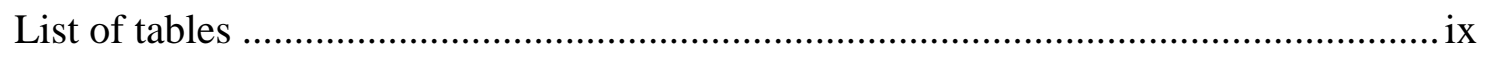

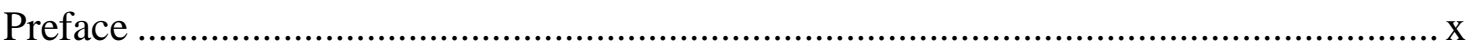

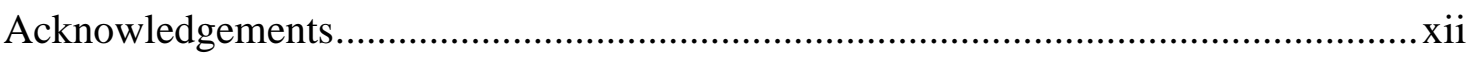

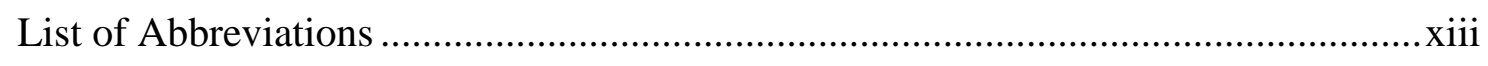

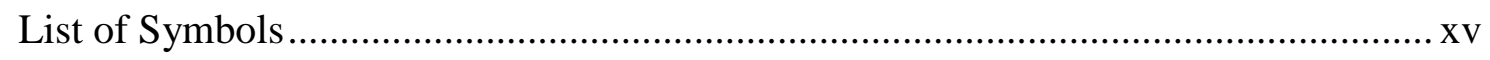

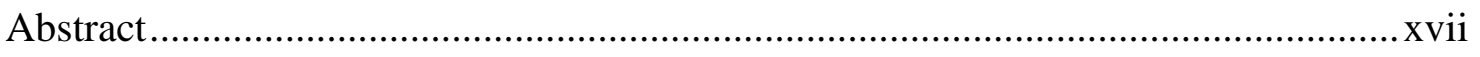

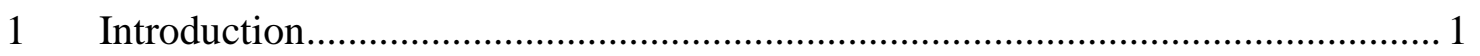

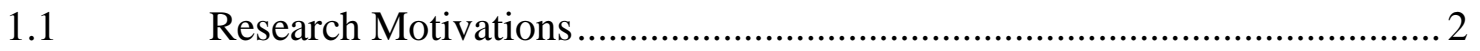

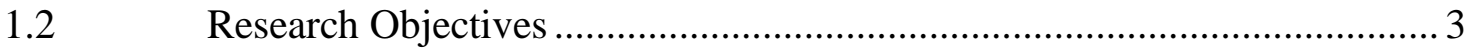

1.2.1 General Objective …....................................................... 3

1.2.2 Specific Objectives ........................................................... 3

2 Membrane Separation Background and Fouling .............................................. 4

2.1 Transport Equation for Flow Through a Membrane ..................................5

2.1.1 Assumptions ................................................................... 7

2.1.2 Continuation of Derivation .................................................... 7

2.2 Membrane and Feed Properties............................................................ 10

2.2.1 Membrane Properties ......................................................... 10

2.2.1.1 Membrane Pore Size ................................................ 10

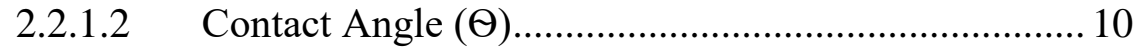

2.2.1.3 Flux ................................................................... 11

2.2.1.4 Rejection $(\%)$...................................................... 11

2.2.2 Feed Parameters in Water Treatment ......................................... 11

2.2.2.1 Turbidity ............................................................ 12

2.2.2.2 Total Organic Carbon (TOC), Chemical Oxygen

Demand (COD) and 5-day Biochemical Oxygen Demand (BOD5)

12

2.2.2.3 Particulate Load/Concentration ............................... 12

2.2.2.4 Total Suspended Solids (TSS) ............................... 12

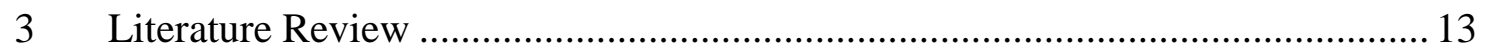

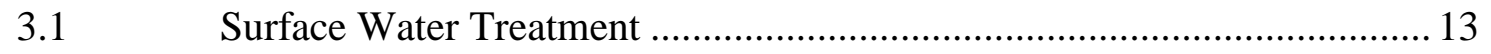

3.1.1 Conventional and Membrane Treatment Processes...................... 13 
3.1.2 Issues with Conventional and Membrane Treatment Systems ..... 15

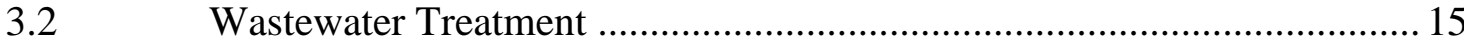

3.2.1 MBR System and its Edge over Conventional Activated Sludge

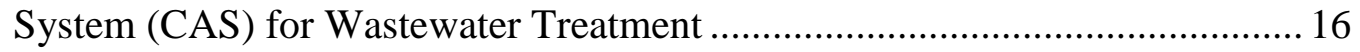

3.2.2 The MBR Landscape ....................................................... 17

3.2.2.1 Readily Biodegradable Feed ................................... 17

3.2.2.1.1 Conventional Aerobic MBR and

Anaerobic MBR ......................................... 17

3.2.2.2 Problem Organic Feeds........................................ 18

3.2.2.2.1 MBR with activated carbon

(MBR+AC) 18

3.2.2.2.2 High retention MBRs (HRMBR)

19

3.2.2.2.3 Biofilm MBR ........................... 20

3.2.2.3 Hostile Environment Feeds.................................... 20

3.2.2.3.1 Extractive MBR (EMBR) ..........20

3.2.3 Challenges with CAS and MBR Systems for Wastewater

Treatment and Reclamation ....................................................................... 21

3.2.3.1 Challenges with CAS System ................................. 21

3.2.3.2 Challenges with CAS System ................................. 21

3.2.4 Highlights of Recent Fouling Control Strategy for Wastewater

Treatment using MBR systems........................................................... 21

3.2.4.1 Operational/Physical Approach .............................. 21

3.2.4.2 Chemical Approach ............................................ 22

3.2.4.3 Electrochemical Approach..................................... 22

3.2.4.4 Membrane Cleaning............................................... 22

3.2.5 Energy Consumption in MBR and its Reduction ...................... 23

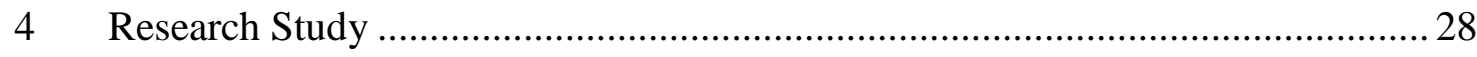

Variables Investigated and Rationales ............................................... 28

$5 \quad$ Methodology

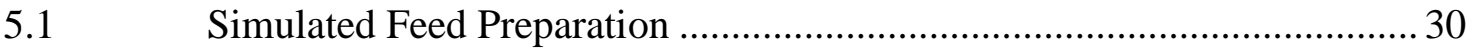

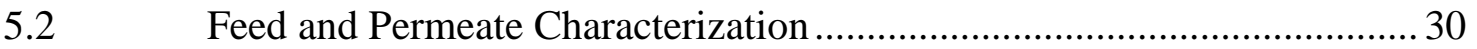

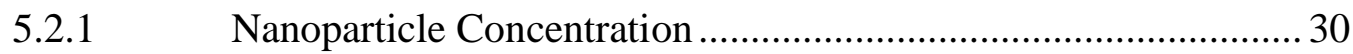

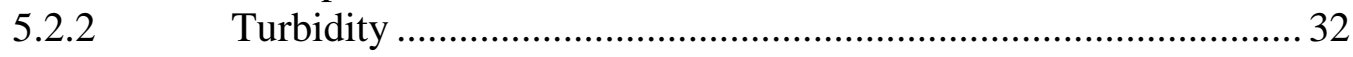

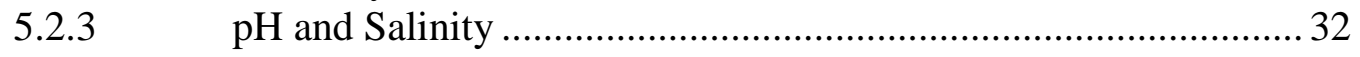

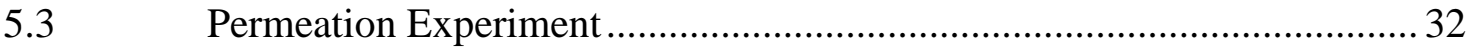

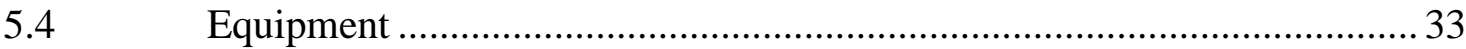

5.5 Experimental Data Description by Blocking Law for Effect of

Nanoparticle Concentration ....................................................................... 33 


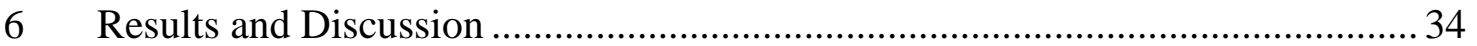

6.1 Effect of pH on Colloidal Fouling ………….......................................... 34

6.2 Effect of Salinity on Colloidal Fouling .......................................................36

6.2.1 Can Dense Cake Layer Formed on UF Membranes by the Silica

Colloids Reject NaCl Salt? ............................................................................ 38

6.3 Influence of Nanoparticle Concentration and Membrane Molecular Weight Cutoff $\quad 41$

6.3.1 Experimental Results 41

6.3.2 Description by Blocking Laws ................................................... 51

$7 \quad$ Conclusions and Recommendations for Future Work ………………………......53

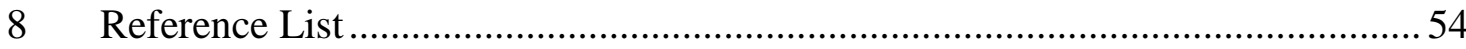

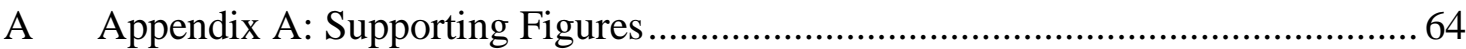

A.1 Absorbance-Concentration Calibration Report I........................................64

A.2 Absorbance-Concentration Calibration Report II .......................................67

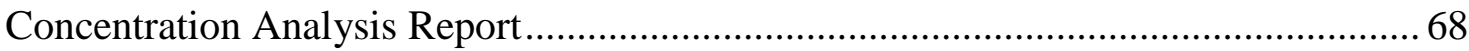

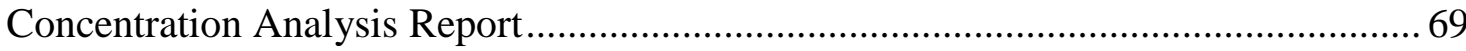

A.3 Conductivity-Salinity Calibration Curve ………………………............. 71

A.4 Data Description by Blocking Laws: Effect of Nanoparticle Concentration at 20psi 72

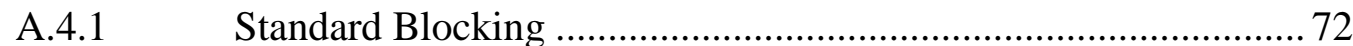

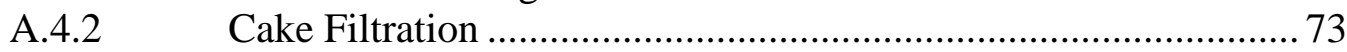

A.4.3 Intermediate Blocking ………………………........................ 74

A.4.4 Complete Blocking ................................................................... 75

A.5 Data Description by Blocking Law: Effect of Nanoparticle Concentration at $50 \mathrm{psi} \quad 76$

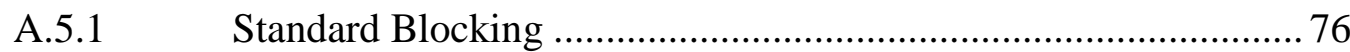

A.5.2 Cake Filtration ....................................................................... 77

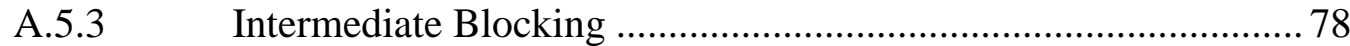

A.5.4 Complete Blocking .................................................................... 79

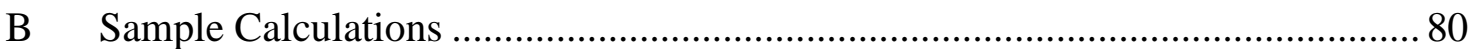

B.1 Calculation used for feed sample preparation by dilution.......................... 80

B.2 Calculation used for description by blocking laws: effect of nanoparticle concentration 


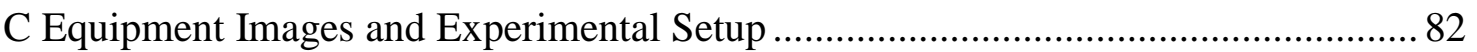

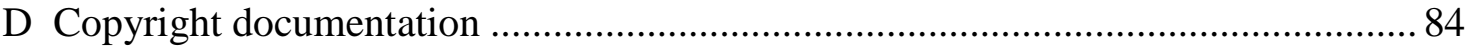




\section{List of figures}

Figure 2.1: Simple Illustration of a Membrane Separation Process ............................. 4

Figure 2.2: Pictorial Illustration of Different Fouling Mechanisms ........................... 5

Figure 2.3: Mathematical Summary of Resistance in Series Model Derivation ............. 6

Figure 2.4:Cylindrical Pore Channel ................................................................... 7

Figure 2.5: Contact Angle and Inherent Physical Implication [23] ........................... 11

Figure 3.1: Conventional Municipal Water Treatment Scheme I............................... 13

Figure 3.2:Conventional Municipal Water Treatment Scheme II. ............................. 14

Figure 3.3: Typical Membrane System for Surface Water Treatment ....................... 15

Figure 5.1:UV-vis spectrophotometric scan of colloidal silica stock solution .............. 31

Figure 6.1:Flux Plots for Effect of Feed pH....................................................... 35

Figure 6.2:Effect of Feed pH on Silica Nanoparticle Rejection................................... 36

Figure 6.3:Flux Plots for Effect of Feed Salinity. .................................................. 40

Figure 6.4:Effect of Feed Salinity on Silica Nanoparticle Rejection and Water

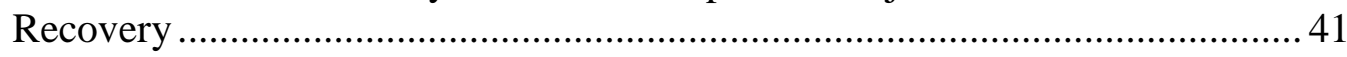

Figure 6.5:Flux Plots for Effect of Concentration at 20 psi on 1kDa Membrane ........ 42

Figure 6.6:Rejection and Recovery Plots for Effect of Concentration at 20 psi on 1kDa

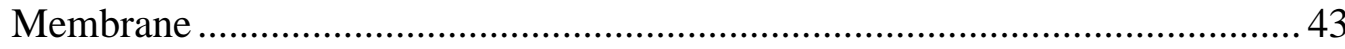

Figure 6.7:Flux Plots for Effect of Concentration at 20 psi on 10kDa Membrane ...... 44

Figure 6.8:Rejection and Recovery Plots for Effect of Concentration at 20 psi on

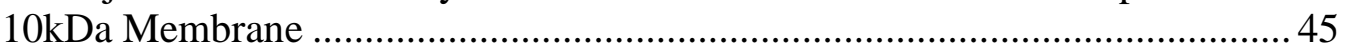

Figure 6.9:Flux Plots for Effect of Concentration at 50 psi on 1kDa Membrane ........ 47

Figure 6.10:Rejection and Recovery Plots for Effect of Concentration at 50 psi on

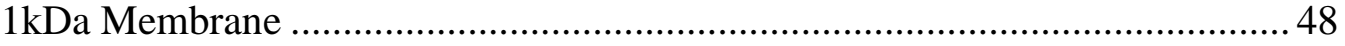

Figure 6.11:Flux Plots for Effect of Concentration at 50 psi on 10KDa Membrane..... 50 
Figure 6.12:Rejection and Recovery Plots for Effect of Concentration at 50 psi on $10 \mathrm{kDa}$ Membrane

Figure 6.13:Plot of t/V vs V for Effect of Nanoparticle Concentration. 52 


\section{List of tables}

Table 3-1:Energy Reduction Strategies, Results and Associated Scale ...................... 26

Table 4-1: Values for Contaminants in Water Sources and Regulations ...................... 28

Table 5-1:experimental design for effect of nanoparticle concentration ..................... 31

Table 5-2:Variables Investigated and Equipment Used ..................................... 33 


\section{Preface}

At the time this Master's thesis is written, materials in some sections of this thesis are part of manuscripts under preparation. Chapter 3 section 2, (that is 3.2) of this thesis is part of a review article being prepared to be published in a scientific journal while materials in chapters 4- 6 of this thesis are part of another work in a data-driven manuscript also being prepared for publication in a scientific journal.

\section{Authors' details for the review manuscript under preparation are as follows (which section 3.2 of this Thesis is part of):}

Andre R. Da Costa ${ }^{\mathrm{a},}$, Ikenna H. Ozofor ${ }^{\mathrm{a}}$, Daniel G. Kulas ${ }^{\mathrm{a}}$, Pierre Le Clech $^{\mathrm{b}}$ and Anthony G. Fane ${ }^{\mathrm{b}}$

a Department of Chemical Engineering, Michigan Technological University, Houghton, MI 49931, USA

${ }^{b}$ UNESCO Centre for Membrane Science and Technology, School of Chemical Engineering, University of New South Wales, Sydney, NSW 2052, Australia

\section{Author Contributions}

Da Costa Conceived research topic, collected articles for review, reviewed and edited the manuscript, and will be responsible for manuscript submission to Scientific Journal

Ozofor Modified review scope, collected articles for review, wrote the manuscript draft, constructed plots for results collection, and analyzed and interpreted data

Kulas Involved in writing some sections of the manuscript, analyzed and interpreted data, and reviewed the draft manuscript

Le Clech Modified and restructured review scope, analyzed and interpreted data, reviewed and edited the manuscript

Fane $\quad$ Modified and restructured review scope, analyzed and interpreted data, reviewed and edited the manuscript 


\title{
Authors' details for the data-driven manuscript under preparation are as follows (which chapters 4- 6 of this Thesis are part of):
}

\author{
Ikenna H. Ozofor ${ }^{\mathrm{a}}$, Andre R. Da Costa ${ }^{\mathrm{a}}$, Audra N. Morse ${ }^{\mathrm{b}}$ \\ aDepartment of Chemical Engineering, Michigan Technological University, Houghton, \\ MI 49931, USA \\ ${ }^{b}$ Department of Civil and Environmental Engineering, Michigan Technological \\ University, Houghton, MI 49931, USA \\ Author Contributions
}

Ozofor Conceived research topic, collected experimental data, constructed plots for results collection, analyzed and interpreted data, and wrote the paper

Da Costa Conceived research topic, analyzed and interpreted data, reviewed paper and will be responsible for manuscript submission to Scientific Journal

Morse Analyzed and interpreted data, reviewed paper and edited the paper. 


\section{Acknowledgements}

My sincere gratitude to the Department of Chemical Engineering, Michigan Technological University for the funding support as a Research and Teaching Assistant.

I am also grateful to my advisors, Dr. Timothy Eisele and Dr. Andre Da Costa for their ever-guiding comments and suggestions throughout the period of this research study. I am also privileged to have Dr. Caneba and Dr. Shonnard serve on my committee under the guidance of the departmental chair, Dr. Agrawal.

My special acknowledgment to Dr. Andre Da Costa, Dr. Tomas Co, late Dr. Dickson Ozokwelu, Dr. Chukwudi Menkiti and Dr, Joseph Nwabanne for their reliable support and professional guidance.

I would also like to thank my research group - Daniel Kulas, Ananya, Sam Jacobs, Noah Williams, Jennifer Wanink and Zachary Olson for their assistance in some of the experiments and insightful suggestions.

My unreserved acknowledgements to Dr. R.G Ong, Alexis and Taana for always taking out time to address my unending questions.

To my parents - Boniface and Celestina Ozofor, and siblings - Nonso, Chidebere, Chinaemere, Ifunanya and Izuchukwu, for showing me irreplaceable and invaluable love and care, I am grateful!

And most importantly to the Almighty God for the gift of life and grace. 


\section{List of Abbreviations}

A/O-MBR anoxic/oxic membrane bioreactor (A/O-MBR)

BEMBR biphasic extractive membrane bioreactor

$\mathrm{BOD}_{5} \quad$ 5-day biochemical oxygen demand

CAS conventional activated sludge

CIP cleaning-in-place

COP cleaning-out-of-place

Da dalton

DBP disinfectant byproduct

DC direct current

EDTA ethylenediaminetetraacetic acid

EMBR extractive membrane bioreactor

FOMBR forward-osmosis membrane bioreactor

GAC granular activated carbon

HAA haloacetic acid

HG-MBR hybrid growth membrane bioreactor

HRMBR high retention membrane reactor

HRT hydraulic retention time

LRV $\quad$ log removal value

$\mathrm{MBR}+\mathrm{AC} \quad$ membrane bioreactor + activated carbon

MBR-NF/RO membrane bioreactor - nanofiltration/reverse osmosis

MBR -UV/GAC membrane bioreactor (MBR), ultraviolet disinfection unit and a granular activated carbon (GAC) column

MCBR membrane bioreactor with coagulation unit 


\begin{tabular}{|c|c|}
\hline MCL & maximum contaminant limit \\
\hline MDBR & membrane distillation bioreactor \\
\hline MF & microfiltration \\
\hline MLSS & mixed liquor suspended solids \\
\hline MP & microplastics \\
\hline MWCO & molecular weight cutoff \\
\hline $\mathrm{NaOCl}$ & sodium hypochlorite \\
\hline $\mathrm{N}_{\mathrm{E}} \mathrm{R}$ & no explicit regulation \\
\hline NF-MBR & nanofiltration membrane bioreactor \\
\hline NOM & natural organic matter \\
\hline NTU & nephelometric turbidity unit \\
\hline ORT & organic retention time \\
\hline PAC & powdered activated carbon \\
\hline PDA & polydopamine \\
\hline PES & polyether sulfone \\
\hline SED & specific energy demand \\
\hline THM & trihalomethanes \\
\hline TMP & transmembrane pressure \\
\hline TOC & total organic carbon \\
\hline TSS & total suspended solids \\
\hline UF & ultrafiltration \\
\hline UMBR & underground membrane bioreactor \\
\hline
\end{tabular}




\section{List of Symbols ${ }^{1}$}

$\mathrm{C}_{\mathrm{f}}$ Concentration of target specie in the feed

$\mathrm{C}_{\mathrm{p}} \quad$ Concentration of target specie in the permeate

$\varepsilon \quad$ Porosity

J Permeate flux

$\mathrm{J}^{*} \quad$ Flux through cylindrical channel

$\mathrm{N}_{\mathrm{tp}} \quad$ Total number of particles

$\mathrm{V}_{\mathrm{ipm}}$ Minimum interparticle volume

$\mathrm{V}_{\text {tip }}$ Total interparticle pore volume

$\mathrm{V}_{\mathrm{tp}} \quad$ Total particle volume

p Pressure, Psi

$\mathcal{P} \quad$ Modified pressure

$\Delta P \quad$ Transmembrane pressure

Q Volumetric flowrate,

Rc Resistance of cake deposited on the membrane

$\mathrm{R}_{\mathrm{f}} \quad$ Resistance caused by the foulants

$\mathrm{R}_{\mathrm{m}} \quad$ Resistance of pristine membrane

$\mathrm{R}_{\mathrm{t}} \quad$ Total resistance to hydraulic flow

$\mathrm{R}_{\text {irr }}$ Irreversible resistance

$\mathrm{R}_{\text {rev }}$ Reversible resistance

$\mathrm{r}_{\mathrm{p}}, \quad$ Pore radius,

${ }^{1}$ Corresponding units of symbols are listed where they appear herein 
$\tau \quad$ Tortuosity

$\mu \quad$ Dynamic solution viscosity

v Flow velocity

$\mathrm{v}_{\mathrm{z}} \quad$ Velocity of flow along $\mathrm{z}$-axis 


\section{Abstract}

This research study first reviewed challenges of conventional and membrane separation systems for water treatment. Though membrane separation systems appeared superior to the conventional counterparts for water and wastewater treatment, wider applications of membrane systems have been limited by some factors, most notably is membrane fouling. Experimental studies were therefore conducted to achieve the goal of this research, which is to investigate how feed properties affect fouling of ultrafiltration (UF) membranes by colloids.

Feed salinity, $\mathrm{pH}$, and nanoparticle concentration were the variables studied to unravel how different UF membranes are fouled by model silica colloids (with average diameter of $25 \mathrm{~nm}$ ). These variables were varied across levels that have practical importance. Results obtained show that ultrafiltration gave high separation efficiency to the nanoparticles with $\geq 90 \%$ rejection in most cases. Electrostatic interactions in the system impacted by changes in feed $\mathrm{pH}$ and salinity were found to affect the ultrafiltration of the model water samples. It was also observed that increase in silica colloid concentration increases rate of permeate flux decline for all the membranes used. When experimental data were fitted with the blocking laws, it was observed that no single law adequately described all the experimental results. However, cake filtration model sufficiently described most of the results. 


\section{Introduction}

Water is one of the most abundant resources on earth yet a surprising fraction of the world's population lacks to access to clean water. Currently, $25 \%$ of the world's population is vulnerable to fecal contaminated water $[1,2]$ and it is predicted that by 2030, half of the global population will face water scarcity [3]. The global water crisis is due to rapid population growth without commensurate provision of suitable water, uneven water reserve and consumption across the globe [4, 5] and climate change [6]. Expectedly, chemical and biological contaminants have prompted serious concerns in all fronts of human endeavors [7, 8] because they pose severe health hazards. For example, heavy metal contaminants in water have been confirmed to cause serious issues when discharged without treatment [7,9] or when the contaminants are not effectively removed to meet regulated discharge limit [7]. Also, bio-contaminated water is unsafe because they contain either any, some or all toxic substances, viruses and bacteria that cause several human diseases. In this era of water scarcity, the reclamation of used water (commonly known as wastewater) has received significant attention and patronage. Also, because the boundaries of surface water are unconfined easy contamination of these reservoir is very likely as agricultural leachates, overflow of municipal drainage and rain runoff could easily transport potential contaminants from different sources and dump them into the water bodies. Broadly, water can be used for either municipal applications or for industrial applications. Surface water (seawater and freshwater), ground water and wastewater are all sources of municipal water supply. For regions that have accessible ground aquifer, ground water serves as the source reservoir. Water scarcity and environmental regulations have recently triggered the use of municipal wastewater as source of water supply. Also, seawater and brackish water desalination which used to be the most important water source to only arid middle east nations (due to scarcity of surface and ground water) have been consistently and recently patronized by both industrialized and developing nations to augment water supply [10]. Composition and volume of underground and surface water bodies vary from place to place, implying the selection of a given treatment/purification technology is key if clean and safe water is to be produced for a given application.

Over the years, various membrane technologies have witnessed rapid development and applications for treatment of all kinds of water (seawater, surface water, underground water and more recently wastewater). For example, among all the desalination technologies available (like multi-effect distillation, multistage flash, electrodialysis, etc.) reverse osmosis RO (a membrane technology) has emerged as the most important process for desalination thereby accounting for more than $50 \%$ world desalination application [10]. Also, wastewater reuse that was seriously limited due to fouling has witnessed rapid growth in applications as ultrafiltration(UF), microfiltration(MF) or membrane bioreactor(MBR) as pretreatment step deliver purer product with much less fouling and chemical usage for further processing than conventional wastewater treatment system [11]. Unlike conventional technology that combines chemical dosing and media filtration for pretreatment, membrane systems using UF/MF membranes rely 
on size exclusion to pretreat surface water of various load thereby ensuring high flux, low membrane replacement rate and less disinfection for the RO polishing step [11]. While membrane technologies have been widely applied both as pretreatment and polishing steps for various water applications, it is important to acknowledge that conventional systems are still in use for certain applications as technical difficulties (especially limited knowledge on membrane fouling mechanism) pose serious hindrance to membrane application in some cases.

Having summarized why and where membrane technologies are applied in water treatment, and having identified membrane fouling as one of the major drawbacks of these processes, this research is focused on investigating how different feed properties affect the fouling of UF membranes by colloids.

\subsection{Research Motivations}

A quarter of the world's population (about 2 billion people) lacks access to clean potable water and hence are vulnerable to fecal contaminated water $[1,2]$. This unsafe water contains viruses, bacteria, etc. that cause several human diseases. Particulates and microorganisms are arguably the worst contaminants in water because they pose severe health hazard. For example, it is estimated that about $50 \%$ of the people in developing nations tests positive to at least one of the six main diseases associated with inadequate water supply and purity (Diarrhea, Ascaris, Dracunculiasis, Hookworm, Schistosomiasis and Trachoma) [12]. And diarrhea, a disease caused by pathogenic microbes in water, has been reported to be among the top two child-killer disease [1, 13].

Water-borne disease resulting from pathogens is also a big issue in developed countries. For example, it was the 1993 outbreak of cryptosporidiosis in Milwaukee, Wisconsin, USA which killed over 100 people (infecting about 400,000 people) that triggered both proactive and reactive approaches in the US drinking-water industry [14]. Also, about 27 outbreaks of pathogenic bacteria have occurred in the UK from 1991 - 2000 infecting many people [15]. Also, the devastating health effects of cyanobacteria both in and off freshwater bodies have equally been documented [16].

In addition to problems caused by pathogenic microorganisms in water, the volume of non-biodegradable particulates in water bodies has buzzed an urgent alarm for remediation. Contamination of these water bodies by particulates (especially microplastics (MP)) is no longer in doubt as their presence in freshwater bodies have been widely reported. For example, the MP composition of Los Angeles midstream river is estimated to be about 12,000 items $/ \mathrm{m}^{3}$ and it discharges nothing less than a billion MP items per day into the Pacific ocean [17]

Aside the health risk associated with particulate-contaminated water, the World Bank estimated the economic loss resulting from scarcity of safe water and sanitation to be 
US $\$ 250$ billion per annum $[1,18]$. Sadly, in addition to the increase in pollution of global surface water, the amount of municipal wastewater generated per capita per day is alarming. Hence the essence of municipal water treatment systems. Conventional water treatment systems involve the use of significant amount of chemicals, a lot of treatment steps and provide water of limited purity. To address these gaps, treatment systems that utilize little or no chemicals while requiring less footprint-membrane systems are preferred. Though membrane systems meet these criteria, membrane fouling is still a major drawback for membrane separation processes. Hence this research is centered on investigating how different feed properties affect colloidal fouling of ultrafiltration membranes.

\subsection{Research Objectives}

\subsubsection{General Objective}

The goal of this master's research project is to investigate the performance of a conservative dead-end ultrafiltration system in treating colloidal feed samples of different compositions at different conditions. The dead-end configuration is a membrane system arrangement where the fluid being treated flows perpendicular to selective surface of the membrane with the retained species accumulating on the membrane surface. Performance indices to be used include permeate flux behavior with time, membrane fouling and nanoparticle rejection.

\subsubsection{Specific Objectives}

This master's thesis will be addressing the following research questions:

I. Elucidate on the effects of nanoparticle concentration and membrane MWCO on fouling of UF membranes.

II. Apply blocking filtration laws to describe the experimental results obtained from the study on effect of nanoparticle concentration.

III. Investigate how UF membranes are affected by electrostatic interactions and feed chemistry corresponding to varying feed $\mathrm{pH}$ and salinity, respectively. 


\section{Membrane Separation Background and Fouling}

As shown in figure 2.1, a typical membrane separation process allows preferential transport of a given solute(s) while retaining other species under pressure differential driving force. Membrane technologies have unique advantages of low footprint, modular system design and less chemical usage.

Membrane technologies used in water treatment for removal of particulates and microorganism are MF and UF. Particulates and microorganisms of few microns (and higher sizes) are treated with MF while viruses and other particles in macromolecular range $(\sim 1 \mathrm{~nm}-100 \mathrm{~nm})$ are rejected by UF. Depending on the particulate load of wastewater, either MF or UF membranes are used in a membrane bioreactor (MBR) system, a system which combines both the physical separation abilities of membranes and bio-decomposition of contaminants in water.

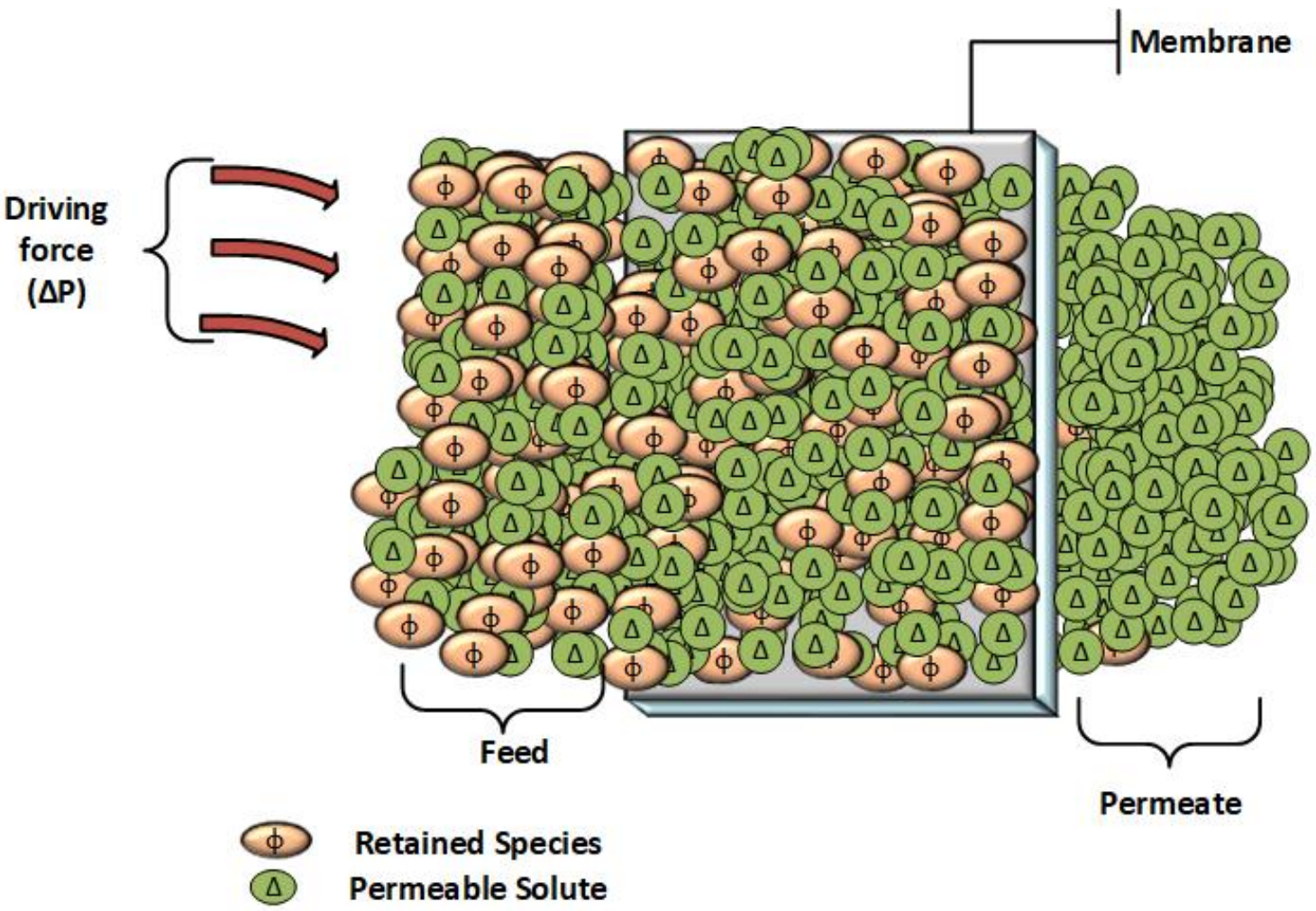

Figure 2.1: Simple Illustration of a Membrane Separation Process

During filtration, permeate flux decreases with time due to resistances offered by the membrane, particles deposited on and within the membrane, and interferences caused by other contaminants. This decline in flux is a direct consequence of membrane fouling. Membrane fouling can be within the pores of the membrane (internal fouling) 
or on the surface of the membrane (surface fouling). Depending on foulant size relative to those of membrane pores, and their electrostatic interactions, foulants can be adsorbed or deposited within the pores of membranes or even deposited as cake layers on the surface of the membrane (see figure 2.2 below).

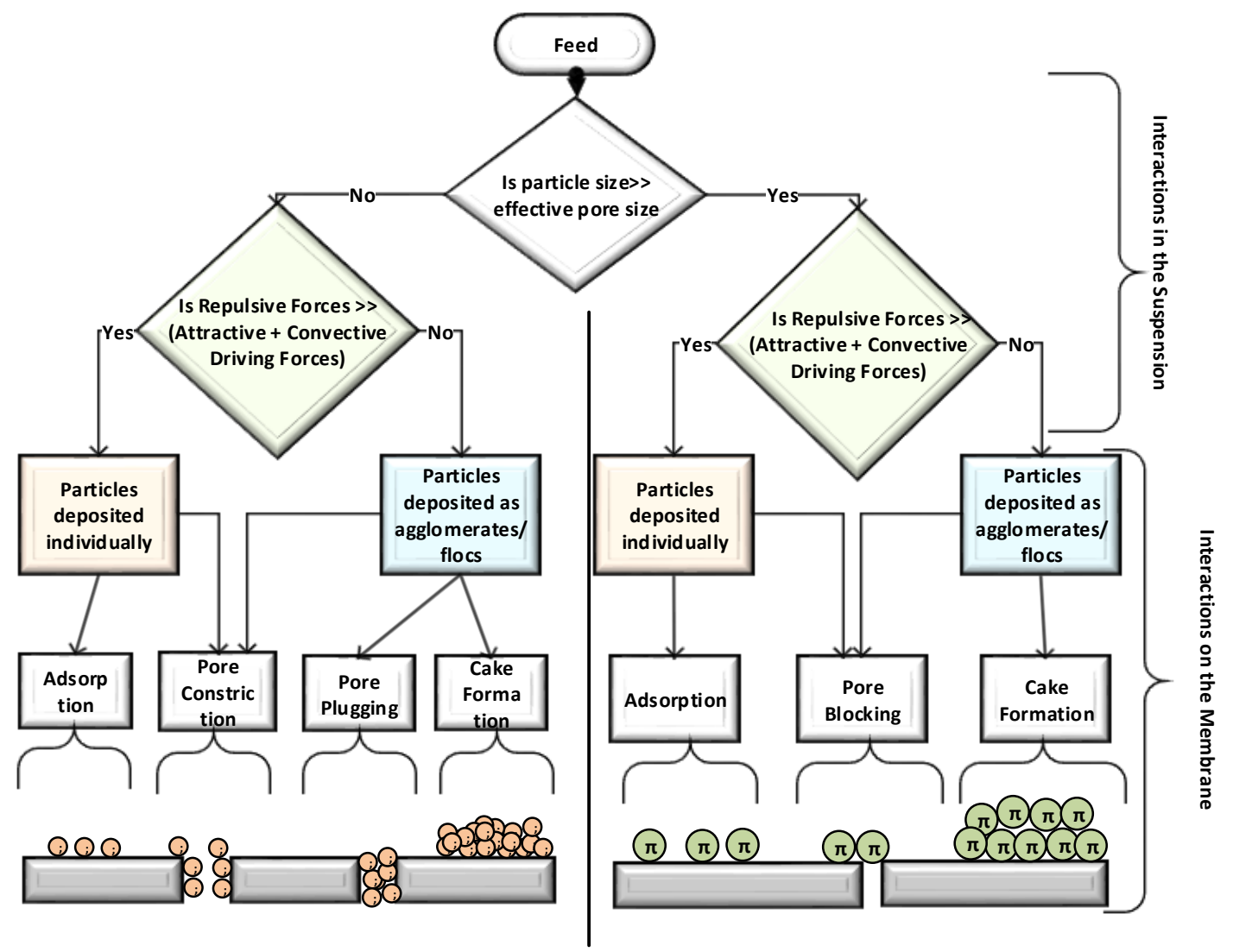

Figure 2.2: Pictorial Illustration of Different Fouling Mechanisms

\subsection{Transport Equation for Flow Through a Membrane}

The respective contributions of membrane, cake layer and other foulants to hydraulic resistance can be adequately determined using the resistance in series model:

$$
J=\frac{\Delta P}{\mu\left(R_{m}+R_{f}\right)}=\frac{\Delta P}{\mu R_{t}}
$$

Where $\mathrm{J}$ is permeate flux at any time $\mathrm{t}, \Delta P$ is the transmembrane pressure, $\mathrm{R}_{\mathrm{t}}$, total resistance to flow through a given membrane is expressed as resistance in series [19] (shown below):

$\mathrm{Rt}=\mathrm{Rm}+\mathrm{Rf}=\mathrm{Rm}+\mathrm{Rrev}+\mathrm{Rirr}$

Where $\mathrm{Rf}$ comprises of resistances resulting from all foulants in the fluid, which are divided into 
reversible resistance (Rrev) and irreversible resistance (Rirr). Figure 2.3 summarizes the mathematical steps for obtaining this model, and its comprehensive derivation can be found in this section

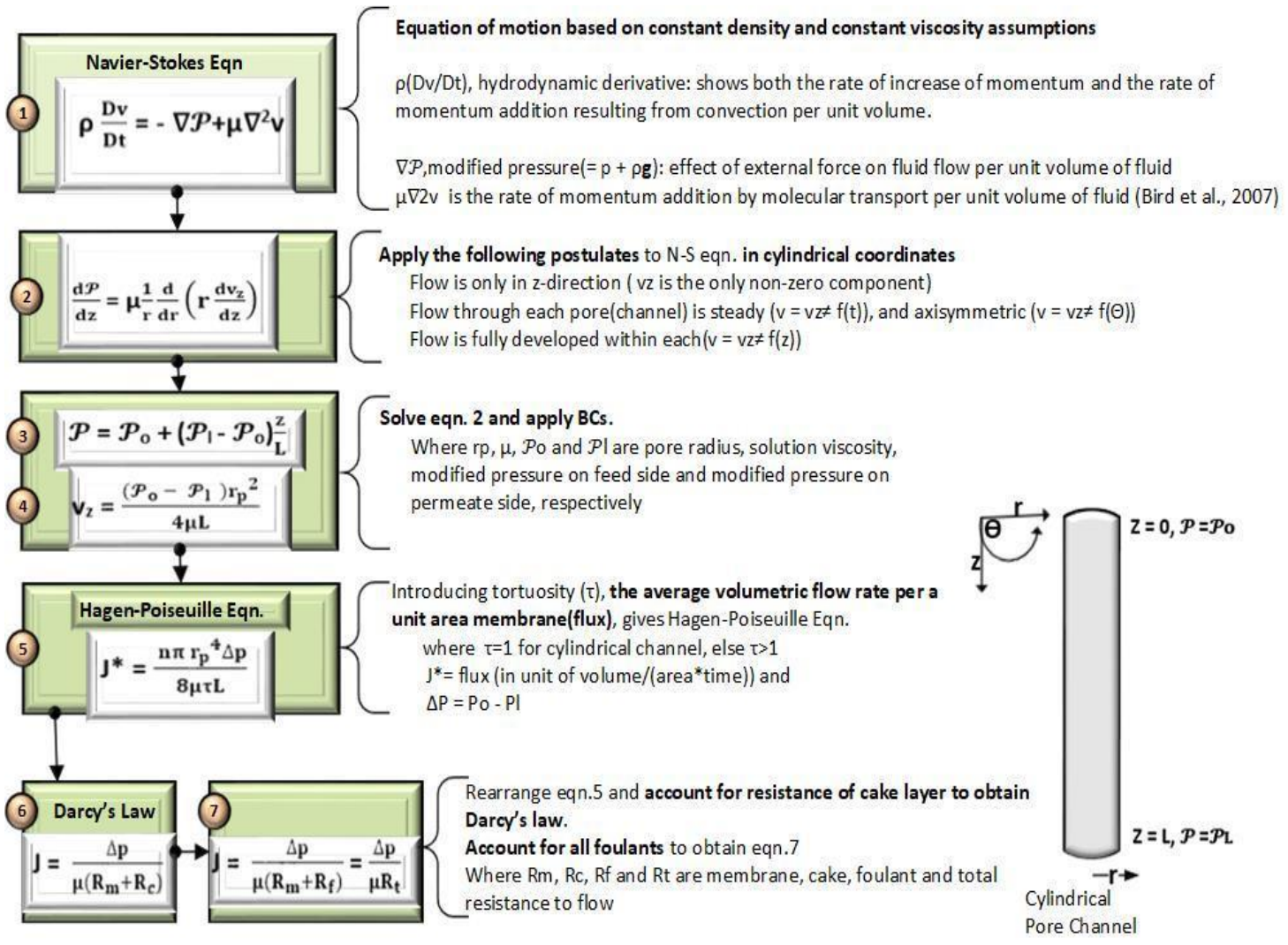

Figure 2.3: Mathematical Summary of Resistance in Series Model Derivation

Derivation of transport equation for flow through a membrane stems from the NavierStokes equation equations 1 or 2 which is a simplified version of equation of motion based on constant density (incompressible flow) and constant viscosity (Newtonian fluid) assumptions [20].

$\rho \frac{D v}{D t}=-\nabla p+\mu \nabla^{2} \mathbf{v}+\rho \mathbf{g}$

or

$\rho \frac{D v}{D t}=-\nabla \mathcal{P}+\mu \nabla^{2} \mathbf{v}$

where $\mathcal{P}$ (modified pressure) $=\mathrm{p}+\rho \mathbf{g}$ and all bolded terms are vector quantities.

The term on the left-hand side of eqn.2 is the hydrodynamic derivative and it shows, in per unit volume, both the rate of increase of momentum and the rate of momentum 
addition resulting from convection. The terms on the right-hand side give the effect of external force on fluid and rate of momentum addition by molecular transport per unit volume of fluid [20].

\subsubsection{Assumptions}

Assuming a membrane under observation consists of n number of cylindrical channels, equation 2 in cylindrical coordinates can be simplified using the following assumptions to obtain equation 3 :

- Flow is only z-direction ( $\mathrm{v}_{\mathrm{z}}$ is the only non-zero component) such that $\mathrm{v}_{\mathrm{r}}=\mathrm{v}_{\theta}=0$

- $\quad$ Flow through each pore (channel) is steady $\left(v=v_{z} \neq \mathrm{f}(\mathrm{t})\right)$ and axisymmetric $\left(\mathbf{v}=\mathrm{v}_{\mathrm{z}} \neq \mathrm{f}(\theta)\right)$

- $\quad$ Flow is fully developed within each $\left(\mathbf{v}=\mathrm{v}_{\mathrm{z}} \neq \mathrm{f}(\mathrm{z})\right)$. This is necessary else continuity equation $(\nabla . \mathbf{v})$ be violated

\subsubsection{Continuation of Derivation}

$\frac{\boldsymbol{d} \mathcal{P}}{\boldsymbol{d z}}=\mu \frac{1}{r} \frac{d}{d r}\left(r \frac{d v_{z}}{d z}\right)$

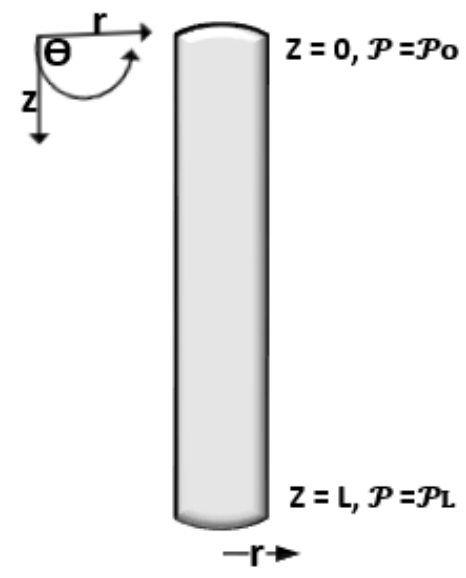

Figure 2.4:Cylindrical Pore Channel

Both sides of eqn.3 can be equated to a common arbitrary constant "A" to give:

$\frac{d \mathcal{P}}{d z}=\mathrm{A}$

and $\mu \frac{1}{r} \frac{d}{d r}\left(r \frac{d v_{z}}{d z}\right)=\mathrm{A}$

Solving the differential equations 4 and 5 give eqn. (6) and eqn. (7), respectively 
$\mathrm{Az}=\mathcal{P}+\mathrm{B}$

and $\mathrm{v}_{\mathrm{z}}=\frac{A r^{2}}{4 \mu}+C \ln r+D$

Applying the boundary conditions shown in figure 11 to equations 6 and 7 give

$\mathcal{P}=\mathcal{P}_{\mathrm{o}}+\left(\mathcal{P}_{1}-\mathcal{P}_{\mathrm{o}}\right) \frac{Z}{L}$

And $\mathrm{v}_{\mathrm{z}}=\frac{\left(\mathcal{P}_{o}-\mathcal{P}_{l}\right) r_{p}{ }^{2}}{4 \mu L}$

Where $\mathrm{r}_{\mathrm{p}}, \mu, \mathcal{P}_{\mathrm{o}}$ and $\mathcal{P}_{1}$ are pore radius, solution viscosity, modified pressure on feed side and modified pressure on permeate side, respectively.

Since the membrane thickness is very small compared to any given datum height $\mathcal{P}_{\mathrm{o}}$ $\left(=\mathrm{p}_{\mathrm{o}}+\rho \mathrm{gh}\right)-\mathcal{P}_{1}\left(=\mathrm{p}_{1}+\rho g h\right)$ becomes $\mathrm{p}_{\mathrm{o}}-\mathrm{p}_{1}$, therefore, eqn. (9) results to

$\mathrm{v}_{\mathrm{z}}=\frac{\left(\mathrm{p}_{\mathrm{o}}-\mathrm{p}_{\mathrm{l}}\right) \mathrm{r}_{\mathrm{p}}{ }^{2}}{4 \mu \mathrm{L}}$

By multiplying the volumetric flowrate obtained from eqn. 10 by the reciprocal of cross-sectional area, average velocity through cylindrical tube [20] which is equivalent to each membrane pore channel becomes

$\mathrm{v}_{\mathrm{Z}}=\frac{\left(\mathrm{p}_{\mathrm{o}}-\mathrm{p}_{\mathrm{l}}\right) \mathrm{r}_{\mathrm{p}}^{2}}{8 \mu \mathrm{L}}$

Multiplying eqn. 12 by cross-sectional area of each pore gives the volumetric flowrate through $n$ pores as

$\mathrm{Q}=\frac{\mathrm{n} \pi\left(\mathrm{p}_{\mathrm{o}}-\mathrm{p}_{\mathrm{l}}\right) \mathrm{r}_{\mathrm{p}}{ }^{4}}{8 \mu \mathrm{L}}$

From eqn. 12 and for a unit area membrane, introducing tortuosity ( $\tau$ to account for irregularity in the pore channels where $\tau=1$ for cylindrical channel) gives the famous Hagen-Poiseuille equation in the form most convenient for flow through membrane as eqn. 13

$\mathrm{J}^{*}=\frac{\mathrm{n} \pi \mathrm{r}_{\mathrm{p}}{ }^{4} \Delta \mathrm{p}}{8 \mu \tau \mathrm{L}}$

Where $\mathrm{J}$ is flux (in unit of volume/(area*time) $)$ and $\Delta \mathrm{p}\left(=\left(\mathrm{p}_{\mathrm{o}}-\mathrm{p}_{\mathrm{l}}\right)\right)$ is the difference between feed-side pressure and permeate=side pressure, typically the driving force of the process and $\mu$ is the dynamic viscosity of the solution.

Introducing porosity $\left(\varepsilon=n \pi r_{p}{ }^{2}\right)$ to account for the fraction of membrane area that is occupied by porous channels, using $\mathbf{J}$ as tortuosity=accounted flux, Hagen-Poiseuille (eqn. 13) becomes 
$\mathrm{J}=\frac{\varepsilon \mathrm{r}_{\mathrm{p}}{ }^{4} \Delta \mathrm{p}}{8 \mu \mathrm{L}}$

Where $\mathrm{R}_{\mathrm{m}}$ (membrane resistance $)=\frac{\Delta \mathrm{p}}{\mu \mathrm{J}}=\frac{8 \mathrm{~L}}{\mathrm{n} \pi \mathrm{r}_{\mathrm{p}}{ }^{4}}$

$\mathrm{R}_{\mathrm{m}}$ is also found from[21]:

$\mathrm{R}_{\mathrm{m}}=\frac{\mathrm{k}(1-\varepsilon)^{2} \mathrm{~S}^{2} L}{\varepsilon^{3}}$

where $S=\frac{2 n \pi r_{p}}{1-\varepsilon}$ and $k=2$ for membranes consisting of uniform cylindrical pores.

In addition to membrane resistance $\left(\mathrm{R}_{\mathrm{m}}\right)$, materials deposited on the membrane surface also offer resistance $\left(\mathrm{R}_{\mathrm{c}}\right.$; cake resistance) to flow through the membrane.

Recognizing both resistances, Darcy's law gives expression to account for the cake resistance as:

$\mathrm{J}=\frac{\Delta \mathrm{p}}{\mu\left(\mathrm{R}_{\mathrm{m}}+\mathrm{R}_{\mathrm{c}}\right)}$

Assuming the cake is assembly of spherical particles, cake resistance $\mathrm{R}_{\mathrm{c}}$ is given as [21]:

$\mathrm{R}_{\mathrm{c}}=\frac{5\left(1-\varepsilon_{c}\right)^{2} S_{c}^{2} \delta_{c}}{\varepsilon_{c}{ }^{3}}$

which is analogous to $R_{m}=\frac{k(1-\varepsilon)^{2} S^{2} L}{\varepsilon^{3}}($ eqn. 16)

To account for all kinds of foulants both materials deposited on the membrane surface and those adsorbed within the pores of the membrane, equation 18 is more accurately expressed as

$\mathrm{J}=\frac{\Delta \mathrm{p}}{\mu\left(\mathrm{R}_{\mathrm{m}}+\mathrm{R}_{\mathrm{f}}\right)}=\frac{\Delta \mathrm{p}}{\mu \mathrm{R}_{\mathrm{t}}}$

Therefore, total resistance to flow through a given membrane is expressed as resistance in series [19](shown below):

$\mathrm{R}_{\mathrm{t}}=\mathrm{R}_{\mathrm{m}}+\mathrm{R}_{\mathrm{f}}=\mathrm{R}_{\mathrm{m}}+\mathrm{R}_{\mathrm{rev}}+\mathrm{R}_{\text {irr }}$

Where $R_{f}$ comprises of resistances resulting from all foulants in the fluid, which are divided into reversible resistance $\left(R_{\text {rev }}\right)$ and irreversible resistance $\left(R_{\text {irr }}\right)$. 


\subsection{Membrane and Feed Properties}

\subsubsection{Membrane Properties}

\subsubsection{Membrane Pore Size}

This is a very important parameter in membrane separation as it gives an indication of solutes a given membrane can reject or allow to pass through the membrane. UF membranes are characterized in Molecular Weight Cut-Off (MWCO). MWCO is the molecular weight of a globular protein that a given membrane can reject by at least $90 \%$. MWCO is expressed in Dalton (Da).

It can also be beneficial to express the MWCO in Da to equivalent size in nanometer. That way, a quick comparison can be made between the contaminant size and pore diameter. For a spherical macromolecule (like protein) the relationship between the size in Dalton and nanometer is expressed as shown below [22]:

$$
R_{\text {min }}=\left(\frac{3 V}{4 \pi}\right)^{\frac{1}{3}}=0.066 M^{\frac{1}{3}}
$$

Where $\mathrm{R}_{\min }$ is the minimum radius (in $\mathrm{nm}$ ) of a smooth spherical protein whose mass is $\mathrm{M}$ (in Dalton) and occupies a volume, $\mathrm{V}\left(\mathrm{nm}^{3}\right)$ [22]. Applying this equation to estimate pore size of UF membranes, it implies for that the minimum size pore diameter of $1 \mathrm{kDa}$ membrane will be $1.320 \mathrm{~nm}$ while that of a $10 \mathrm{KDa}$ membrane will be $2.844 \mathrm{~nm}$. Comparing these pore sizes with average sizes of colloidal contaminants $(\sim 1 \mathrm{~nm}-$ $100 \mathrm{~nm}$ ), and assuming that all colloids are spherical, high colloidal rejection is to be expected by UF membranes. However, both membrane pore and colloids differ in shape. Hence there still lies some uncertainties that research will uncover.

\subsubsection{Contact Angle ( $\theta)$}

This property of a membrane reveals its inherent hydrophilicity or hydrophobicity. $\Theta$ $<90$ degrees implies the membrane is hydrophilic while theta $>90$ degrees indicates the membrane is hydrophobic. 

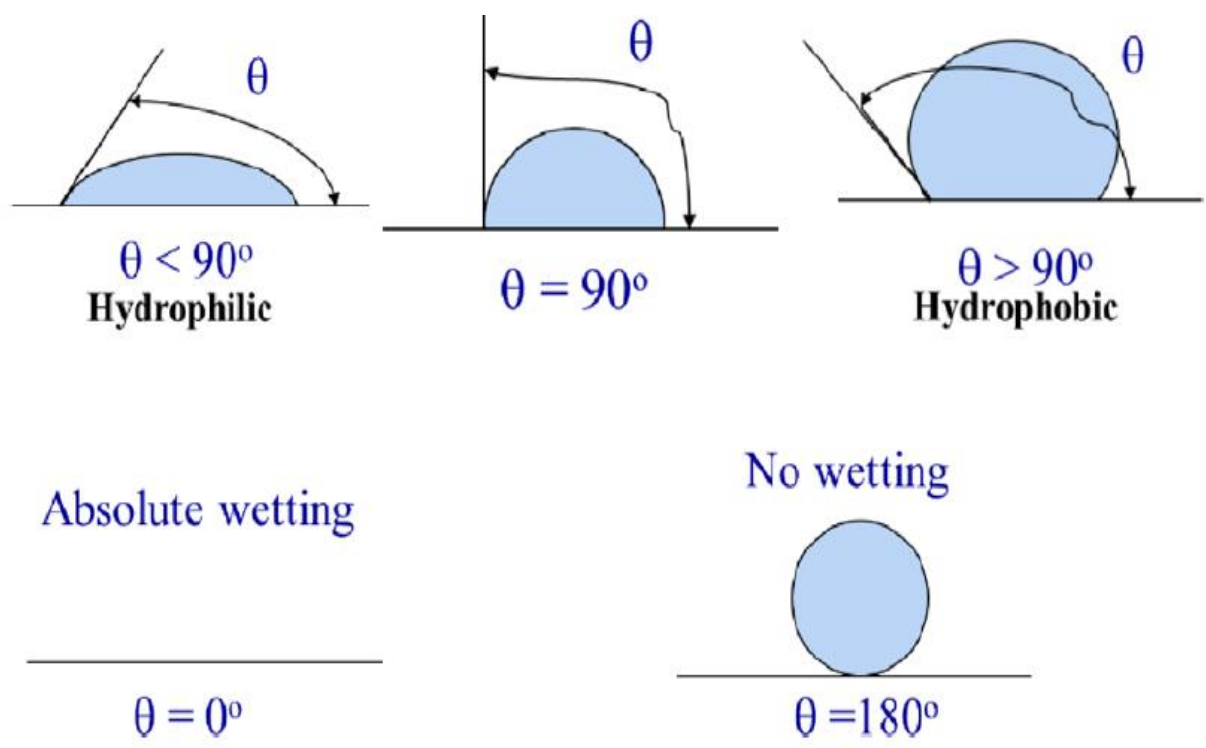

Figure 2.5: Contact Angle and Inherent Physical Implication [23]

\subsubsection{Flux}

Flux is a performance parameter of membrane system that gives the volume of permeate produced per unit area per unit time by the system. It is expressed in $L / M^{2} H$, also written as LMH.

\subsubsection{Rejection (\%)}

Percentage rejection is another performance parameter of membrane system that indicates amount of solute(s) the system retains/rejects at a given operating condition. It is expressed in percentage (\%) or in log removal value (LRV) (as in MF for quantifying bacteria rejection). The separation efficiency of a given membrane process is estimated in terms of percentage rejection as defined below.

Rejection $(\%)=\frac{\mathrm{C}_{\mathrm{f}}-\mathrm{C}_{\mathrm{p}}}{\mathrm{C}_{\mathrm{f}}} * 100$ and LRV $=\log _{10}\left(\frac{\mathrm{C}_{\mathrm{f}}}{\mathrm{C}_{\mathrm{p}}}\right)$

where $\mathrm{C}_{\mathrm{f}}$ and $\mathrm{C}_{\mathrm{p}}$ are the feed particle concentration and permeate particle concentration, respectively.

\subsubsection{Feed Parameters in Water Treatment}

Because UF membranes are used for separations of particulates, colloids and suspended particles from fluid stream, the main solution/colloidal parameters in this technology are turbidity and particulate load/concentration. 


\subsubsection{Turbidity}

Turbidity is a property of a solution, colloid or suspension that depicts how hazy or cloudy the fluid is. Turbidity, measured in Nephelometric Turbidity Unit (NTU) gives an indication of particles/solutes in a given solvent.

\subsubsection{Total Organic Carbon (TOC), Chemical Oxygen Demand (COD) and 5-day Biochemical Oxygen Demand $\left(B O D_{5}\right)$}

TOC is parameter that measures the amount of organic carbon in a given solution. Its measurement is done by recording the quantity of $\mathrm{CO}_{2}$ formed from the oxidation or combustion of organic carbon in the solution. $\mathrm{BOD}_{5}$ is an assay that quantifies the concentration of organic matter in water based on the amount of oxygen consumed from biological activity on the organic matter. $\mathrm{BOD}_{5}$ is done by incubating microbes over a five-day period. Both $\mathrm{BOD}_{5}$ and COD measure organic matter content of a solution using the oxygen depletion. However, while $\mathrm{BOD}_{5}$ is based on bioconsumption of the oxygen, COD is the based on the consumption of solution oxygen as a result of chemical oxidation reactions(https://mantech-inc.com/blog/cod-vs-toc-inwater-and-wastewater-treatment/).

\subsubsection{Particulate Load/Concentration}

This parameter is a measure of the number of particulates in a given volume of solvent. It is expressed either in $\mathrm{mg} / \mathrm{L}, \%$ or $\mathrm{ppm}$ ).

Where $1 \%=10,000 \mathrm{mg} / \mathrm{L}=10,000 \mathrm{ppm}$

In addition to the parameters explained above, other key solution properties of concern in an MBR for water treatment include natural organic matter (NOM), TOC, BOD5, $\mathrm{COD}$, nitrate, etc. Among these parameters, the most important ones in wastewater treatment for the scope of this research are TOC, COD TSS and $\mathrm{BOD}_{5}$ because they provide direct indication on the quality of the solution based on organic contaminants.

\subsubsection{Total Suspended Solids (TSS)}

TSS is a physical parameter of the solution, in this study, water or wastewater, that gives an indication of the suspended particles and other solids in water. Several standard methods that can be used to measure TSS include 2540D and EPA (1983), Method 160.2 (Residue, nonfilterable), etc. 


\section{$3 \quad$ Literature Review}

Colloids, particulates and microbial contaminants in water results from effluents and runoffs from sewage treatment plants, agricultural sites, etc. This section discusses conventional and membrane systems used in surface and wastewater treatment and the issues associated with each.

\subsection{Surface Water Treatment}

\subsubsection{Conventional and Membrane Treatment Processes}

Conventional treatment technologies utilize series of treatment steps in converting water from source reservoir (underground aquifers or surface waters) to potable water. The treatment process for a conventional treatment plant that utilize surface water as feed is as shown in figures 3.1 and 3.2. Typically comprising (1) initial disinfection by either chlorination or ozonation, (2) chemical dosing of coagulants (ferric chloride or aluminum sulfate) to aid flocculation of suspended particles followed by (3) sedimentation. Residual suspended particles are removed by passing the fluid stream through (4) dual media filtration (coal/carbon and sand filter beds) and then (5) chlorine disinfection is applied for further inactivation of pathogens. (6) Fluoridation (in (7) another reservoir storage), (8) corrosion control (by addition of phosphorous compound) and (9) chloramine protection are then employed for special functions like prevention of tooth decay, reduction of pipeline corrosion and transit bacteria protection, respectively. Similar steps apply for treatment plants sourcing feed from underground aquifer. However, because groundwater is slightly acidic in $\mathrm{pH}$ and prone to heavy metal contamination, additional two units are engaged for (1) oxidation of heavy metals (like iron, manganese, etc.) using potassium permanganate and (2) $\mathrm{pH}$ enhancement using soda ash to reduce pipeline corrosion. City of Houghton Water Treatment Facility utilizes underground aquifer as the source reservoir.

\section{Milwaukee Water Works Drinking Water Treatment Process}

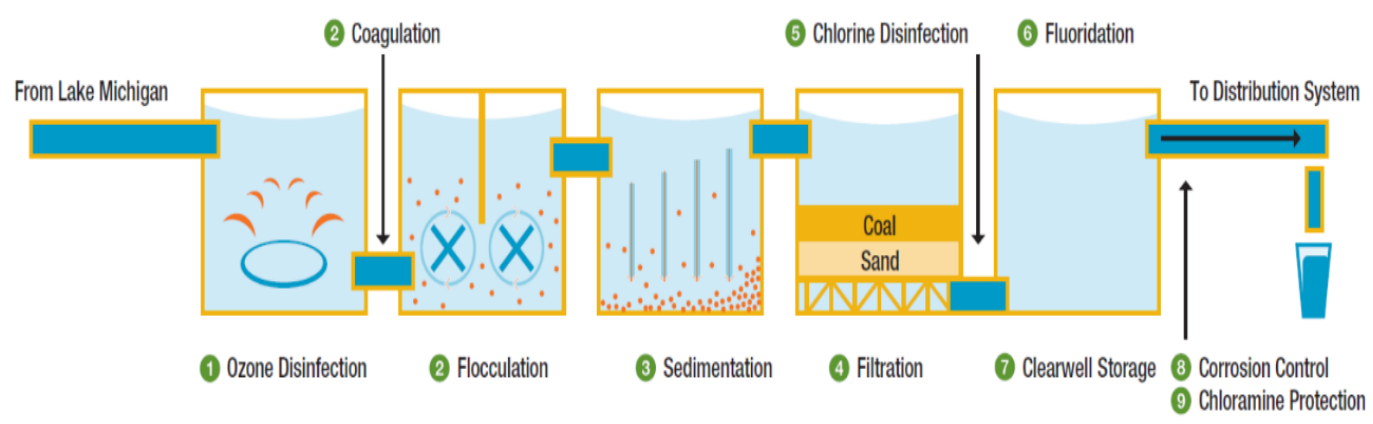

Figure 3.1: Conventional Municipal Water Treatment Scheme I. Adapted from Milwaukee Water Works Consumer Confidence Report (2018). Ninestep process. Source water: Lake Michigan 


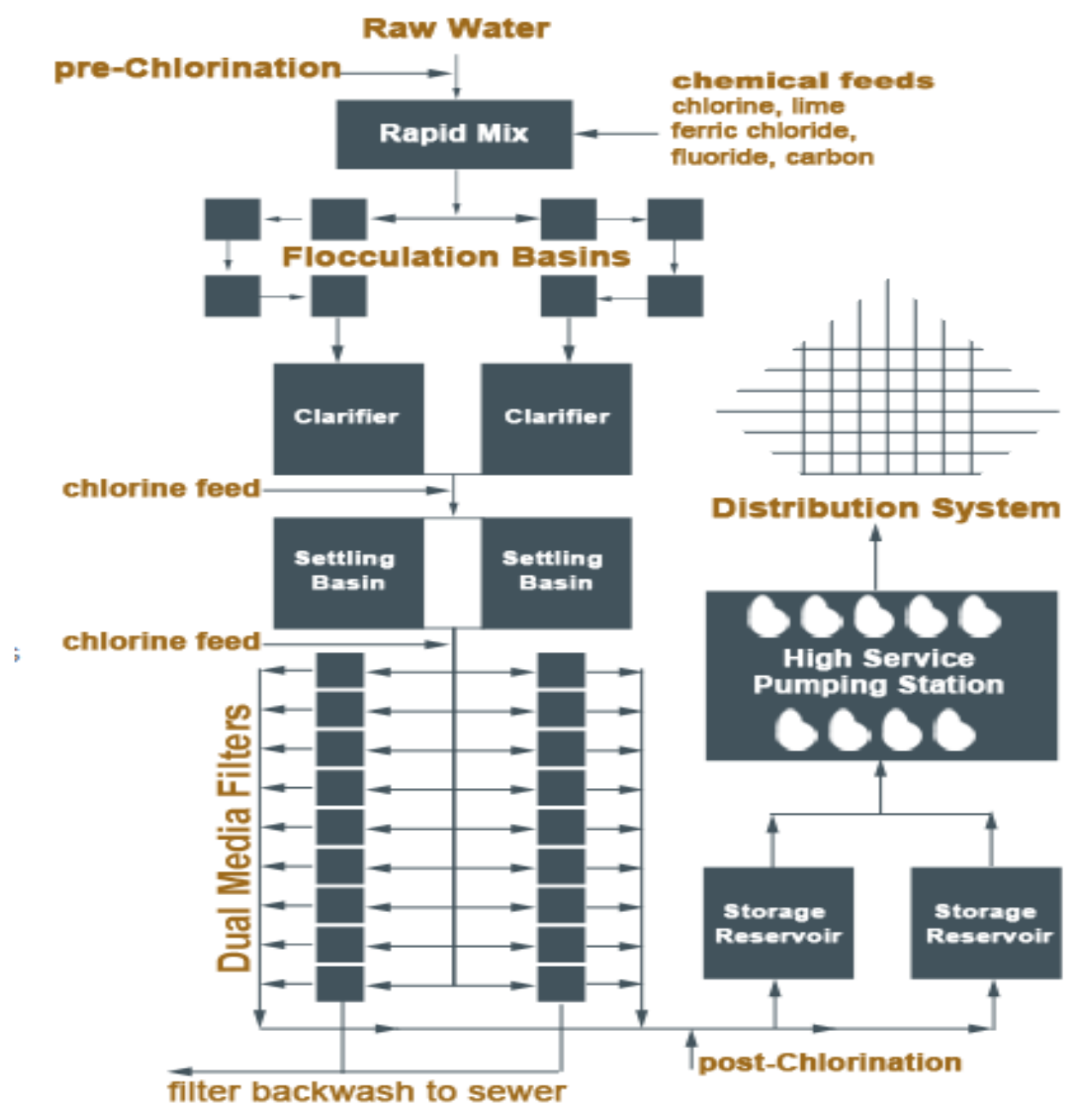

Figure 3.2:Conventional Municipal Water Treatment Scheme II.

Adapted from City of Saginaw, MI Water Treatment Process . Ten-step process. Source water: Lake Huron 


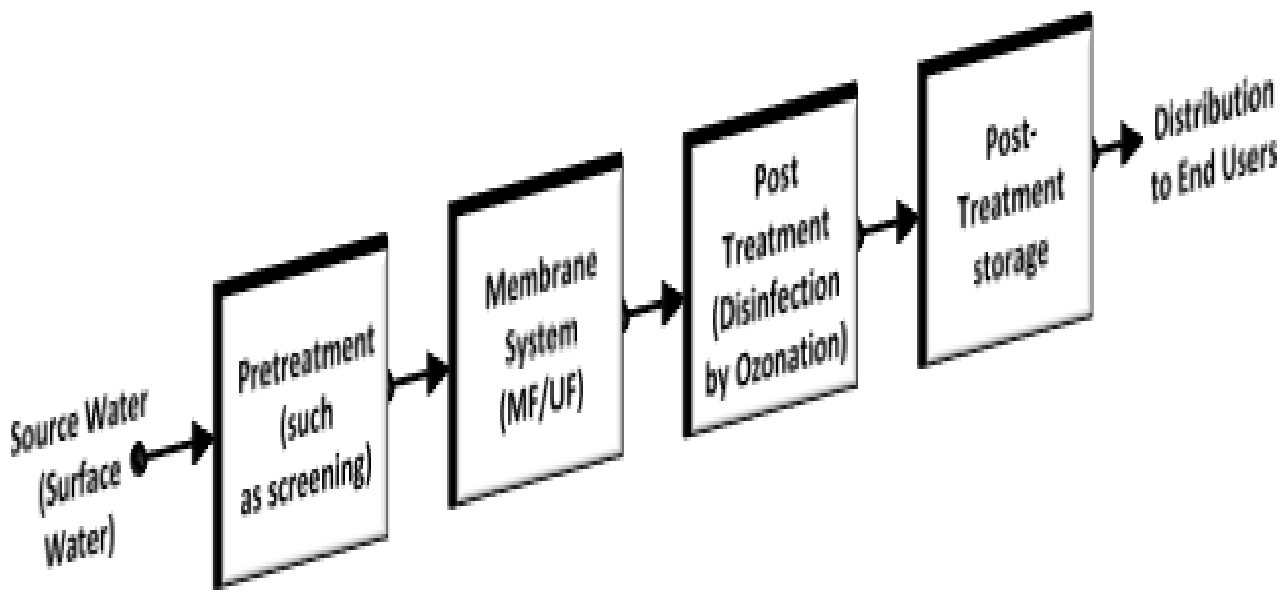

Figure 3.3: Typical Membrane System for Surface Water Treatment

\subsubsection{Issues with Conventional and Membrane Treatment Systems}

\section{Issues with Conventional Surface Water Treatment Systems}

- $\quad$ Requires many treatment steps

- Ineffective in virus removal because viruses are very minute in size [1]

- $\quad$ High usage of chemicals (chlorine, ozone, aluminum sulfate, ferric chloride etc.)

- $\quad$ High running cost from chemical purchase, fluid circulations

- More environmental issues from chemical disposals

- Leads to formation of disinfection byproducts (DBP). DBPs have been linked to cancer and reproductive problems [24].

○ chlorine disinfectant in water (in form of hypochlorite and hypochlorous acid) reacts with natural organic matter (such as humic and fulvic acids) to form DBPs like trihalomethanes (THM), haloacetic acids

(HAAs), nitrosamines, etc.

\section{Issues with MF/UF for surface Water Treatment}

- $\quad$ Membrane Fouling

- $\quad$ Limited knowledge in mechanism of membrane fouling.

- Relatively high initial capital investment

\subsection{Wastewater Treatment}

The conventional process for wastewater treatment typically involves initial screening of the influent wastewater followed by sedimentation of settleable solids. After these two steps, a conventional activated sludge system (CAS) biological process (divided 
into anoxic zone and aerobic zone) and secondary clarifier (a secondary sedimentation) are employed to provide biodegradation and separation of biologic flocs from the fluid after which media filtration is used to remove residual suspended solids. While for a membrane bioreactor (MBR) system for municipal wastewater treatment, after initial screening of the influent wastewater followed by sedimentation of settleable solids, an MBR unit is engaged to provide both biodegradation and physical separation of particles. Disinfection is normally applied as a post-treatment step for both CAS and MBR systems.

\subsubsection{MBR System and its Edge over Conventional Activated Sludge System (CAS) for Wastewater Treatment}

In a typical MBR process, suspended particles are almost totally rejected by the membrane. Systems using microfiltration membranes reject among other things all bacteria in the system while nanofiltration membranes also totally inhibit viruses in the feed [25]. Due to their unique features and capabilities, MBR systems have been widely recognized and deployed for various applications. And, the acceptance and applicability of MBR continue to grow. Obviously, MBR systems have largely replaced conventional activation systems (CAS) in water treatment because the latter lack the ability to provide some outstanding features MBRs are known for. The MBR clearly outperforms CAS in many ways; it is relatively more compact, more reliable and gives a higher purity effluent [26]. Also, MBR systems are uniquely suitable for treating industrial wastewater like those from electronics industry to a water quality suitable for reuse[27] and are more cost effective than CAS [28]. For reclamation purposes (like recycling or reusing the water), permeates from MBRs require little or no post treatment because they are devoid of cells or solids [29].

Also, an MBR system requires relatively less equipment than a CAS system. For instance, a sludge holding tank/clarifier is not included in an MBR system, leading to a significantly smaller foot print than in CAS. In fact, it has been reported that an MBR system will require just half the area of a CAS for a full-scale application [30, 31]. Simply put, MBRs require smaller land-to-throughput ratio $\left(\mathrm{m}^{2} /\left(\mathrm{m}^{3} / \mathrm{d}\right)\right)$ than CAS. Specifically, Xiao, Liang [32] reported the mean values of $\sim 0.8 \mathrm{~m}^{2} /\left(\mathrm{m}^{3} / \mathrm{d}\right)$ for municipal wastewater treatment MBR and $1.4 \mathrm{~m}^{2} /\left(\mathrm{m}^{3} / \mathrm{d}\right)$ for CAS (with tertiary treatment step needed to achieve comparable product quality. It is important to mention that this small footprint feature made it possible to develop underground MBRs (UMBRs). And as expected, the use of UMBR units has increased remarkably. For example, underground MBRs (UMBRs), which were first introduced about a decade ago have had significant endorsement as about 25 large scale underground MBRs (with cumulative throughput of 2 million $\mathrm{m}^{3} /$ day) are already in operation in China alone [32]. A process using an MBR system comprises a pretreatment step and the actual MBR system. Post treatment might be required depending on the product purity demand and on the feed used. 


\subsubsection{The MBR Landscape}

MBRs can be used to treat wastewater from both municipal (sewage) and industrial sources. Conventional MBRs are readily capable of treating municipal wastewater, which is typically readily biodegradable, and low in 'problem' organics. Industrial wastewaters, however, often contain 'problem' organic species that could include (i) recalcitrant organic compounds that are slow to degrade, (ii) trace organic priority pollutants or (iii) organics in difficult environments (saline, $\mathrm{pH}$ extremes, etc.).

For problem organics (i) and (ii) the strategy is to achieve organic retention time (ORT) >> hydraulic retention time (HRT). For problem organics type (iii) the strategy is to protect the bioprocess from the feed environment. Conventional and Novel MBRs that have been developed to facilitate these strategies are briefly described below and summarized in figure3.6.

\subsubsection{Readily Biodegradable Feed}

\subsection{Conventional Aerobic MBR and Anaerobic MBR}

A unique capability of MBR systems is that they can be operated either in aerobic condition or in anaerobic environment. Aerobic and anaerobic MBRs have their respective pros and cons. For example, while aerobic membrane bioreaction is more energy intensive than the anaerobic counterpart because relatively high energy is needed for organic matter oxidation in the former [33], anaerobic systems experience lower microbial growth and reduction in biodegradation. And while anaerobic digestion produces a smaller amount of biosolids, its side products require careful handling. For instance, the by-product of anaerobic bioreaction - methane- has been reported to require safe containment to avoid contamination of ambient air [34]. Worthy of mention is that anaerobic systems allow nutrient and energy recovery which has consequently attracted researchers' interest. A recent review by Robles, Ruano [35] highlights these trends. The use of either aerobic or anaerobic depends mostly on the organic load of the wastewater. Aerobic MBRs are generally used for treating effluents of low strength like municipal wastewater [36] while contaminant-laden wastewater like industrial effluents are commonly treated using anaerobic systems [37]. The key issues with aerobic and anaerobic MBR include membrane selection, fouling control (Biogas/vibration/fluidization, etc.), permeate quality (BOD, N, P), membrane integrity and energy $\left(\mathrm{kWh} / \mathrm{m}^{3}\right)$ while biogas collection is an issue peculiar to anaerobic MBR. 


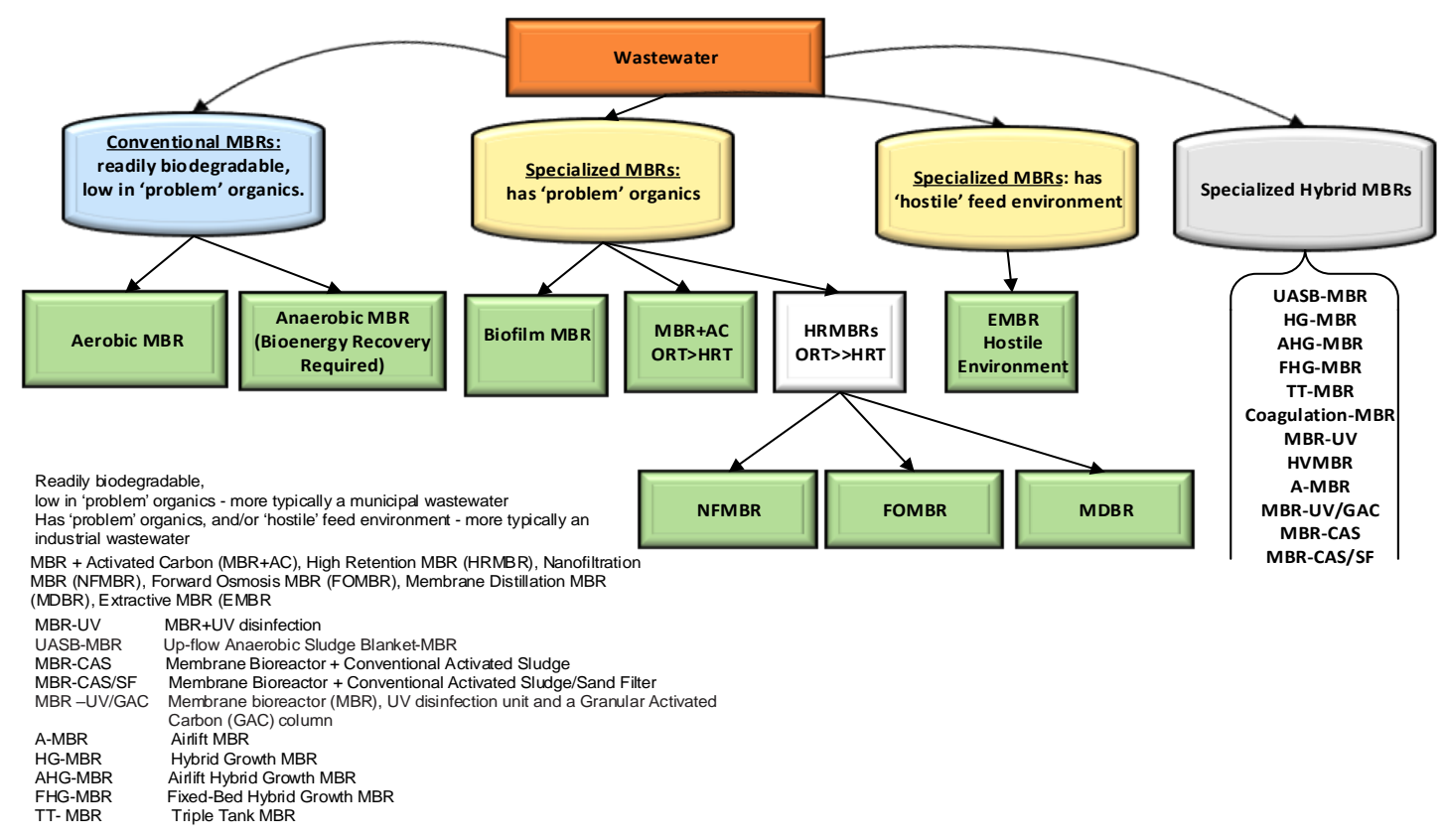

Figure 3.4: The MBR Landscape (Da Costa et al., 2019 (in preparation))

Membranes for these systems need to be robust due to movements induced for fouling control, such as bubbling, vibrations, or fluidized bed scouring [38], forces imposed by intermittent backwash, and chemical stresses due to cleaning agents. Ideally these membranes would be close to isoporous to minimize pathogen transport and fouling caused by oversized pores, have high permeability to minimize pressure requirement and would be hydrophilic to minimize fouling potential. Module geometry and fluid management should be optimized to avoid "clogging' (that is, physical blocking of the spaces between membranes). This differs from surface fouling but it can exacerbate fouling by disturbing the hydrodynamics of the module. Clogging is a serious challenge for all submerged MBRs that is not yet well understood [39].

\subsubsection{Problem Organic Feeds}

\subsection{MBR with activated carbon $(\mathrm{MBR}+\mathrm{AC})$}

Activated carbon, both in powdered (PAC) and granular (GAC) form, has been found to be effective in removing contaminants present in trace amounts [40-42]. This system allows for the uncoupling of ORT and HRT, with ORT values for adsorbed species being higher than HRT. The PAC (GAC) provides a sink for organic compounds that are then degraded by biomass associated with the PAC surface. Key issues with the 'MBR+AC' system include the need for robust membranes, PAC size, load, replacement, problem organics in the bleed and energy. 


\subsection{High retention MBRs (HRMBR)}

These MBR systems incorporate (partially) retentive membranes that allow for a longer retention time of organic compounds with the aim of the ORT to be >> than HRT. Three types of HRMBR have been developed.

\subsection{Nanofiltration MBR (NFMBR)}

The NFMBR was promoted by Rautenbach and Mellis [43], and then Choi, Dockko [44]. The use of NF membranes provided retention of recalcitrant organics, increasing their probable degradation. The NFMBR of Rautenbach involved an energy penalty with use of relatively high pressures and crossflow. To counter this Yamamoto proposed a submerged MBR with NF membranes, but this operated with very low fluxes because of the limited driving force under suction. Recent developments have used NF hollow fibers in a side stream and modest pressures [45]. The use of NF membranes increases salinity in the MBR and halophiles are the preferred biomass. Challenges with the 'NFMBR' systems that require urgent research efforts include development of special membranes, addressing salt build up (halophiles), high $\Delta \mathrm{P}$ (pressure) requirements, bleed stream and energy issues. The preferred format for the NFMBR system is pressurized module with shell-side feed in the side-stream arrangement with hollow fibres. Hollow fibres require shell-side feed as lumen-feed is prone to blocking. Ideal NF membranes would have a high-water permeability to minimize pressure requirements and high organics retention combined with low/partial salts transmission to minimize salinity build up.

\subsection{The Forward Osmosis MBR (FOMBR)}

The FOMBR uses FO membranes, which are RO-like and have low solute transmission. This MBR can operate with ORT $>>$ HRT. Challenges for the FOMBR include development of suitable FO membranes, draw-solute regeneration and the impact of high salinity on the bioprocess (due to solute retention). There are suggestions of lower fouling (or easier cleaning) [46, 47], and examples of better product water [48, 49]. The FOMBR has been used to treat domestic wastewater [48], remove trace organic contaminants [50], as well as to remove pharmaceutical compounds [51]. Like the NFMBR, the key issues with FOMBR include need for special membranes, addressing salt build up (halophiles), draw solute, bleed stream and energy issues. As with NFMBR, the preferred format is hollow fibre with the feed on the outside. Due to the draw solute the lumen side feed requires frequent flushing to prevent blocking[52]. Ideal FO membranes are thin film composite membranes (which is difficult to make in hollow fibre form) that have good FO characteristics (High A, low $\mathrm{B}$, small $\mathrm{S}$ values) without a loss of robustness.

\subsection{The Membrane Distillation MBR (MDBR)}


The MD membrane is a barrier to (nonvolatile) solute transmission and provides another strategy for ORT > HRT operation. The MDBR combines a thermophilic bioprocess with MD $[53,54]$ to achieve a high-quality product water where flux is thermally driven by waste heat. An interesting application is in the petrochemical industry [55]. The biomass needs to be both thermophilic and halophilic to deal with salt build-up and high temperatures. The MDBR has the potential to be a low GHG option for wastewater reclamation [56]. The issues with MDMBR include need for special membranes, halophiles and thermophiles to handle salt build up and high temperatures, the requirement for waste heat to be economical, bleed stream, and energy. MDBR membranes can be either hollow fibre or flat sheet but preferably in submerged module arrangement. Hydrophilic coatings can be used to minimize fouling and ideally the membrane would be close to isoporous to minimize wetting of oversized pores.

\subsection{Biofilm MBR}

The biofilm MBR system allows for the partial separation of ORT from HRT, and is like the MBR (AC), as the biofilm initially provides an adsorptive 'sink' for organics. The biofilm MBR was also designed to be a more compact system, with lower energy requirements and different design arrangements [57].

\subsubsection{Hostile Environment Feeds}

\subsection{Extractive MBR (EMBR)}

In the EMBR, the ORT is not a function of HRT. This marks an alternative strategy in the development of MBR systems to treat organic recalcitrant and organics in difficult feeds. In the process, the organic compounds of interest are removed from the waste stream by diffusion through a membrane into a biological medium, where it can undergo biodegradation by suitable microorganisms. The biological medium can be optimized and maintained independently from the potentially harsh environment of the waste stream. This is very useful for treatment of several industrial waste streams [58]. The key issues with biofilm MBR and EMBR include the need for special membranes, reactors in series, biofilm control and energy. The specialized membrane can be either hollow fibre or flat sheet with an organophilic selective skin layer (TFC) on a porous support suited to external biofilm [59]. Other MBRs are the evolving specialized MBRs like coagulation-MBR, airlift-MBR, hybrid-growth MBR, etc.

It is important to state that conventional MBRs are the dominant MBRs while specialized MBRs are systems being developed to address more specific issues in wastewater treatment and for potentially niche applications. 


\subsubsection{Challenges with CAS and MBR Systems for Wastewater Treatment and Reclamation}

\subsubsection{Challenges with CAS System}

- Inferior to MBR in terms of permeate quality

- Limited use in treating industrial wastewater

- Not suitable for water reclamation purpose; will require many more tertiary treatment steps to meet reuse criteria

- High footprint because of many treatment steps

- Not modular in nature; will be difficult to scale-up or scale-down a CAS system

\subsubsection{Challenges with CAS System}

- Membrane fouling

- Relatively high energy consumption

- Operational challenges

Recent approaches deployed to address membrane fouling and high energy consumption in MBR systems are briefly presented in sections 3.2.4 and 3.2.5 below.

\subsubsection{Highlights of Recent Fouling Control Strategy for Wastewater Treatment using MBR systems}

Several approaches have been deployed towards reducing fouling. These different approaches can be categorized under three groups (operational, chemical and electrochemical approaches) as described below.

\subsubsection{Operational/Physical Approach}

This approach involves adjusting one or more measurable variables of an MBR system and/or changing the routine procedure(s) of operating the system. Aeration: gas diffusing device is usually incorporated in an MBR system to provide tangential force and aid random motion (in MBR) in view of minimizing the adhesion of foulants on membrane surface. Common operational methods that have been reported to successfully reduce fouling include air sparging [60, 61] backwashing [62] pressure relaxation and frequent cycle operation [63, 64]. In their study to investigate pressure relaxation and membrane backwash on adenovirus removal in a membrane bioreactor, Yin, Tarabara [64] found out that, at constant filtration time/relaxation time ratio (tTMP $>0 /$ tTMP $=0$ ), more frequent cycle leads to less fouling. They explained that this trend could be due to fouling occurring over the whole filtration period while air sparging (to remove fouling during relaxation) have the capability of removing only 
the recently formed layer. Aslam, Ahmad [65] also identified quorum quenching, use of composite membranes and microbiological immobilization as ways to control biofouling. Also, Li, Wu [66] proposed a novel strategy for developing a UF membrane with good antifouling and antibacterial activity. The novel strategy consisted of polydopamine (PDA) modification, Ag catalytic activation, and electroless $\mathrm{Cu}$ plating. The resulting membranes showed significantly enhanced antibacterial activity against live E. coli.

\subsubsection{Chemical Approach}

Here, fouling in MBR is reduced by adding chemicals in the feed solution or embedding performance-improving materials on the membrane surface. This approach typically includes addition of agglomerating agents [67-69]. For example, in the study to investigate the applicability of nano-PAC flocculant in mitigating fouling in MBR, it was observed that the normal system (MBR) reached $50 \mathrm{kPa}$ TMP in 29 days while the system with coagulant addition unit (MCBR) took 45 days to reach $50 \mathrm{kPa}$, they also noticed that the latter could run for additional 16 days even when it has reached 50 $\mathrm{kPa}$, implying that addition of nano-PAC can significantly control fouling [70]. The use of synthesized composite membranes has been reported to significantly reduce biofouling[65] in addition to the promising method of quorum quenching [71].

\subsubsection{Electrochemical Approach}

Recently, there has been a growing trend of using direct current electricity to bring about electrochemical changes in the MBR system that significantly reduce fouling. For example, researchers discovered that incorporation of a DC supply in an MBR significantly reduced fouling as the 'DC-ed' environment enhanced greater microbial activities and electro-induced agglomeration with resultant reduction in fouling as a result of improved biodegradation and flocculation [72-75]. In the study carried by Hou, Kuang [76] using an iron anode in a membrane electrobioreactor (MEBR), the positively charged iron ion produced from the anode as a result of the electrolytic effect of a DC supply neutralized the negative charges of the colloidal particles and sludge flocs (which would ordinarily repel each other) and thus enhanced their flocculation in the MEBR.

\subsubsection{Membrane Cleaning}

Practically, membranes used for various purposes (water reclamation, etc.) still get fouled thereby making cleaning necessary. Membranes typically regain some level of their permeability after they have been subjected to cleaning. The extent of that recovery depends on both the nature of the fouling (reversible or irreversible) and on the cleaning approach used (physical or chemical method). For instance, it was found that permeability of a membrane that was fouled in the treatment of oily wastewater 
was restored to $60 \%$ and to $95 \%$ after physical and subsequent chemical cleaning, respectively [77].

Chemical and mechanical cleaning methods represent the major types of cleaning and include [78] cross-flow, air scouring, backwashing, and pressure relaxation as the mechanical cleaning techniques while cleaning-in-place (CIP, usually done on a regular basis, say, weekly or biweekly) and cleaning-out-of-place ( COP, usually done after a long period of time, say quarterly, annually, etc.) are the chemical cleaning techniques. Some of the chemicals used in these techniques for cleaning membranes in MBR systems include: $\mathrm{NaOCl}$, EDTA, oxalic acid, citric acid, etc. While most membrane vendors stipulate cleaning conditions for their products, best cleaning condition for cleaning reagents are often found from practice. Full-scale municipal plants normally use these chemicals within these average concentrations: $\mathrm{NaOCl}, 200$ - 3,000 mg/L, citric acid, $450-15,000 \mathrm{mg} / \mathrm{L}, \mathrm{H}_{2} \mathrm{O}_{2}, 2,000-20,000 \mathrm{mg} / \mathrm{L}[79]$. And their applicability varies from one purpose to another. For example, $\mathrm{Lu}, \mathrm{Li}[80]$ in their study of how feed virus concentration affects its removal by microfiltration had their membrane cleaned by filtering an aqueous solution of $0.01 \%$ sodium hypochlorite $(\mathrm{NaOCl})$ and $5 \mathrm{mM}$ ethylenediaminetetraacetic acid (EDTA) at the transmembrane pressure of 0.4 bar. Furthermore, Cho, Song [81] used sodium hyperchloride $(\mathrm{NaOCl})$ solution to clean their membranes by having them soaked in the solution for 3 hours following by rinsing with deionized water. While membrane cleaning serves a crucial role towards recovering the performance of the system, it is important to note that membrane cleaning should be carried out only when it is necessary as membrane cleaning affects both treatment operating conditions as well as the service life of the membrane. Loss of membrane integrity may occur as a result of periodic pauses and use of chemicals during membrane cleaning [29]. It is also important to acknowledge that some of these agents oxidize organics, while others complex ions and still others alter surface charge zeta potential.

Even though significant improvements in fouling reduction have been recorded by researchers (as highlighted earlier in this article), it is important to state that fouling is still one of the prime challenges of MBR operation. This position is in agreement with the outcome of the review done by Qin, Zhang [82] where the authors identify big challenges in worldwide application of MBR technology to include low microbial activity of activated sludge and membrane fouling

\subsubsection{Energy Consumption in MBR and its Reduction}

High energy consumption is among the major challenges facing the wider deployment of MBR in water treatment and reclamation. Therefore, to further encourage the use of MBR for both municipal and industrial applications, it is imperative to leverage the successes recorded by some recent energy reduction approaches. The goal of this section is to discuss and analyze these strategies. 
Various operations contribute to the overall energy consumption of an MBR system. Major contributors to energy usage in an MBR system include air blowing, fluid circulation, sludge transport and cooling utilities transport [83-87]. For example, process blowers and air scouring have been identified to be the chief consumers in an MBR system with $41 \%$ and $15 \%$ contributions, respectively to the total energy consumption (https://www.pub.gov.sg/). Also, Krzeminsk et al. in their study on operation of Municipal waste water treatment plants over a couple of years, found that aeration is a major energy consumer, often exceeding 50\% share of total energy consumption, with a minimum of $35 \%$ for membrane aeration [88]. The membrane module used, membrane pore size and hydraulic load have equally been reported to have effects on the overall energy consumption. It was hypothesized that, given the same effective tank volume and membrane pore size, MBR systems with hollow fiber membranes consume less power than those with operating with flat sheet membranes, while among MBR systems with hollow fiber membranes, membrane pore size is inversely related to power consumption [89]. The effect of membrane module on energy consumption is not yet well understood. Hence, there is still a need for more research in this area to validate or modify those findings. Regarding the effect of hydraulic load, it might seem plausible to expect that higher load will require more energy for treatment. However, from a fundamental stand point, it is likely to be the other way around as a higher load corresponds to a greater source of organic contaminants which favor higher rate of biodegradation. This increased biodegradation consequently translates to faster treatment of fluid with resultant reduction in specific energy consumption. This hypothesis has been confirmed by few authors. For instance, from the assessment of energy consumption of several full-scale MBRs over a couple of years, Gabarrón et al. found that a plant utilizing MBR with flat sheet membrane consumed $2.1 \mathrm{KWh} / \mathrm{m}^{3}$ when operated at $22 \%$ of design hydraulic load but $0.51 \mathrm{~kW}$ $\mathrm{h} / \mathrm{m}^{3}$ was recorded under operation at $70 \%$ design hydraulic load, and similar trend was observed by the authors for another plant utilizing MBR with hollow fibers; energy consumed per unit volume of treated wastewater was found to change from 1.80 $\mathrm{kWh} / \mathrm{m}^{3}$ (at $42 \%$ hydraulic load) to $0.77 \mathrm{kWh} / \mathrm{m}^{3}$ (at over $100 \%$ hydraulic load) [90].

Because of the limiting barriers posed by high energy requirement in MBR systems, over the years, researchers have addressed these challenges with diverse approaches (ranging from flux adjustment, optimization of various operating conditions, addition of specialty components in the traditional MBR, use of novel MBRs, etc.) and significant progress is being constantly made. For example, Xiong, Zheng [91] found that with negative pressure steam-stripping pretreatment energy consumption in MBR system was significantly reduced (to about $60 \%$ compared to MBR system without the pretreatment) In their pilot-scale study for the removal of $\mathrm{NH}_{3}-\mathrm{N}$. It has also been found that incorporating and optimizing a biosorption process installed upstream of an MBR system significantly reduced its energy consumption to $0.25-0.28 \mathrm{kwh} / \mathrm{m}^{3}$ with energy generating potential of $0.2 \mathrm{kwh} / \mathrm{m}^{3}$ resulting to net energy consumption of 0.1 $\mathrm{kwh} / \mathrm{m}^{3}$ ( https://www.pub.gov.sg/). 
Furthermore, Ho, Smith [92] in their pilot study, found that a reciprocating MBR (rMBR) has overall less energy requirement than conventional MBR systems (in the ratio of $1 \mathrm{kWh} / \mathrm{m}^{3}: 4 \mathrm{kWh} / \mathrm{m}^{3}$ energy consumption favoring the rMBR) since the energy spent in membrane reciprocation is less than energy expenditure as a result of coarse air scouring used in traditional MBR systems. However, to truly appreciate the magnitude of the net energy saved by adopting the reciprocating system, more research, especially that geared to full-scale system is needed [92]. The various energy reduction strategies, reduction achieved and their associated scale are illustrated in Table 1.0

As can been seen from Table 3.1, there have been remarkable reductions in MBR energy consumption over the past decade because of innovative approaches. It is worthy of mention that in China, the SED for large-scale municipal wastewater treatment MBRs which averaged $0.6 \mathrm{kwh} / \mathrm{m}^{3}$ for $2006-2014$ reduced to $0.4 \mathrm{kwh} / \mathrm{m}^{3}$ for 2015 - 2018 [32]. This reduction rate shows that with improved design and optimized aeration the energy consumption of MBRs will even be lower than that of CAS (without tertiary treatment) that is, in the range of $0.3-0.6 \mathrm{kWh} / \mathrm{m}^{3}$ [61].

It is important to conclude this section by adding that while we advance further in the search for more optimum strategies of achieving even higher energy reduction, caution should be taken in order not to compromise effluent quality for lower energy. Other researchers recognized that potential trade-off and stated that energy consumption and TSS, COD, BOD, N-Total and TKN concentrations in the effluent indicate a potential for energy optimization studies without immediate danger of affecting the quality of the produced effluent [93]. The next section explores recent MBR applications with highlights on MBR hybrid processes and on the use of novel MBRs for the removal of difficult contaminants. 
Table 3-1:Energy Reduction Strategies, Results and Associated Scale

\begin{tabular}{|c|c|c|c|c|}
\hline $\begin{array}{l}\text { MBR } \\
\text { Plant } \\
\text { Scale }\end{array}$ & $\begin{array}{l}\text { Strategy } \\
\text { Deployed }\end{array}$ & $\begin{array}{l}\text { Year(s) } \\
\text { Strategy } \\
\text { was } \\
\text { Applied }\end{array}$ & $\begin{array}{l}\begin{array}{l}\text { Reduction } \\
\text { Achieved }\end{array} \\
\left(\mathrm{kwh} / \mathrm{m}^{3}\right) \text { or \% }\end{array}$ & Reference \\
\hline Full scale & $\begin{array}{l}\text { Reduction of } \\
\text { MLSS } \\
\text { concentration, } \\
\text { modification of } \\
\text { biologic } \\
\text { aeration and } \\
\text { equipment }\end{array}$ & 2011 & $\begin{array}{l}\text { From } 1.12 \\
\left(\mathrm{kwh} / \mathrm{m}^{3}\right) \text { to } \\
0.71\left(\mathrm{kwh} / \mathrm{m}^{3}\right)\end{array}$ & \multirow[t]{3}{*}{ [90] } \\
\hline Full scale & $\begin{array}{l}\text { Adjustment of } \\
\text { biological } \\
\text { aeration, } \\
\text { permeate } \\
\text { cycles, and on } \\
\text { the use of } \\
\text { membrane } \\
\text { blower }\end{array}$ & $2011-2012$ & $\begin{array}{l}\text { From } \begin{array}{r}1.54 \\
\left(\mathrm{kwh} / \mathrm{m}^{3}\right) \\
1.12\left(\mathrm{kwh} / \mathrm{m}^{3}\right)\end{array} \text { to }\end{array}$ & \\
\hline Full scale & $\begin{array}{l}\text { Installation of } \\
\text { control system } \\
\text { for biological } \\
\text { aeration, and } \\
\text { reduction in flux } \\
\text { and air scouring }\end{array}$ & $2011-2018$ & $14.5 \%$ & \\
\hline Full scale & $\begin{array}{l}\text { Real-time } \\
\text { dynamic control } \\
\text { strategy }\end{array}$ & $2012-2013$ & $\begin{array}{lr}\text { From } & 0.47 \mathrm{kwh} / \\
\mathrm{m}^{3} \text { to } & 0.45 \\
\mathrm{kwh} / \mathrm{m}^{3} & (4 \% \\
\text { reduction) } & \\
\end{array}$ & [86] \\
\hline $\begin{array}{l}\text { Pilot } \\
\text { Plant }\end{array}$ & $\begin{array}{l}\text { Increasing } \\
\text { membrane flux }\end{array}$ & \multirow{2}{*}{$\begin{array}{l}\text { sequentially } \\
\text { from } 2003 \\
\text { to } 2005\end{array}$} & $\begin{array}{l}\text { From } 1.3 \text { to } 1.0 \\
\mathrm{kwh} / \mathrm{m}^{3}\end{array}$ & \multirow[t]{2}{*}{ [94] } \\
\hline $\begin{array}{l}\text { Pilot } \\
\text { Plant }\end{array}$ & $\begin{array}{l}\text { Reduction of } \\
\text { Air } \\
\text { supply(achieved } \\
\text { by the use of air } \\
\text { blower of }\end{array}$ & & $\begin{array}{lr}\text { From } & 1.0 \\
\mathrm{kwh} / \mathrm{m}^{3} & \text { to } \\
0.8 \mathrm{kwh} / \mathrm{m}^{3} & \end{array}$ & \\
\hline
\end{tabular}




\begin{tabular}{|c|c|c|c|c|}
\hline & $\begin{array}{l}\text { variable } \\
\text { frequency } \\
\text { drive) }\end{array}$ & & & \\
\hline \multirow[t]{4}{*}{$\begin{array}{l}\text { Municipal } \\
\text { Plant }\end{array}$} & $\begin{array}{l}\text { Optimizing } \\
\text { MLSS }\end{array}$ & \multirow{3}{*}{$\begin{array}{l}\text { sequentially } \\
\text { from } 2005 \\
\text { to } 2009\end{array}$} & $\begin{array}{l}\text { From } 0.7 \text { to } \\
0.549 \mathrm{kWh} / \mathrm{m}^{3}\end{array}$ & \\
\hline & $\begin{array}{l}\text { Optimizing } \\
\text { MLSS } \\
\text { Recirculation }\end{array}$ & & $\begin{array}{l}\text { From } 0.549 \text { to } \\
0.535 \mathrm{kWh} / \mathrm{m}^{3}\end{array}$ & \\
\hline & $\begin{array}{l}\text { Reduction of } \\
\text { Process } \\
\text { Aeration }\end{array}$ & & $\begin{array}{l}\text { From } 0.535 \text { to } \\
0.475 \mathrm{kWh} / \mathrm{m}^{3}\end{array}$ & \\
\hline & $\begin{array}{l}\text { Optimization of } \\
\text { Scouring Rate } \\
\text { (switched from } \\
\text { 10s on: } 10 \text { s off } \\
\text { to } 10 \text { s on : } 30 \mathrm{~s} \\
\text { off) }\end{array}$ & $2009-2013$ & $\begin{array}{l}0.475 \text { to } 0.37 \\
\mathrm{kWh} / \mathrm{m}^{3}\end{array}$ & \\
\hline $\begin{array}{l}\text { Pilot } \\
\text { Scale }\end{array}$ & $\begin{array}{l}\text { Membrane } \\
\text { Reciprocation } \\
\text { and Substituted } \\
\text { Air Scouring }\end{array}$ & 2014 & $\begin{array}{lr}\text { Reduction } & \text { of } \\
\text { scouring } & \text { energy } \\
\text { to } & 0.072 \\
\mathrm{kWh} / \mathrm{m}^{3} & \\
\text { (against } & \\
\text { aeration } & \text { energe } \\
\text { of } & 0.29 \\
\mathrm{kWh} / \mathrm{m}^{3} \text { reported } \\
\text { by }(\mathrm{Judd}, 2011) \text { ) }\end{array}$ & [92] \\
\hline $\begin{array}{l}\text { Pilot } \\
\text { Scale }\end{array}$ & $\begin{array}{l}\text { Optimization of } \\
\text { Biosorption } \\
\text { aeration and } \\
\text { bioreactor } \\
\text { mixing }\end{array}$ & 2018 & $\begin{array}{l}\text { Reduction of } \\
\text { Scouring energy } \\
\text { to } 0.04 \mathrm{kWh} / \mathrm{m}^{3} \\
\text { with resultant } \\
\text { total process } \\
\text { energy in the } \\
\text { range of } 0.25- \\
0.28 \mathrm{kWh} / \mathrm{m}^{3}\end{array}$ & $\begin{array}{l}\text { https://www. } \\
\text { pub.gov.sg/ } \\
\text { (Tao et al., } \\
2018 \text { ) }\end{array}$ \\
\hline
\end{tabular}




\section{$4 \quad$ Research Study}

\subsection{Variables Investigated and Rationales}

Water bodies and sources are rarely uniform in composition. Both dissolved and suspended contaminants in water can alter the chemistry and quality of water, which will in turn affect the performance of a system utilized for water treatment purpose. To effectively apply ultrafiltration for retention of colloids in different feed water samples of varying compositions, knowledge of how feed properties and operating conditions affect the performance of the UF system is necessary. Variables investigated include nanoparticle concentration, membrane $\mathrm{MWO}$, feed $\mathrm{pH}$ and salinity. These parameters were chosen for study based on their high variability in feeds treated in several water treatment and process industry applications. Particularly, the choice of values for the concentration was informed by typical solids and particulate concentration in surface water and wastewater (as shown in table 4.1 below) while saline conditions tested represent typical salt content of brackish water and seawater, respectively.

Table 4-1: Values for Contaminants in Water Sources and Regulations

\begin{tabular}{|l|l|l|l|l|}
\hline $\begin{array}{l}\text { Particulate } \\
\text { Characteristics }\end{array}$ & $\begin{array}{l}\text { Found in } \\
\text { Surface } \\
\text { Water** }\end{array}$ & $\begin{array}{l}\text { Found in } \\
\text { Municipal } \\
\text { Wastewater } \\
95]\end{array}$ & $\begin{array}{l}\text { Studied } \\
\text { Range }\end{array}$ & $\begin{array}{l}\text { EPA } \\
\text { Regulated } \\
\text { Limit/ } \\
\text { MCL" }\end{array}$ \\
\hline $\begin{array}{l}\text { Concentration/ } \\
\text { TSS (ppm) }\end{array}$ & $1-153$ & $20-600$ & 30 & 1000 \\
\hline $\begin{array}{l}\text { Turbidity } \\
\text { (NTU) }\end{array}$ & $*<50$ & $50-70$ & $\mathrm{~N}_{\mathrm{E}} \mathrm{R}$ & \\
\hline & & & 58 & ${ }^{+\leq 0.3-0.5}$ \\
\hline pH & $6.9-9.0$ & $7.5-8.5$ & $7.0-9.0$ & ${ }^{++} 6.5-8.5$ \\
\hline
\end{tabular}

+ primary MCL and are enforceable by EPA

${ }^{++}$secondary MCL are recommended but not enforceable 
* based on study done by Stubblefield et al.[96] on Lake Tahoe, California Blackwood Creek MCL: Maximum Contaminant Limit is the highest amount of a contaminant that is allowed in drinking water

** based on 8-year sampling period from Funayamabash, one of the 13 different monitoring locations on Fuji River, Japan [97]

"https://www.epa.gov/

$\mathrm{N}_{\mathrm{E}} \mathrm{R}$ : No explicit regulation/recommendation

MCL: Maximum Contaminant Limit 


\section{$5 \quad$ Methodology}

\subsection{Simulated Feed Preparation}

Commercially available silica nanoparticles (Ludox TM-50) purchased from SigmaAldrich, Co, USA were used to model colloids. These silica nanoparticles were chosen for this study because their average size (diameter $\sim 25 \mathrm{~nm}$ ) represent typical length scale of colloidal contaminants. For effect of nanoparticle concentration, feed sample of a given concentration was prepared by dilution of the colloidal silica stock solution. See Appendix B for sample calculation

For effect of $\mathrm{pH}$ and salinity, $1000 \mathrm{ppm}$ colloidal silica feed was used. Different feed $\mathrm{pH}$ conditions were obtained by adding ACS grade of hydrochloric acid was carefully added to prepared $1000 \mathrm{ppm}$ colloidal silica feed samples without altering the suspension volume to obtain samples while for influence of salinity, ACS grade sodium chloride $(\mathrm{NaCl})$ crystals were added to distilled water to prepare solution of known salinity. Calibration curve was obtained by measuring conductivity of solutions of known salinity and later used to obtain feed sample of desired salinity.

\subsection{Feed and Permeate Characterization}

Both feed and permeate solutions were characterized for nanoparticle concentrations, salt content (for effect of salinity), turbidity and $\mathrm{pH}$.

\subsubsection{Nanoparticle Concentration}

Concentrations were measured by taken advantage of concentration-dependency of visible light absorbance via spectrophotometry. An ultraviolet-visible spectrophotometer was used to measure both feed and permeate concentrations at $235 \mathrm{~nm}$ after obtaining the absorbance-concentration calibration curve. $235 \mathrm{~nm}$ was used for this study as the model colloid (silica nanoparticle) gave distinctive absorbance at this wavelength (see figure 5.1 below). The reports of absorbance-concentration calibration curves and equations obtained by measuring the absorbances of samples of known nanoparticle concentration at $235 \mathrm{~nm}$ in Summer and Fall seasons are shown in Appendix A. When necessary the intercept of the calibration equation was adjusted to read the absorbance of distilled water to avoid having negative concentration. The calibration equation was then used to confirm the concentration of prepared feed samples and analyze concentration of the permeate. 


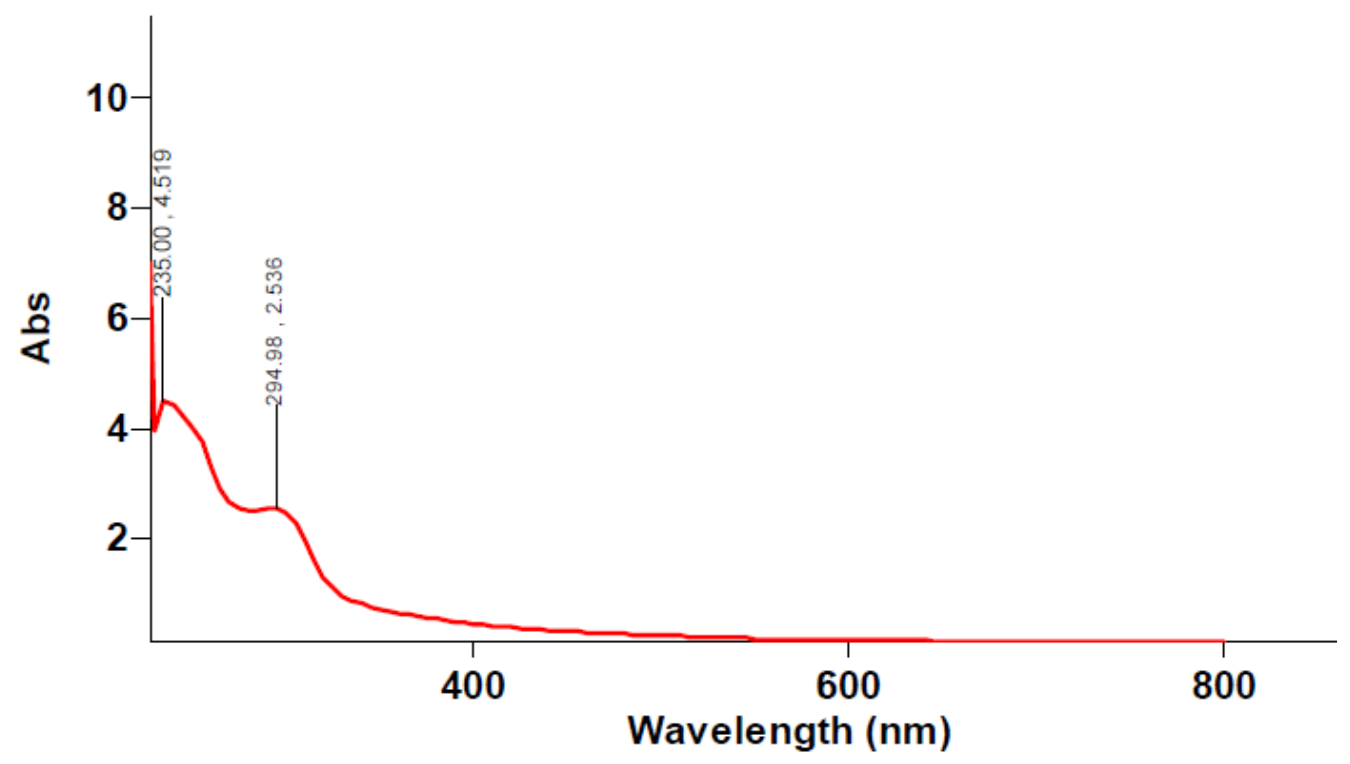

Figure 5.1:UV-vis spectrophotometric scan of colloidal silica stock solution

The influence of nanoparticle concentration on colloidal fouling was studied by filtering the feed samples on membranes of two different MWCO (1kDa and 10kDa) and at two different applied pressure (20psi and 50psi) as detailed in table 5.1 below.

Table 5-1:experimental design for effect of nanoparticle concentration

\begin{tabular}{|c|c|c|c|}
\hline $\mathrm{S} / \mathrm{N}$ & $\begin{array}{l}\text { Membrane } \\
\text { MWCO }\end{array}$ & $\begin{array}{l}\text { Applied } \\
\text { Pressure (Psi) }\end{array}$ & $\begin{array}{l}\text { Nanoparticle } \\
\text { Concentration } \\
\text { (ppm) }\end{array}$ \\
\hline 1 & \multirow[t]{6}{*}{$1 \mathrm{KDa}$} & \multirow[t]{3}{*}{20} & 50 \\
\hline 2 & & & 200 \\
\hline 3 & & & 1000 \\
\hline 4 & & \multirow[t]{3}{*}{50} & 30 \\
\hline 5 & & & 200 \\
\hline 6 & & & 600 \\
\hline 7 & \multirow[t]{6}{*}{$10 \mathrm{KDa}$} & \multirow[t]{3}{*}{20} & 50 \\
\hline 8 & & & 200 \\
\hline 9 & & & 1000 \\
\hline 10 & & \multirow[t]{3}{*}{50} & 30 \\
\hline 11 & & & 200 \\
\hline 12 & & & 600 \\
\hline
\end{tabular}




\subsubsection{Turbidity}

Turbidity of samples were equally measured using a digital turbidimeter. Prior to each measurement, the equipment accuracy was checked by measuring turbidity of known standards.

\subsection{3 pH and Salinity}

$\mathrm{pH}$ of samples was measured using digital $\mathrm{pH}$ meter while salinity was measured indirectly by conductivity-salinity relation. Conductivity-salinity calibration curve (and equation shown below) was obtained by plotting conductivities against salinities of solutions of known $\mathrm{NaCl}$ salt content.

Salinity $(\%)=($ Conductivity -0.0005$) / 15.433$. Where conductivity is in $\mathrm{mS} / \mathrm{cm}$. See Appendix A

Four different feed $\mathrm{pH}$ conditions $(\mathrm{pH} 1, \mathrm{pH} 3, \mathrm{pH} 5$ and natural $\mathrm{pH}$ of the $1000 \mathrm{pm}$ feed at $\mathrm{pH} 8.9$ ) were investigated while three feed saline conditions were studied: unmodified $1000 \mathrm{ppm}$ colloidal silica feed (no salt dosed), $1000 \mathrm{ppm}$ feed with $1 \%$ salinity and $1000 \mathrm{ppm}$ feed with $3.5 \%$ salinity.

\subsection{Permeation Experiment}

All permeation experiments were conducted on dead-end mode without turbulence using 50mL Amicon Stirred Cell (EMD Millipore Corporation, MA, USA). The driving force is supplied by nitrogen cylinder while the feed is treated by a Polyethersulfone (PES) membrane in the Amicon cell. Permeate flux is automatically measured and relayed in data logging unit while the permeate is collected in a beaker and analyzed for $\mathrm{pH}$, turbidity and nanoparticle concentration. All experiment was conducted using pristine membranes. The membranes were preconditioned by soaking in distilled water and storing in refrigerator overnight. After the ultrafiltration process, the separation efficiency of the process is estimated in terms of percentage rejection as defined below:

Rejection $(\%)=\frac{C_{f}-C_{p}}{C_{f}} * 100$ where $C_{f}$ and $C_{p}$ are the feed particle concentration and permeate particle concentration, respectively. Also, the average percentage water recovery was estimated using the equation defined below:

$<$ Water Recovery $>(\%)=\frac{<\text { After Water Flux }>* 100}{\text { Initial Water Flux }}$

Where $<$ Water Recovery $>$ is the average percentage water recovery in $\%$ and $<$ After Water Flux> is the mean water flux (in $\mathrm{L} / \mathrm{M}^{2} \mathrm{H}$ ) obtained by conducting experiment using distilled water immediately after treating each particle suspension. 


\subsection{Equipment}

Equipment utilized in measuring the investigated variables are listed in the table below.

Table 5-2:Variables Investigated and Equipment Used

Variable Measured

Nanoparticle concentration (via absorbance at 235nm)

Turbidity

$\mathrm{pH}$

Salinity (via conductivity)
Equipment/setup

Cary 60 UV-vis Spectrophotometer

Digital Hach Turbidimeter

Accumet $\mathrm{pH}$ meter

Accumet $\mathrm{pH}$ meter

\subsection{Experimental Data Description by Blocking Law for Effect of Nanoparticle Concentration}

Dominant fouling mechanisms corresponding to effect of nanoparticle concentration on membrane of different MWCO were investigated using well known filtration blocking laws. To explore the effects of nanoparticle concentration on prevalent fouling behavior, experimental results obtained at both 20psi and 50psi for 30ppm CS, 50ppm CS, 200ppm CS, 600ppm CS, 1000ppm CS on 10kDa were tested using the blocking laws.

The underlying blocking mechanism governing the observed results were investigated by fitting the collected experimental data on the following blocking laws:

Cake filtration [98]: $\frac{t}{V}=\frac{K_{c}}{2} V+\frac{1}{Q_{o}}$

Standard blocking [98]: $\frac{t}{V}=\frac{K_{s}}{2} t+\frac{1}{Q_{o}}$

Intermediate blocking [99]: $\frac{1}{J}-\frac{1}{J_{o}}=K_{i} t$

complete blocking [99]: $\ln (\mathrm{J})=\ln \left(J_{o}\right)-K_{b} t$

where $\mathrm{t}$ is time, $\mathrm{V}$ is the cumulative permeate volume at any time $\mathrm{t}$ during the filtration, $\mathrm{J}$ is permeate flux at any time $\mathrm{t}$ and $J_{o}$ is diwater flux on pristine membrane, $Q_{o}(=$ $\left.\frac{J_{o}}{\text { membrane surface area }}\right)$ is the diwater flowrate on pristine membrane and $K_{c}, K_{S}, K_{i}$ and $K_{b}$ are the blocking constants corresponding to the four filtration laws. 


\section{Results and Discussion}

\subsection{Effect of pH on Colloidal Fouling}

The influence of feed $\mathrm{pH}$ was investigated using $1000 \mathrm{ppm}$ CS feed samples at four different $\mathrm{pH}$ conditions. The feed samples were filtered using $20 \mathrm{kDa}$ Synder $^{\mathrm{TM}}$ membranes at $50 \mathrm{psi}$ without turbulence/stirring. Figures 6.1 and 6.2 show the flux plots and nanoparticle rejection for influence of feed $\mathrm{pH}$, respectively. As evident in figure 6.1 permeate fluxes obtained in all conditions decrease as the filtration time increase. Specifically, exponential decay trend was observed for all $\mathrm{pH}$ conditions. The reasons for this flux behavior are two folds: high concentration of silica nanoparticles (1000ppm CS) and the use of membrane of high MWCO. These two conditions result to rapid transport of water through the membrane leading to high concentration polarization as the nanoparticles are being retained by the membrane.

While similar decay trend was observed for different $\mathrm{pH}$ conditions, the decay rate is severely affected by feed $\mathrm{pH}$. Specifically, the flux decay rate increases with acidity of the feed. While it took about 35 minutes to filter $50 \mathrm{~mL}$ of $1000 \mathrm{ppm} \mathrm{CS}$ (natural $\mathrm{pH}$ ), same feed samples at acidic conditions require longer filtration times because of the relatively low flux observed over time for the acidic feed samples. For example, about an hour was enough to individually treat these feed samples at $\mathrm{pH} 3$ and $\mathrm{pH} 5$ while same feed sample at $\mathrm{pH} 1$ took over two hours for filtering same volume of feed. This behavior suggests that transport of water and these nanoparticles towards/through the membrane is influenced by the electrostatic interactions associated with change in feed $\mathrm{pH}$.

As evident in figure 6.2, though the UF membranes gave high rejection for the nanoparticles, the separation efficiency was observed to depend on the feed $\mathrm{pH}$. Specifically, rejections of the silica colloids slightly reduce at acidic $\mathrm{pH}$ conditions (figure 6.2). Relatively low silica nanoparticle rejection is obtained in acidic conditions. Because at acidic conditions, there are relatively high concentrations of hydrogen ion in the feed sample that resulted to net positive surface charge for the colloids, improved electrostatic attractions between the negatively charged membrane surface and positively charged nanoparticles tend to dominate at these conditions. This is supported on the ground that isoelectric point (IEP) of silica is $\mathrm{pH} 2.57$ [100], implying that below this $\mathrm{pH}$ value, the surface charge of silica nanoparticle changes from negative to positive. It is important to state that the negative surface charge of the PES membrane at different $\mathrm{pH}$ values has been reported by other researchers. For example, it was observed that zeta potentials of PES membranes are negative at both acidic and basic conditions even for slightly saline feed [101] 


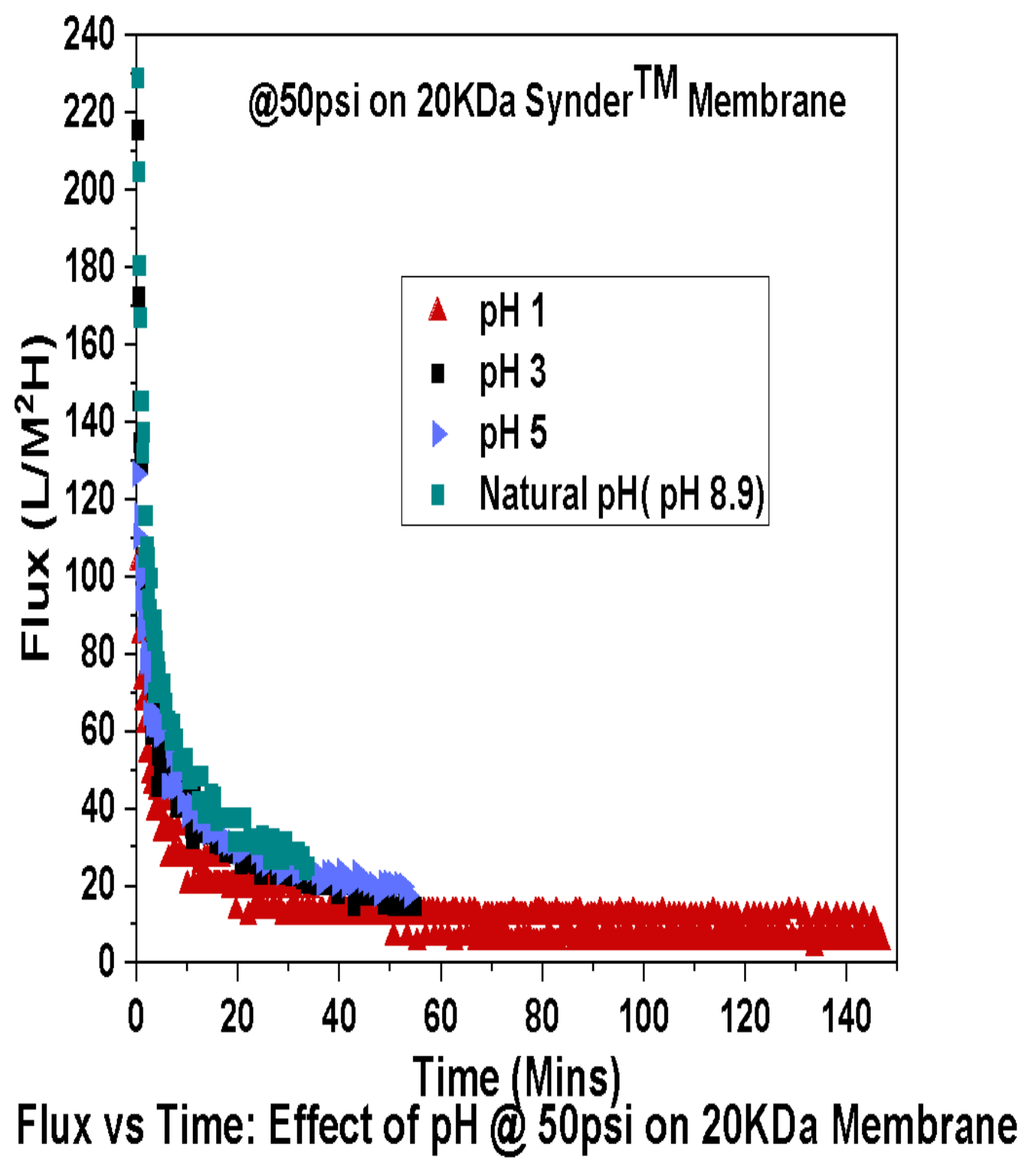

Figure 6.1:Flux Plots for Effect of Feed pH. 


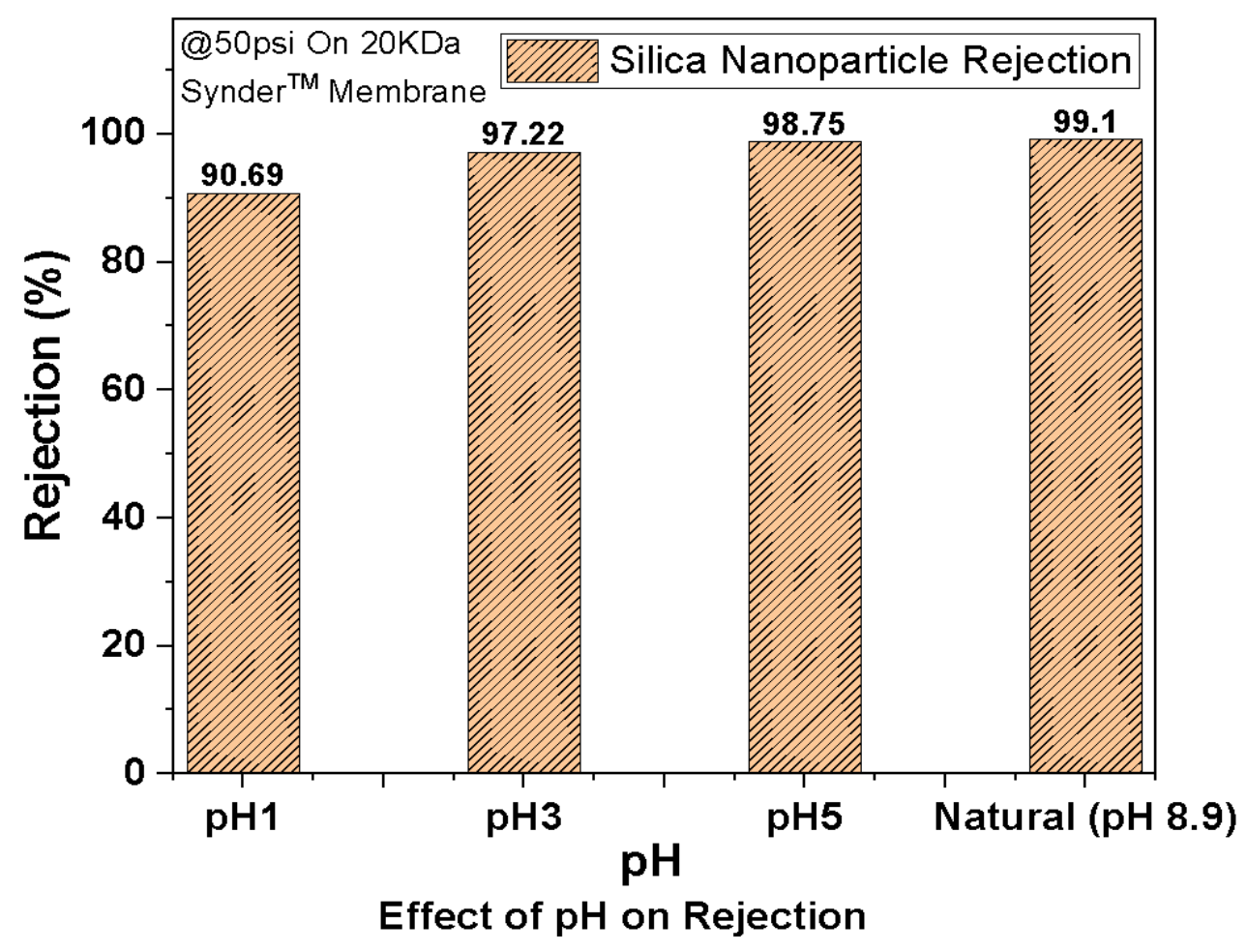

Figure 6.2:Effect of Feed pH on Silica Nanoparticle Rejection.

\subsection{Effect of Salinity on Colloidal Fouling}

The effect of feed salinity was investigated using $1000 \mathrm{ppm}$ CS feed samples at three different $\mathrm{pH}$ conditions. The feed samples were filtered using $20 \mathrm{kDa}$ Synder ${ }^{\mathrm{TM}}$ membranes at 50 psi without turbulence/stirring. Figures 6.3 and 6.4 illustrate the flux plots and nanoparticle rejection for influence of feed salinity, respectively. As shown in figure 6.3 permeate fluxes reduce with filtration time for the studied feed saline conditions. This decrease in permeate flux is because as the filtration proceeds more particles are deposited on the surface and within the pores of the membrane thereby leading to increase in hydraulic resistance. Again, exponential flux decay is obtained by filtering these three feed saline conditions, which are equally described on the grounds that high silica nanoparticle concentration (1000ppm CS) and the use of membrane of high MWCO result to rapid fouling of the membrane. Though similar decay trend is observed for all studied feed saline conditions, 6.3 shows that more saline feed result to increase in flux drop. Specifically, the feed sample of highest salinity (3.5\%) led to the fastest flux decay unlike those feed samples with less salt content (1\% salinity and the feed with no added salt). This behavior is justified on the basis that 
increase in feed salinity increases feed osmotic pressure which result to reduction in driving force for the separation process.

Similar to the explanation for effect of $\mathrm{pH}$ on silica nanoparticle rejection, increase in feed salinity slightly reduce electrostatic repulsion between the membrane and the nanoparticles which result to slight reduction in nanoparticle rejection. This observation suggests that for more saline feed samples, silica nanoparticles are attracted more to the membrane which makes it easier for the nanoparticles to slip through the membrane. This explanation is also supported by how the percent water recovery increases as the feed salinity decreases.

The influence of salinity on colloidal fouling can further be explained by considering effect of salinity on metastability of these silica nanoparticles. A changing but stable layer of colloids formed during filtration represents metastable layer. This layer can be distorted to have the colloids resuspended when enough energy or turbulence is applied. Simply put, metastable region is the intermediate region between colloidal suspension and colloidal aggregation.

In addition to osmotic pressure effect, thickness of the foulant layer on the surface of the membrane affects the rate of fouling of UF membranes by silica colloids. Specifically, it was shown that increase in feed salt content resulted to denser foulant layer with consequent transition to colloidal metastable region [102]. Hence, in terms of flux behavior, rate of colloidal fouling increase with salinity because of reduction in effective driving force and increase in density of foulant layer on membrane surface.

Furthermore, relatively low nanoparticle rejection observed as the salinity increased was because of reduced electrostatic repulsion between the nanoparticles and the membrane. This behavior is explained based on results obtained by other researchers on the variation of surface zeta potential of silica nanoparticle with salinity for a fixed silica nanoparticle concentration. Specifically, Sim, Taheri [102] observed that for a fixed $400 \mathrm{mg} / \mathrm{L}(=400 \mathrm{ppm})$ colloidal silica feed, the zeta potential value of the feed increases from $-59.05 \mathrm{mv}$ at $0 \mathrm{~g} / \mathrm{L} \mathrm{NaCl}$ to -21.75 at $8 \mathrm{~g} / \mathrm{L} \mathrm{NaCl}$, suggesting that increase in salinity reduces the negativity of silica surface charge. Remembering that PES membranes used in this research are negatively charged and the feed samples utilized for this study were of same colloid concentration (1000ppm colloidal silica), the slight drop in colloidal rejection observed with increased salinity was therefore caused by reduced electrostatic repulsion between the membrane and the silica colloids. This trend is further by supported by projection made by other researchers; that for high salinity feed, reduced repulsion is expected between the negatively charged silica colloids and the negatively charged PES membranes as a result of the compression of the their electrical double layers [102] . 


\subsubsection{Can Dense Cake Layer Formed on UF Membranes by the Silica Colloids Reject $\mathrm{NaCl}$ Salt?}

UF membranes are known to offer little or no rejection for salts because the ionic sizes of salts are very small compared to UF pore sizes. Specifically, Han, Zhang [103] observed $0 \%$ rejection for $\mathrm{NaCl}$ and $\mathrm{Na}_{2} \mathrm{SO}_{4}$ using UF membranes of ether sulfone materials. During ultrafiltration of colloidal contaminants (like silica), rejected nanoparticles are continuously deposited on the membrane surface thereby forming porous cake. Therefore, a feasible route that will result to salt rejection during the ultrafiltration of saline colloidal feed is salt rejection caused by the deposited cake. Hence the need for a scientific explanation on whether the pores formed by the deposited nanoparticles on the surface of the membrane will allow passage of the salts.

The pores formed by these nanoparticles when deposited on the membrane surface are herein, termed the interparticle pore. Possibility of retention or passage of $\mathrm{NaCl}$ salt by the deposited cakes are ascertained below by comparing the interparticle pore size and the salt size.

It has been proven using different approaches that maximum packing density of spherical particles is 0.74 for regular packing [104] and 0.64 for irregular packing [105, 106]. This limit of packing density is for three-dimensional considerations, and it implies that the maximum fraction of available volume that can be occupied by spherical particles is $74 \%$. This maximum packing density corresponds to densest cake formed by the spherical particles with resultant minimal interparticle pore volume (space).

Silica nanoparticles deposited on the membrane surface during ultrafiltration will have packing density less than 0.74 since the deposition of particles is unlikely to result to regular packing. Hence, the packing density of 0.74 used in the analysis below represent the condition that will give smallest possible interparticle pore spaces.

1000ppm CS feed utilized for this study correspond to total silica nanoparticle volume, $\mathrm{V}_{\mathrm{tp}}$ of $1.887 \times 10^{19} \mathrm{~nm}^{3}(=0.01887 \mathrm{~mL})$ using the formula shown below:

$$
\begin{gathered}
\qquad \mathrm{V}_{\mathrm{tp}}(\mathrm{mL})= \\
\text { Feed Concentration }\left(\frac{\mathrm{mg}}{\mathrm{L}}\right) \times \text { Feed Volume }\left(\frac{\mathrm{mL}}{1}\right) \times \frac{1}{\text { Density of Silica }}\left(\frac{\mathrm{L}}{\mathrm{mg}}\right)
\end{gathered}
$$

Where feed volume $=50 \mathrm{~mL}$, density of silica $=2.65\left(\mathrm{~g} / \mathrm{cm}^{3}\right)=2.65 \times 10^{6}(\mathrm{mg} / \mathrm{L})$

Therefore, using the extreme $74 \%$ pore density (that is, $26 \%$ interparticle pore volume), total interparticle pore volume, $V_{\text {tip }}$ formed by the deposited nanoparticles is $6.63 \times$ $10^{18} \mathrm{~nm}^{3}$ as obtained using the equation: 


$$
\mathrm{V}_{\text {tip }}=\frac{0.26 \times \mathrm{V}_{\mathrm{tp}}}{.74}
$$

Assuming the silica nanoparticles are nondeformable, minimum number of particles required to form a close space (pore) is 3 . This implies that the minimum possible interparticle volume formed by the nanoparticles can be obtained by dividing the total interparticle pore volume by a third of total number of particles in the system.

Remembering that average diameter of silica nanoparticles used in this study is $25 \mathrm{~nm}$, total number of particles, $\mathrm{N}_{\mathrm{tp}}$ in 1000ppm CS feed is calculated below:

$$
\begin{aligned}
& \mathrm{N}_{\mathrm{tp}}=\frac{\text { Mass of particles in the feed }}{\text { Mass of one prticle }}=\frac{\text { Feed concentration } \times \text { Feed volume }}{\text { Volume of 1 particle } \times \text { Density of silica }}= \\
& \frac{1000\left(\frac{\mathrm{mg}}{\mathrm{L}}\right) \times 0.05(\mathrm{~L})}{\frac{\pi \times 25^{3}}{6}\left(\mathrm{~nm}^{3}\right) \times \frac{1 \times 10^{-24}(\mathrm{~L})}{1\left(\mathrm{~nm}^{3}\right)} \times 2.65 \times 10^{6}(\mathrm{mg} / \mathrm{L})}=2.306 \times 10^{15} \text { particles }
\end{aligned}
$$

Therefore, minimum interparticle volume $\left(\mathrm{V}_{\mathrm{ipm}}\right)$ formed by three particles is given by:

$$
\mathrm{V}_{\mathrm{ipm}}=\frac{\mathrm{V}_{\mathrm{tip}}}{\frac{\mathrm{N}_{\mathrm{tp}}}{3}}=\frac{3 \times 6.63 \times 10^{18}\left(\mathrm{~nm}^{3}\right)}{2.306 \times 10^{25}}=8624.304 \mathrm{~nm}^{3}
$$

The corresponding radius of a spherical particle that can pass through this minimum interparticle volume is $12.72 \mathrm{~nm}$. Since estimated effective size of $\mathrm{NaCl}$ is $0.15 \mathrm{~nm}$ [107] and the calculated radius of a sphere to pass through the minimum interparticle volume is over eight times larger $(12.72 \mathrm{~nm})$, therefore, it follows that even the densest cake formed by silica nanoparticles on the surface of a UF membrane will have little or no rejection for $\mathrm{NaCl}$ salt. 


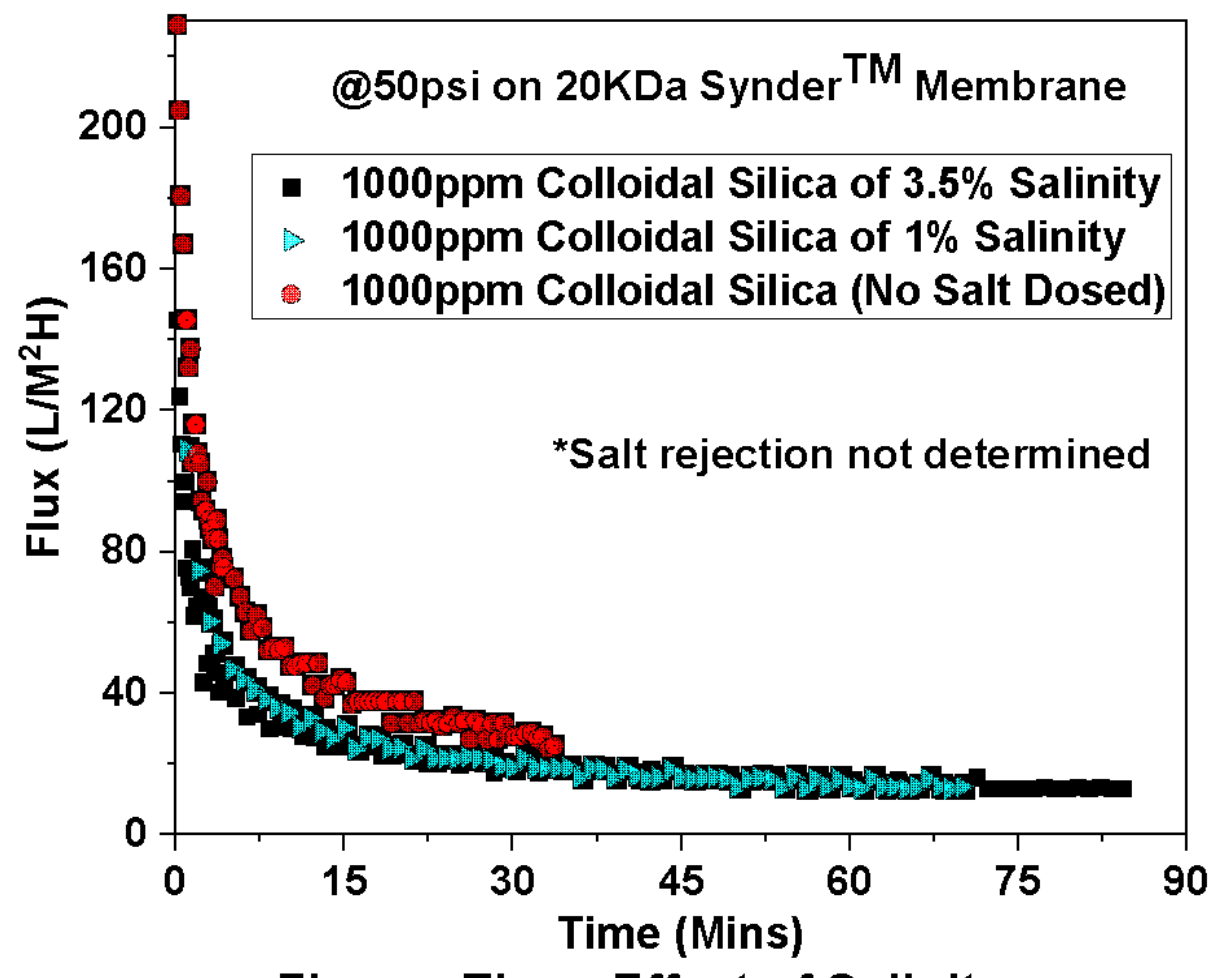

Flux vs Time: Effect of Salinity

Figure 6.3:Flux Plots for Effect of Feed Salinity. 


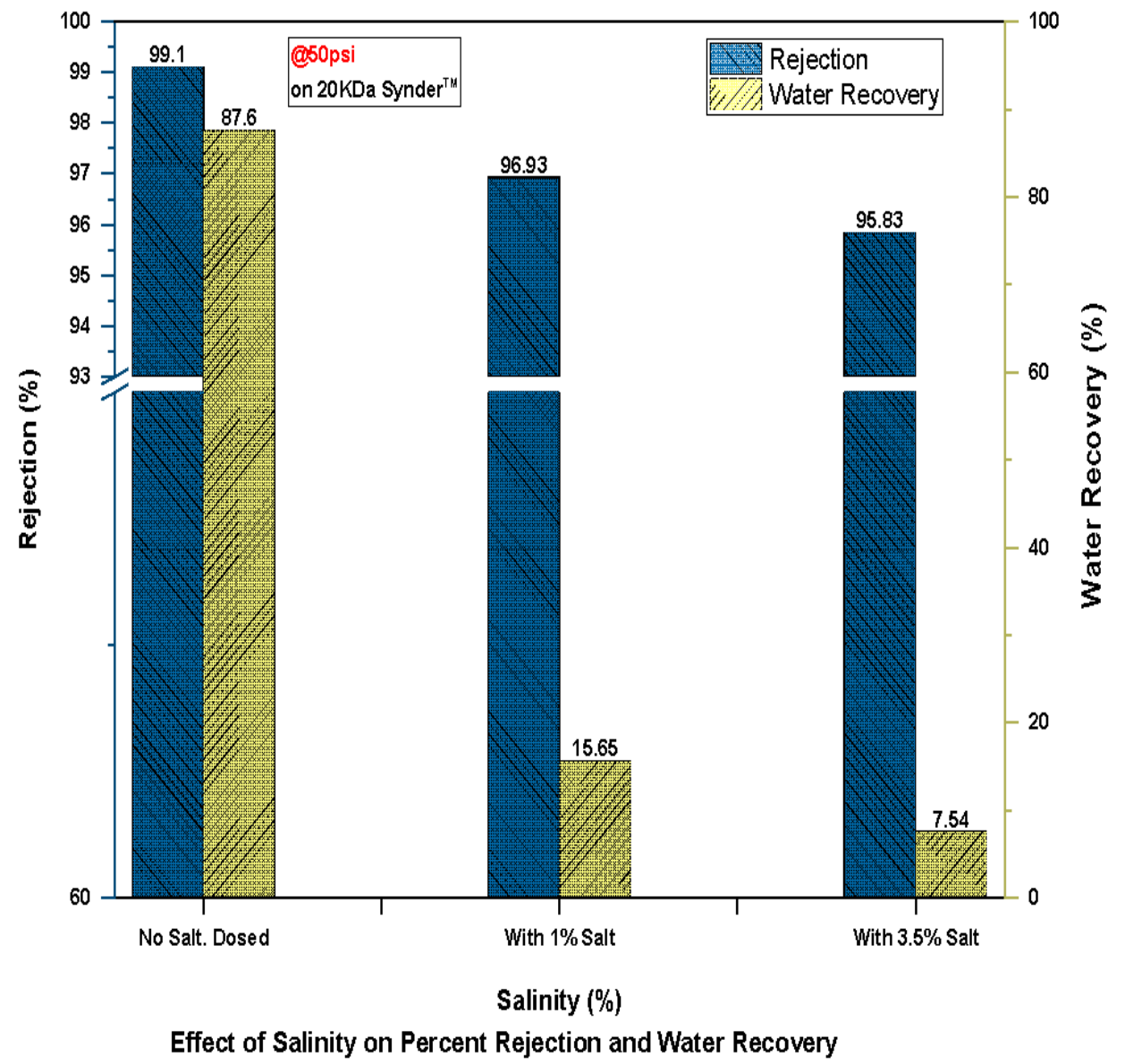

Figure 6.4:Effect of Feed Salinity on Silica Nanoparticle Rejection and Water Recovery

\subsection{Influence of Nanoparticle Concentration and Membrane Molecular Weight Cutoff}

\subsubsection{Experimental Results}

The influence of nanoparticle concentration on colloidal fouling was studied by filtering the feed samples on membranes of two different MWCO and at two different applied pressure as detailed in table 5.1. 


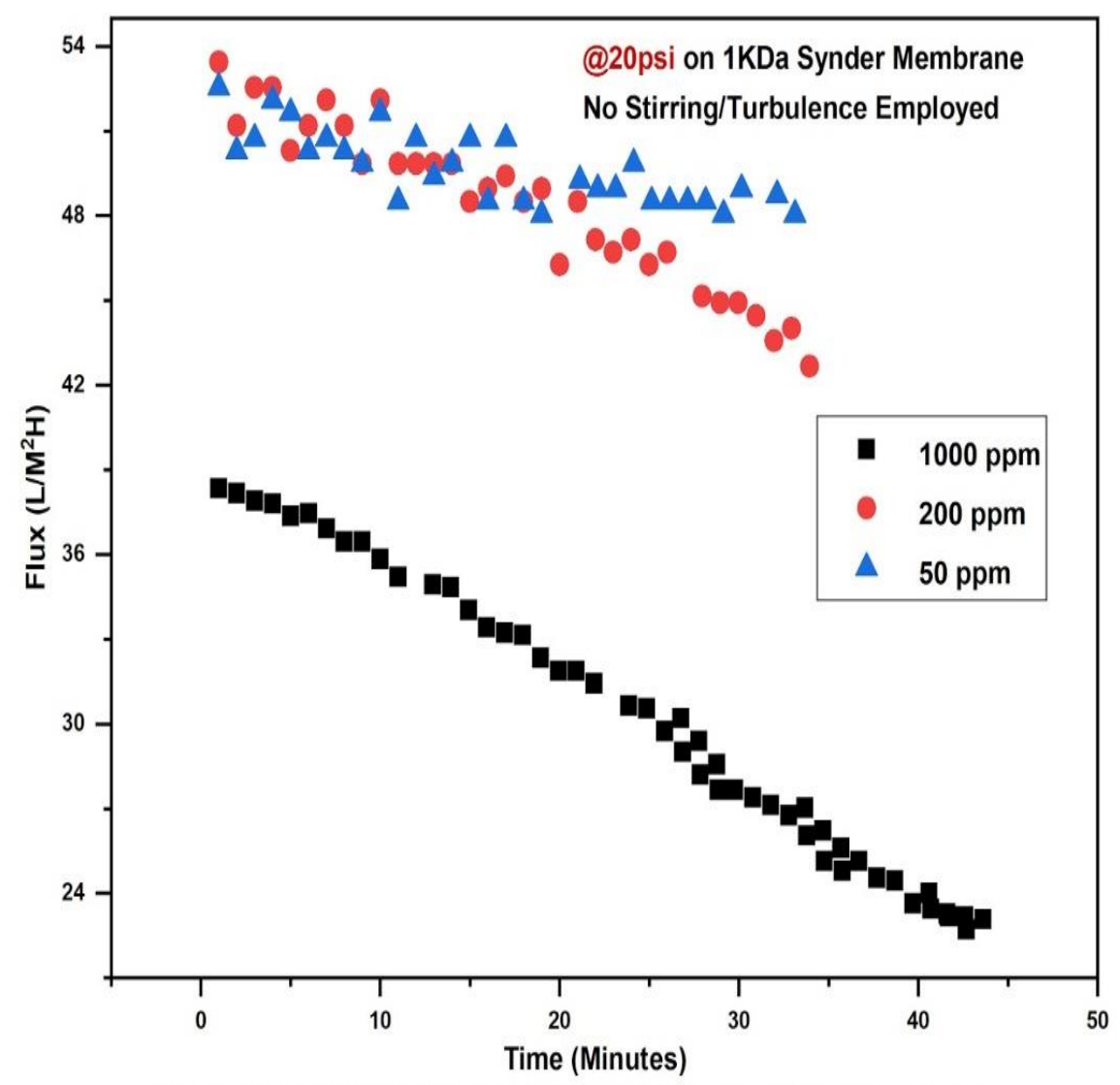

Flux vs Time: Effect of Concentration @ 20psi on 1KDa Membrane

Figure 6.5:Flux Plots for Effect of Concentration at 20 psi on 1kDa Membrane 


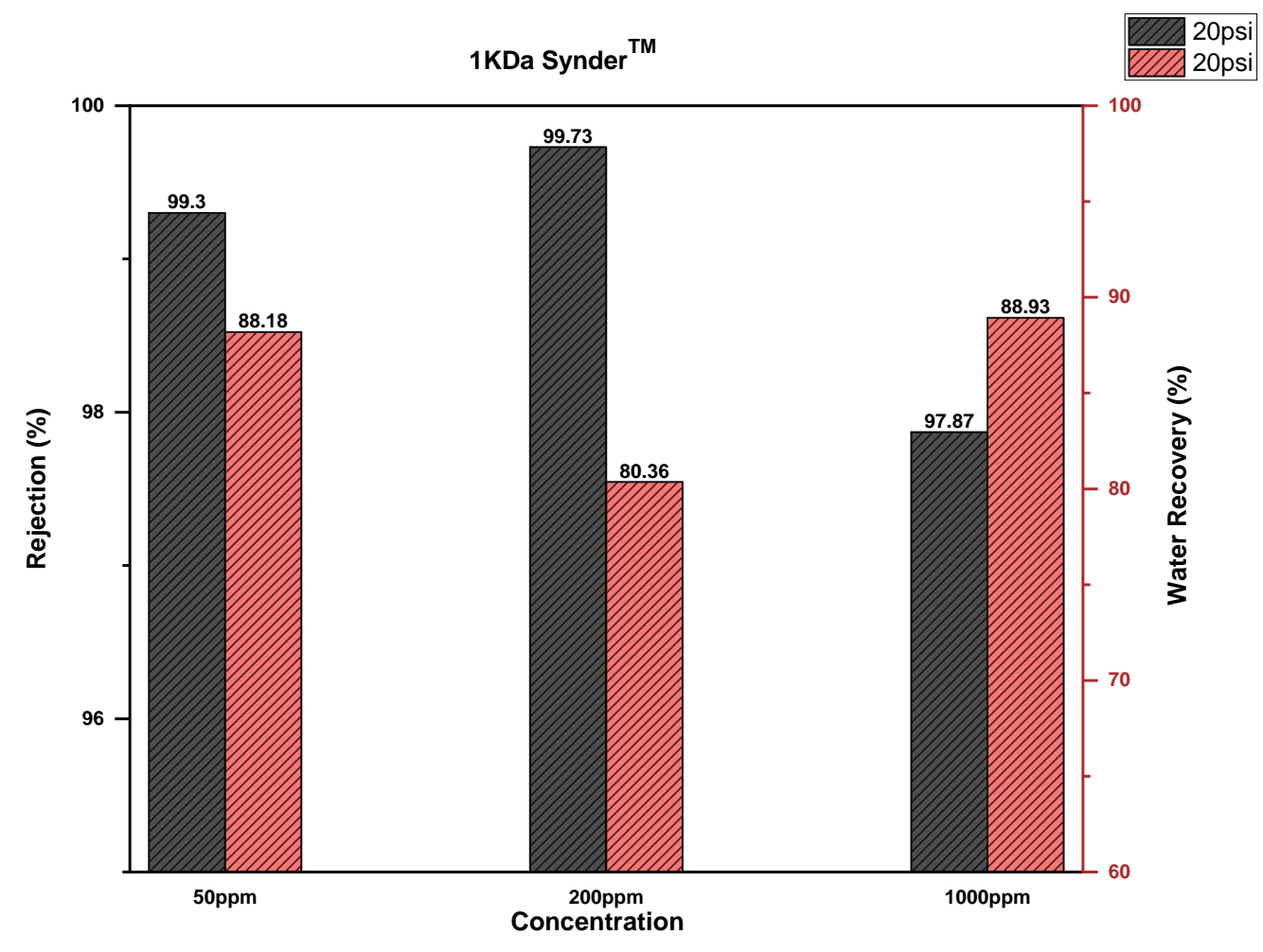

Percentage Rejection and Water Recovery as Functions of concentration @20psi on 1KDa

Figure 6.6:Rejection and Recovery Plots for Effect of Concentration at 20 psi on $1 \mathrm{kDa}$ Membrane

Figures $6.5-6.12$ show the plots for effect of concentration, applied pressure and MWCO. Figures 6.5 and 6.6 show the flux and rejection plots for different concentrations at 20 psi on $1 \mathrm{kDa}$ membranes. Figure 6.5 shows that for all the concentrations, the permeate flux decrease as the filtration time increases while the least concentrated feed $(50 \mathrm{ppm})$ experienced the least decay rate. It is important to note that a linear trend between flux and time is observed for all the three concentrations at the experimental conditions (20 psi on $1 \mathrm{kDa}$ membrane), which suggests that formation of consolidated cake layer on the membrane surface is highly unlikely at these conditions. Particles in the feed solutions are likely adsorbed individually on the membrane surface with particles from the most concentrated feed (1000 ppm) having more tendency of blocking the membrane pores. Figure 6.6 illustrate percent rejection and water recovery obtained for the three concentrations. High performance is achieved in the removal of virus-sized particles (colloidal silica); for the three concentrations at $20 \mathrm{psi}$ on $1 \mathrm{kDa} ; \geq 97 \%$ rejection. Highest rejection is observed for $200 \mathrm{ppm}$ suggesting that for the 200ppm feed, deposited cake on the membrane surface functioned as filter and that the particles are not too concentrated to slip through the pores. Also observed in the figure 6.6, average water recovery showed direct opposite trend as rejection; 200 ppm: least water recovery showing that cake layer for the $200 \mathrm{ppm}$ feed is likely due to high concentration polarization taking place. 


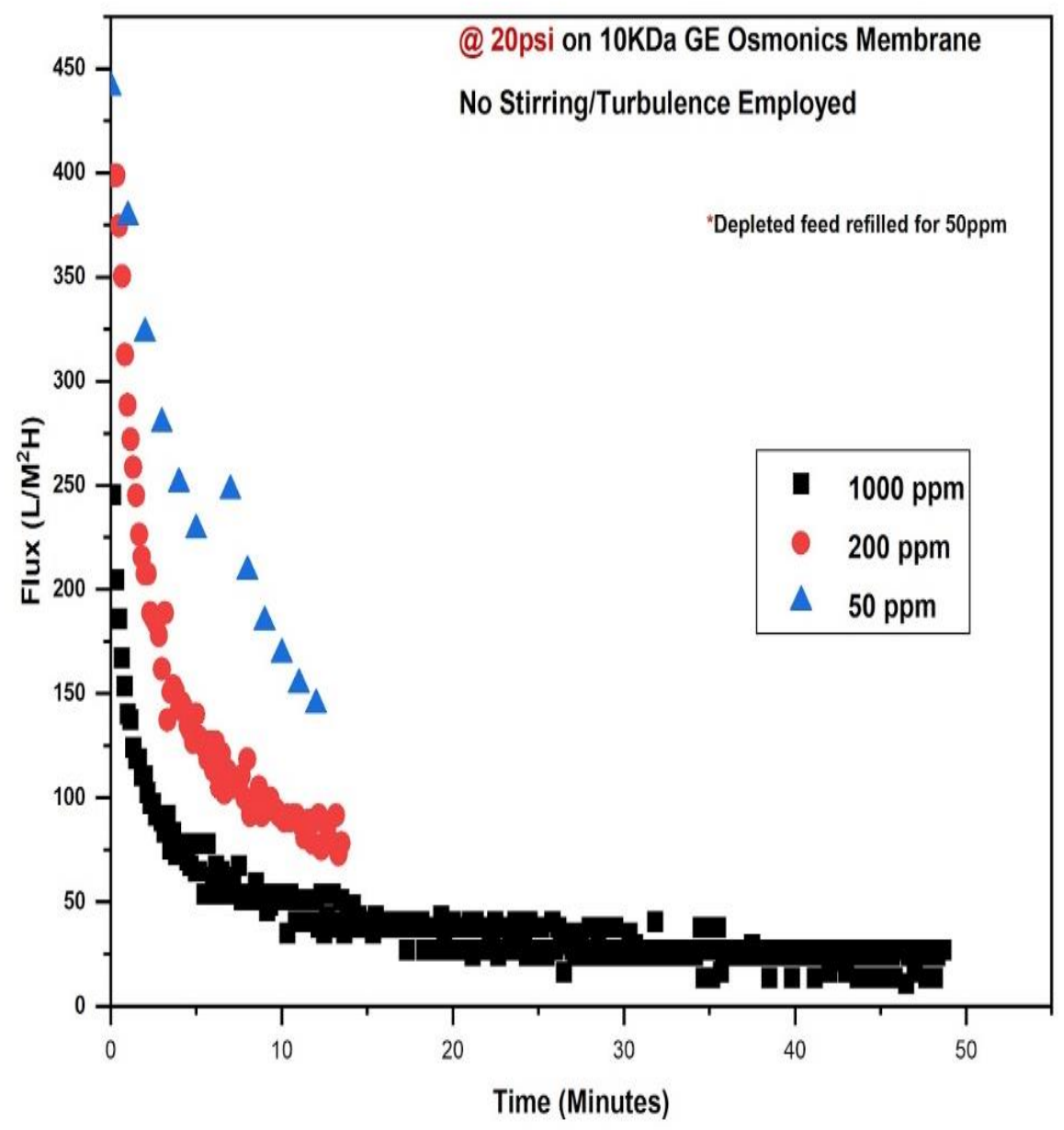

Flux vs Time: Effect of Concentration @ 20psi on 10KDa Membrane

Figure 6.7:Flux Plots for Effect of Concentration at 20 psi on 10kDa Membrane 


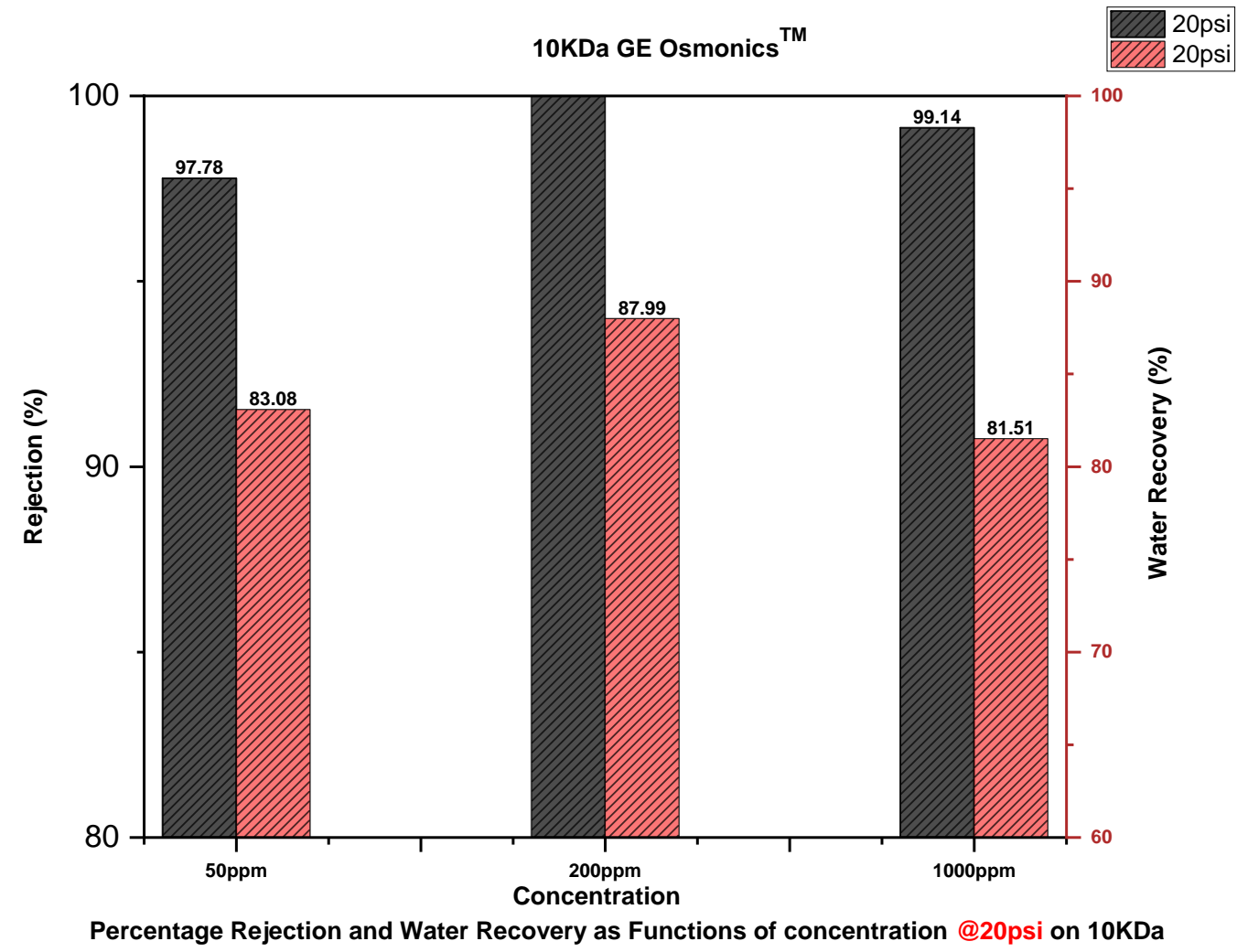

Figure 6.8:Rejection and Recovery Plots for Effect of Concentration at $20 \mathrm{psi}$ on $10 \mathrm{kDa}$ Membrane

Figures 6.7 and 6.8 illustrate respectively, flux and rejection plots for different concentrations (50 ppm, $200 \mathrm{ppm}$ and $1000 \mathrm{ppm}$ ) at $20 \mathrm{psi}$ on 10kDa membranes. From figure 15a, as expected, the flux for all the concentrations decrease with filtration clearly showing that as the process advances more particles are deposited on or within the membrane thereby reducing the effective path for fluid transport. Even though studies plotted in figures 6.5 and 6.7 were carried at same concentrations (50 ppm, $200 \mathrm{ppm}$ and $1000 \mathrm{ppm}$ ) and applied pressure (20 psi) (but with different MWCO), a striking difference is observed in their flux trend. Unlike in figure 6.5 where a linear flux decay is observed, the flux decline in figure 6.7 are clearly non-linear, exponential flux decay. This distinction in trend shows that even for same concentration and pressure, the fouling mechanism of the particle suspension is dependent on the MWCO of the membrane. Though membranes with higher MWCO (10kDa in this case), allow relatively high flux through the membrane, fouling of these $10 \mathrm{kDa}$ membranes were fast and more severe as almost steady-state fluxes were observed for all the concentrations within the first 15 minutes of the filtration time which suggests that pore plugging and blocking are more likely for the high MWCO membranes. Figure 6.8 shows the percentage particle rejection and water recovery for feed samples of three different concentrations treated using $10 \mathrm{kDa}$ membranes at 20psi. As shown in figure $6.8, \geq 97 \%$ particle rejection was observed for all the three concentrations showing that high removal of these virus-size particles was achieved by a UF 
process. Again, like figure 6.5, highest rejection is observed for $200 \mathrm{ppm}$ suggesting that for the 200ppm feed, particles deposited on the membrane were like blocking the membrane pores and forming cake on the membrane surface, which the deposited particles in turn functioned as secondary filter on the membrane surface. In comparison to the $200 \mathrm{ppm}$ feed, the relatively low rejection for the $1000 \mathrm{ppm}$ feed sample suggests some particles did slip through the membrane pore due to the very high number of particles deposited on the membrane surface for the $1000 \mathrm{ppm}$ feed. The trend observed for average water recovery in figure 6.8 shows rather an interesting feature as no clear relationship between particle rejection and water recovery is observed. A plausible assertion to make about this observation is that $200 \mathrm{ppm}$ feed having the highest water recovery formed the most stable permeable cake on the membrane surface while the least water recovery observed for the $1000 \mathrm{ppm}$ feed is because of consolidated pore blocking on the membrane surface. 


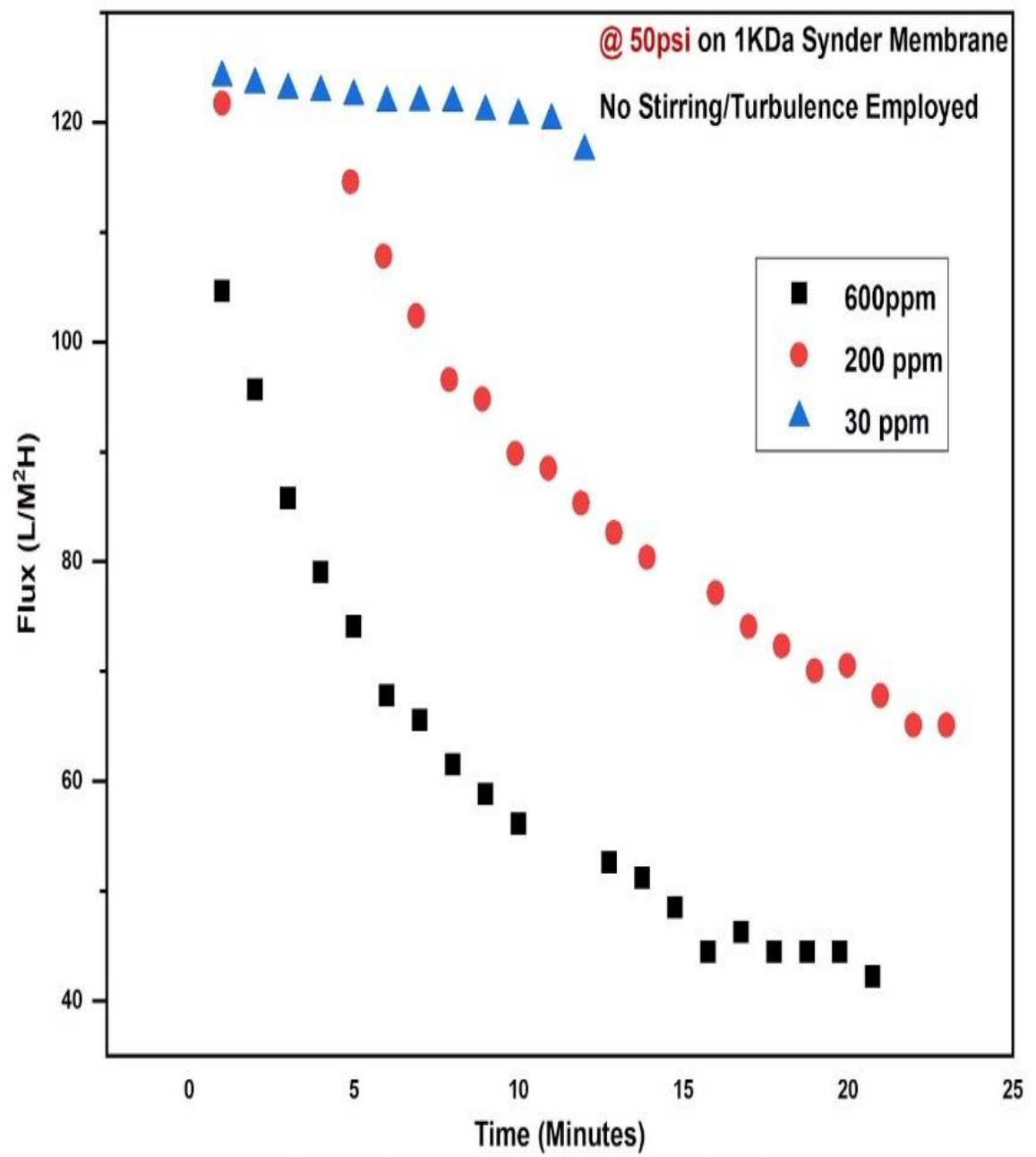

Flux vs Time: Effect of Concentration @ 50psi on 1KDa Membrane

Figure 6.9:Flux Plots for Effect of Concentration at 50 psi on 1kDa Membrane 


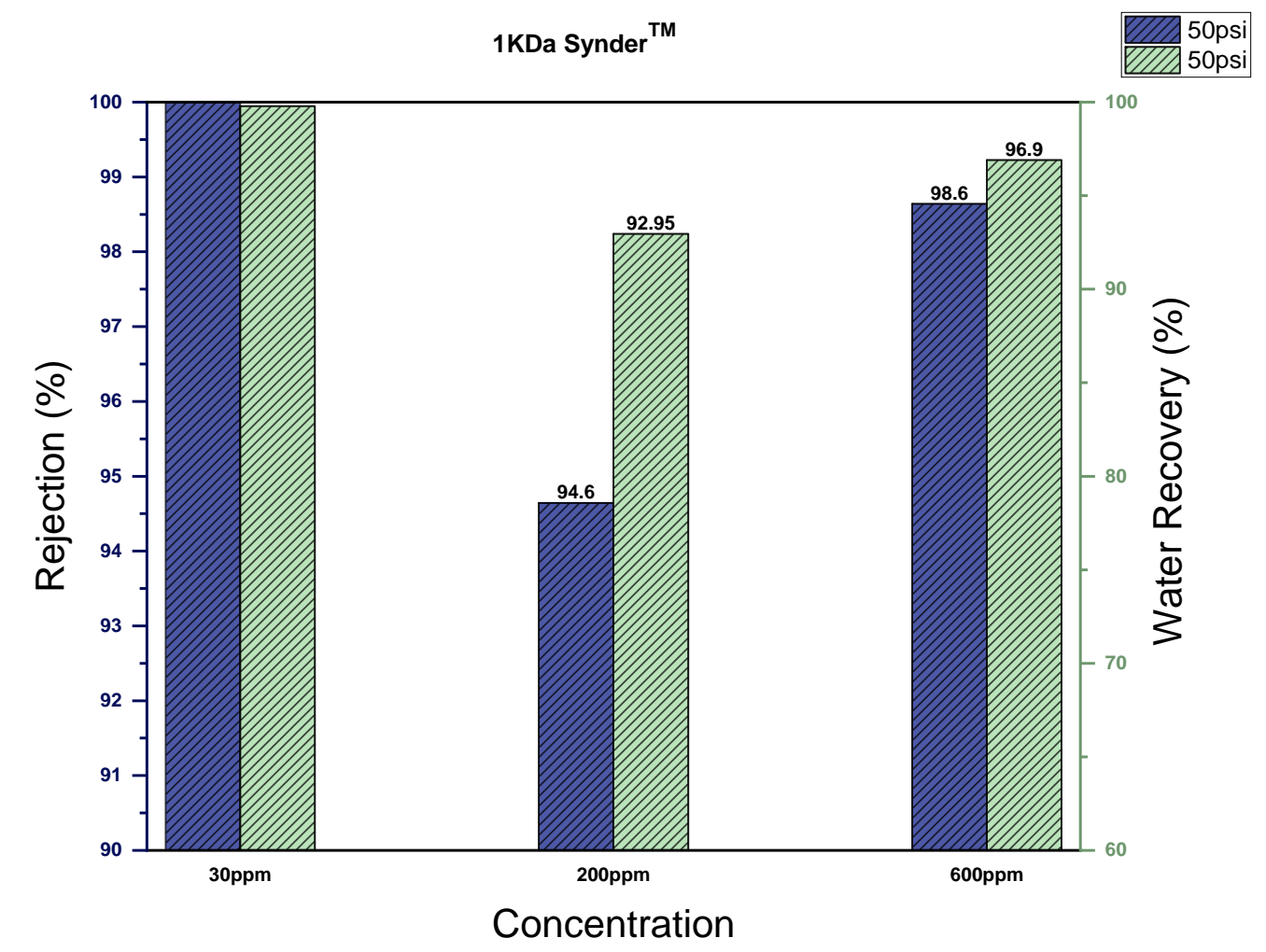

Percentage Rejection and Water Recovery as Functions of concentration @50psi on 1KDa

Figure 6.10:Rejection and Recovery Plots for Effect of Concentration at 50 psi on $1 \mathrm{kDa}$ Membrane

Figure 6.9 shows flux-time plots for three concentrations (30 ppm, 200 ppm and 600 ppm) treated using $1 \mathrm{kDa}$ membranes at 50 psi. Again, a concentration-dependent flux is observed; the least-concentrated feed $(30 \mathrm{ppm})$ experienced the least flux decline while the most concentrated feed $(600 \mathrm{ppm})$ was fouled the most, illustrating that as the ultrafiltration process progresses, more particles are deposited on or within the membrane for feed samples having high particle concentrations, which results in more reduction of transport channel for fluid passage. Figure 6.9 show similar trend as in figure $14 \mathrm{a}$ in that the flux-time plots for all the concentrations are almost linear, and the reason for this similarity is because the treatment of feed samples plotted on figures 6.5 and 6.9 were carried out using membranes of same MWCO $(1 \mathrm{kDa})$ suggesting that the fouling mechanisms observed in these two plots are almost same considering their flux trends.

Figure 6.11 presents the flux-time plots for three feeds of different concentrations (30 ppm, $200 \mathrm{ppm}$ and $600 \mathrm{ppm}$ ) treated using 10kDa membranes at $50 \mathrm{psi}$. Like figure 6.7, exponential flux decay is observed for all the concentrations. This non-linear flux decay that is more obvious for $10 \mathrm{kDa}$ membranes is due to relatively large pore size of membranes that allow high, fast but short-lived transport of fluid through the 
membrane. Owing to its larger pore size (for 10kDa), in addition to surface fouling due to cake layer formation, there is high tendency of pore plugging by the particles which in turn results to the membrane surface and pore areas being saturated with deposited particles.

The relatively high flux observed in figures 6.9 and $6.11 \mathrm{~S}$ (in comparison with figures 6.5 and 6.7, respectively) is because the studies on the plot were conducted at relatively high pressure (50 psi). Percentage rejection and water recovery obtained for the studies illustrated in figures 6.10 and 6.12 show that the least concentrated feed sample (30 ppm) experienced the highest particle rejections $(100 \%$ for both $1 \mathrm{kDa}$ and $10 \mathrm{kDa}$ membranes) while the least rejections ( $94 \%$ for $1 \mathrm{kDa}$ and $89 \%$ for $10 \mathrm{kDa}$ membrane) are observed for the 200ppm solution. Similar trend is also observed for water recovery. The perfect rejections observed for the $30 \mathrm{ppm}$ in these cases (figure 6.10 and figure 6.12 ) is due to two complementary reasons: (i) the size of the colloidal silica particles $(\approx 25 \mathrm{~nm})$ is significantly greater than the estimated average sizes of the membranes $(\approx 1.3 \mathrm{~nm}$ for $1 \mathrm{KDa}$ and $\approx 3 \mathrm{~nm}$ for $10 \mathrm{kDa}[108])$ and (ii) the particle concentration is too low that it is unlikely for particle slipping through the membrane pore. The least rejections observed for $200 \mathrm{ppm}$ feed samples for both cases illustrated in figures 6.10 and 6.12 is due to high tendency of particle slip-through occurring when the membrane is challenged by very concentrated solutions. Expectedly, the rejection obtained for $200 \mathrm{ppm}$ feed treated using $10 \mathrm{kDa}$ membrane $(\approx 89 \%)$ is less than that obtained for $200 \mathrm{ppm}$ treated using $1 \mathrm{kDa}(\approx 94 \%)$ confirming that the higher the MWCO, the higher the potential of particle slip-through, which in turn results to lower particle rejection. It is important to acknowledge that high rejection observed for 600 ppm feed samples in comparison with those for $200 \mathrm{ppm}$ is because $600 \mathrm{ppm}$ samples possess more particles to form consolidated cake layer (which acts as another rejecting medium) on the membrane surface. At these conditions (30 ppm, 200 ppm and 600 ppm feed samples), no clear relationship between water recovery and rejection (function of particle concentrations, applied pressure and MWCO) is found. 


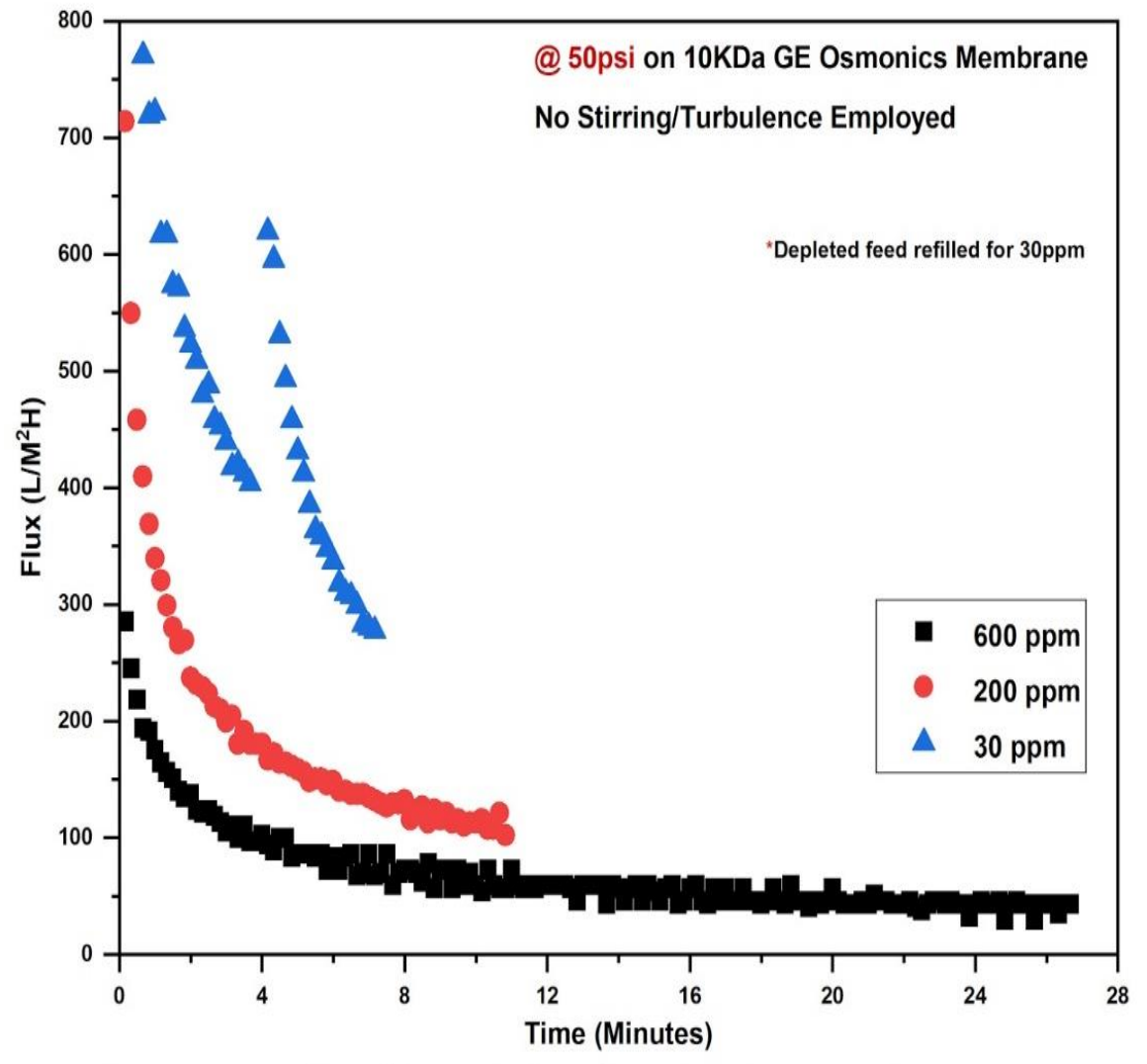

Flux vs Time: Effect of Concentration @ 50psi on 10KDa Membrane

Figure 6.11:Flux Plots for Effect of Concentration at 50 psi on 10KDa Membrane 


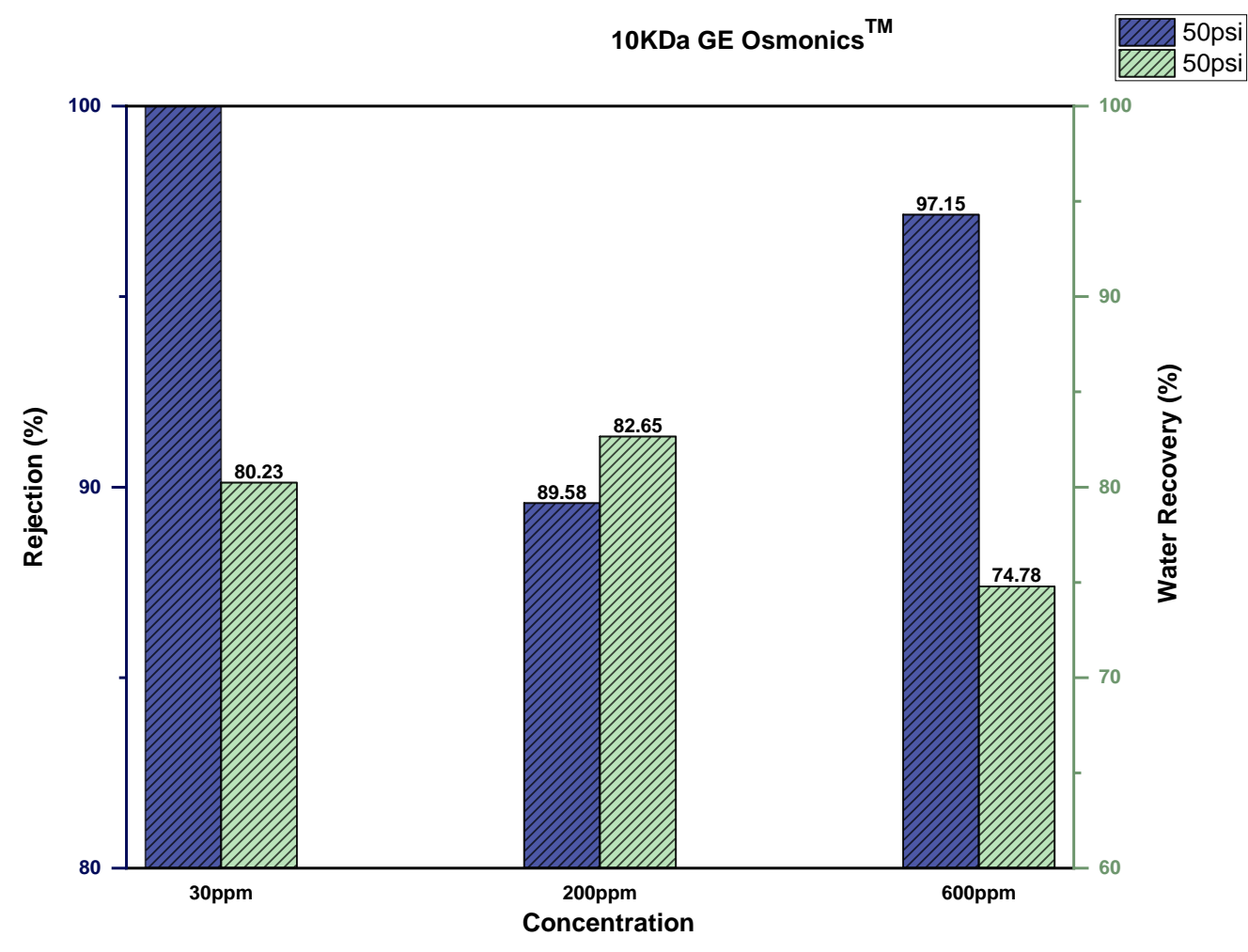

Percentage Rejection and Water Recovery as Functions of concentration @50psi on 10KDa

Figure 6.12:Rejection and Recovery Plots for Effect of Concentration at 50 psi on 10kDa Membrane

\subsubsection{Description by Blocking Laws}

Figure 13 shows plots of $\frac{t}{V}$ vs $\mathrm{V}$ used to assess how the experimental data were sufficiently described by cake filtration mechanism for effects nanoparticle concentration. The data were equally fitted to the other three laws by plotting $\frac{t}{V} \mathrm{vs} t$, $\frac{1}{J}-\frac{1}{J_{o}}$ vs $\mathrm{t}$ and $\ln (\mathrm{J})$ vs $\mathrm{t}$ for standard blocking, intermediate blocking and complete blocking, respectively (plots shown in Appendix A.5.1 - A.5.4). How well each law predicted the experimental data was quantified in terms of the well-known coefficient of determination.

As mathematically evident from these equations, a linear relationship should exist between the relevant dependent and independent variables corresponding to each law. Specifically, figure 6.13 shows the linear trend expected between the volume of permeate and the time required to obtain a given permeate volume. In this case, the two most important things for these linear plots are their slopes and their corresponding 
coefficient of determination $\left(\mathrm{R}^{2}\right)$. The slopes of the plots represent indices of fouling while the $\mathrm{R}^{2}$ shows how well the data were predicted.

From figure 6.13 as expected, a linear relationship is obtained for all the nanoparticle concentrations, with the line gradient increasing with colloid concentration. The reason for this increase in slope with concentration is that feeds with more colloid concentration cause more particles to be deposited on or within the membrane during filtration. This outcome is particularly as expected the ultrafiltration process was conducted via dead-end mode without turbulence. It is important to state that while cake filtration model accurately predict data obtained for most concentrations (30ppm at 50psi, 200ppm at 50psi and 1000ppm at 20psi), standard blocking most correctly describe result for 200ppm at 50psi and no law sufficiently describe the results 50ppm and 600ppm. Results obtained by analyzing accuracy of other laws to predict these data are shown in figures A.5.1 - A.5.4 in appendix A. Result for 30ppm was also adequately predicted by intermediate blocking law. This outcome is rationalized on the basis that $10 \mathrm{KDa}$ membrane has pores large enough to be partially constricted by the nanoparticle. The nonuniformity time spacing of points in figure 6.13 was because the data were logged at different time interval.

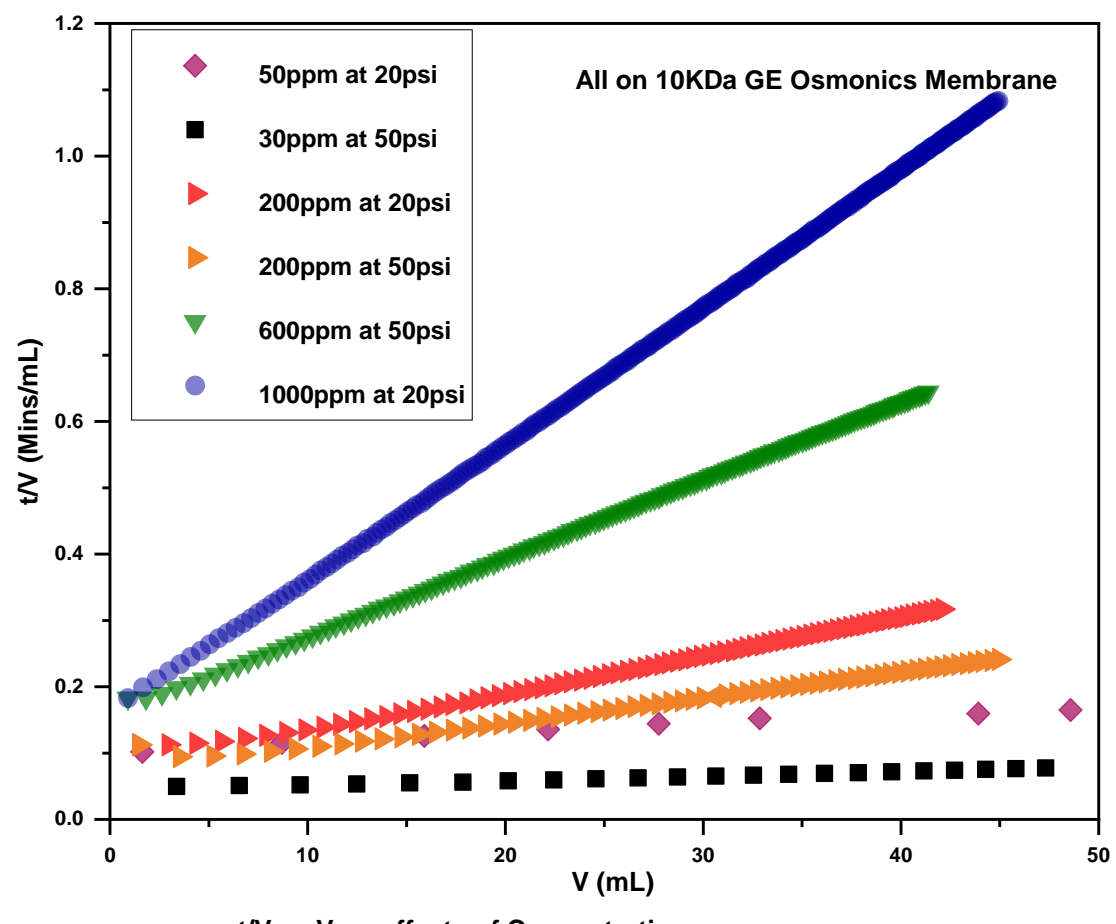

$t / V$ vs $V$ on effects of Concentration.

Figure 6.13:Plot of t/V vs V for Effect of Nanoparticle Concentration. 


\section{Conclusions and Recommendations for Future Work}

Application of MBR has grown beyond the treatment of readily degradable to problematic industrial feeds. This was made possible by improved performance of novel and hybrid MBR systems that have been recently developed. Problematic feeds lead to biological and membrane operational challenges. The review also confirmed that membrane fouling remains a challenge to membrane systems for water treatment. There is equally urgent need for means of sustainable membrane integrity

This research study also investigated how different feed properties affect colloidal fouling of UF membranes. Feed $\mathrm{pH}$ and salinity have been found to strongly affect silica colloid-membrane electrostatic interactions with consequent effects on fouling of UF membranes. Increase in colloid concentration equally result to increase fouling rate for all the membranes used, even at different at different operating pressure. No single blocking law adequately predicted the experimental results obtained for the effect of nanoparticle concentration.

While the results of this work revealed the mechanism of UF membrane fouling by colloids, it is important to acknowledge that the used nanoparticles are inorganic particles, and their behavior may not represent those of organic colloids. Hence, a systematic investigation of how organic colloids in water affect fouling of UF membranes is strongly recommended. 


\section{Reference List}

1. Gall, A.M., et al., Waterborne viruses: a barrier to safe drinking water. PLoS pathogens, 2015. 11(6): p. e1004867.

2. Supply, W.U.J.W. and S.M. Programme, Progress on drinking water and sanitation: 2014 Update. 2014: World Health Organization.

3. Fane, A.G., R. Wang, and M.X.J.A.C.I.E. Hu, Synthetic membranes for water purification: status and future. 2015. 54(11): p. 3368-3386.

4. Kummu, M., et al., The world's road to water scarcity: shortage and stress in the 20th century and pathways towards sustainability. Scientific Reports, 2016. 6: p. 38495 .

5. Gosling, S.N. and N.W. Arnell, A global assessment of the impact of climate change on water scarcity. Climatic Change, 2016. 134(3): p. 371-385.

6. Schewe, J., et al., Multimodel assessment of water scarcity under climate change. Proc Natl Acad Sci U S A, 2014. 111(9): p. 3245-50.

7. Uzoh, C.F., et al., Electrocoagulation of $\mathrm{Pb2}+, \mathrm{Co} 2+$ and $\mathrm{Mn} 2+$ from Simulated Wastewater: An Algorithmic Optimization using Hybrid RSM-GA-PSO.

8. Bazrafshan, E., et al., Heavy metals removal from aqueous environments by electrocoagulation process-a systematic review. 2015. 13(1): p. 74.

9. Hunsom, M., et al., Electrochemical treatment of heavy metals (Cu2+, Cr6+, $\mathrm{Ni2+)}$ from industrial effluent and modeling of copper reduction. 2005. 39(4): p. 610-616.

10. Lattemann, S., et al., Chapter 2 Global Desalination Situation, in Sustainability Science and Engineering, I.C. Escobar and A.I. Schäfer, Editors. 2010, Elsevier. p. 7-39.

11. Pearce, G., UF/MF pre-treatment to $R O$ in seawater and wastewater reuse applications: a comparison of energy costs. Desalination, 2008. 222(1-3): p. 6673.

12. Gadgil, A., Drinking water in developing countries. Annual review of energy and the environment, 1998. 23(1): p. 253-286.

13. UNICEF, W., Pneumonia and diarrhoea: Tackling the deadliest diseases for the world's poorest children. New York: UNICEF, 2012. 2013. 
14. Shannon, M.A., et al., Science and technology for water purification in the coming decades, in Nanoscience and technology: a collection of reviews from nature Journals. 2010, World Scientific. p. 337-346.

15. Lightfoot, N., Bacteria of potential health concern. Heterotrophic Plate Counts of Drinking-water Safety, 2003: p. 62-79.

16. Duy, T.N., et al., Toxicology and risk assessment of freshwater cyanobacterial (blue-green algal) toxins in water, in Reviews of Environmental Contamination and Toxicology. 2000, Springer. p. 113-185.

17. Wagner, M., et al., Microplastics in freshwater ecosystems: what we know and what we need to know. Environmental Sciences Europe, 2014. 26(1): p. 12.

18. Hulton, G. and W.H. Organization, Global costs and benefits of drinking-water supply and sanitation interventions to reach the MDG target and universal coverage. 2012, World Health Organization.

19. Tian, J.-y., et al., Effect of particle size and concentration on the synergistic UF membrane fouling by particles and NOM fractions. Journal of membrane science, 2013. 446: p. 1-9.

20. Bird, R.B., W.E. Stewart, and E.N. Lightfoot, Transport phenomena. 2007: John Wiley \& Sons.

21. Baker, R.W., Membrane technology and applications. 2012: John Wiley \& Sons.

22. Erickson, H.P.J.B.p.o., Size and shape of protein molecules at the nanometer level determined by sedimentation, gel filtration, and electron microscopy. 2009. 11(1): p. 32.

23. Simpson, J.T., S.R. Hunter, and T. Aytug, Superhydrophobic materials and coatings: a review. Reports on Progress in Physics, 2015. 78(8): p. 086501.

24. Nieuwenhuijsen, M.J., et al., Chlorination disinfection byproducts in water and their association with adverse reproductive outcomes: a review. 2000. 57(2): p. 73-85.

25. Ahn, K.-H., J.-H. Song, and H.-Y. Cha, Application of tubular ceramic membranes for reuse of wastewater from buildings. Water Science and Technology, 1998. 38(4-5): p. 373-382.

26. Stephenson, T., et al., Membrane bioreactors for wastewater treatmentIWA Publishing. 2000, London. 
27. Chen, T., et al., MBR/RO/ozone processes for TFT-LCD industrial wastewater treatment and recycling. Water Science and Technology, 2005. 51(6-7): p. 411419.

28. Côté, P., M. Masini, and D. Mourato, Comparison of membrane options for water reuse and reclamation. Desalination, 2004. 167: p. 1-11.

29. Jeison, D. and J.B. van Lier, Cake layer formation in anaerobic submerged membrane bioreactors (AnSMBR) for wastewater treatment. Journal of Membrane Science, 2006. 284(1-2): p. 227-236.

30. Brepols, C., et al., Upgrading and retrofitting of municipal wastewater treatment plants by means of membrane bioreactor (MBR) technology. Desalination, 2008. 231(1-3): p. 20-26.

31. Visvanathan, C., R.B. Aim, and K. Parameshwaran, Membrane Separation Bioreactors for Wastewater Treatment. Critical Reviews in Environmental Science and Technology, 2000. 30(1): p. 1-48.

32. Xiao, K., et al., Current state and challenges of full-scale membrane bioreactor applications: A critical review. Bioresource technology, 2019. 271: p. 473-481.

33. Lee, M., et al., Water-energy nexus for urban water systems: A comparative review on energy intensity and environmental impacts in relation to global water risks. Applied Energy, 2017. 205: p. 589-601.

34. Smith, A.L., et al., Perspectives on anaerobic membrane bioreactor treatment of domestic wastewater: a critical review. Bioresour Technol, 2012. 122: p. 14959.

35. Robles, A., et al., A review on anaerobic membrane bioreactors (AnMBRs) focused on modelling and control aspects. Bioresour Technol, 2018. 270: p. 612626.

36. Liao, B.-Q., J.T. Kraemer, and D.M. Bagley, Anaerobic membrane bioreactors: applications and research directions. Critical Reviews in Environmental Science and Technology, 2006. 36(6): p. 489-530.

37. Lin, H., et al., Membrane bioreactors for industrial wastewater treatment: a critical review. Critical reviews in environmental science and technology, 2012. 42(7): p. 677-740.

38. Wu, B., P.C.Y. Wong, and A.G. Fane, The potential roles of granular activated carbon in anaerobic fluidized membrane bioreactors: effect on membrane fouling and membrane integrity. Desalination and Water Treatment, 2015. 53(6): p. $1450-1459$. 
39. Buzatu, P., et al., Clogging vs. fouling in immersed membrane bioreactors. Water Research, 2018. 144: p. 46-54.

40. Delgado, L.F., et al., The removal of endocrine disrupting compounds, pharmaceutically activated compounds and cyanobacterial toxins during drinking water preparation using activated carbon-a review. Science of the total environment, 2012. 435: p. 509-525.

41. Li, X., F.I. Hai, and L.D. Nghiem, Simultaneous activated carbon adsorption within a membrane bioreactor for an enhanced micropollutant removal. Bioresource technology, 2011. 102(9): p. 5319-5324.

42. Yoon, Y., et al., Removal of endocrine disrupting compounds and pharmaceuticals by nanofiltration and ultrafiltration membranes. Desalination, 2007. 202(1-3): p. 16-23.

43. Rautenbach, R. and R. Mellis, Waste water treatment by a combination of bioreactor and nanofiltration. Desalination, 1994. 95(2): p. 171-188.

44. Choi, J.-H., et al., A novel application of a submerged nanofiltration membrane bioreactor (NF MBR) for wastewater treatment. Desalination, 2002. 146(1-3): p. 413-420.

45. Tay, M.F., et al., The feasibility of nanofiltration membrane bioreactor (NF$M B R)+$ reverse osmosis $(R O)$ process for water reclamation: Comparison with ultrafiltration membrane bioreactor $(U F-M B R)+R O$ process. Water research, 2018. 129: p. 180-189.

46. Cornelissen, E., et al., Membrane fouling and process performance of forward osmosis membranes on activated sludge. Journal of membrane science, 2008. 319(1-2): p. 158-168.

47. Zhao, S., et al., Recent developments in forward osmosis: opportunities and challenges. Journal of membrane science, 2012. 396: p. 1-21.

48. Achilli, A., et al., The forward osmosis membrane bioreactor: a low fouling alternative to MBR processes. Desalination, 2009. 239(1-3): p. 10-21.

49. Cath, T., A. Childress, and M. Elimelech, Forward osmosis: Principles, applications, and recent developments. Journal of Membrane Science, 2006. 281(1-2): p. 70-87.

50. Alturki, A., et al., Performance of a novel osmotic membrane bioreactor (OMBR) system: flux stability and removal of trace organics. Bioresour Technol, 2012. 113: p. 201-6. 
51. Lay, W.C.L., et al., Effect of Pharmaceuticals on the Performance of a Novel Osmotic Membrane Bioreactor (OMBR). Separation Science and Technology, 2012. 47(4): p. 543-554.

52. Zhang, J., et al., Membrane biofouling and scaling in forward osmosis membrane bioreactor. Journal of Membrane Science, 2012. 403: p. 8-14.

53. Phattaranawik, J., et al., A novel membrane bioreactor based on membrane distillation. Desalination, 2008. 223(1-3): p. 386-395.

54. Phattaranawik, J., et al., Experimental Study and Design of a Submerged Membrane Distillation Bioreactor. Chemical Engineering \& Technology, 2009. 32(1): p. 38-44.

55. Khaing, T.-H., et al., Feasibility study on petrochemical wastewater treatment and reuse using a novel submerged membrane distillation bioreactor. Separation and Purification Technology, 2010. 74(1): p. 138-143.

56. Goh, S., et al., Membrane Distillation Bioreactor (MDBR) - A lower GreenHouse-Gas (GHG) option for industrial wastewater reclamation. Chemosphere, 2015. 140: p. 129-42.

57. Sun, C., et al., Comparison of membrane filtration performance between biofilmMBR and activated sludge-MBR. Desalination and Water Treatment, 2012. 48(13): p. 285-293.

58. Livingston, A.G., A novel membrane bioreactor for detoxifying industrial wastewater: I. Biodegradation of phenol in a synthetically concocted wastewater. Biotechnology and Bioengineering, 1993. 41(10): p. 915-926.

59. Liao, Y., et al., Effects of internal concentration polarization and membrane roughness on phenol removal in extractive membrane bioreactor. Journal of Membrane Science, 2018. 563: p. 309-319.

60. De Temmerman, L., et al., The effect of fine bubble aeration intensity on membrane bioreactor sludge characteristics and fouling. Water Res, 2015. 76: p. 99-109.

61. Krzeminski, P., et al., Membrane bioreactors $-A$ review on recent developments in energy reduction, fouling control, novel configurations, LCA and market prospects. Journal of Membrane Science, 2017. 527: p. 207-227.

62. Di Bella, G., D. Di Trapani, and S. Judd, Fouling mechanism elucidation in membrane bioreactors by bespoke physical cleaning. Separation and Purification Technology, 2018. 199: p. 124-133. 
63. Dizge, N., et al., Effects of cationic polyelectrolyte on filterability and fouling reduction of submerged membrane bioreactor (MBR). Journal of Membrane Science, 2011. 377(1-2): p. 175-181.

64. Yin, Z., V.V. Tarabara, and I. Xagoraraki, Effect of pressure relaxation and membrane backwash on adenovirus removal in a membrane bioreactor. Water Res, 2016. 88: p. 750-757.

65. Aslam, M., R. Ahmad, and J. Kim, Recent developments in biofouling control in membrane bioreactors for domestic wastewater treatment. Separation and Purification Technology, 2018. 206: p. 297-315.

66. Li, R., et al., A novel strategy to develop antifouling and antibacterial conductive Cu/polydopamine/polyvinylidene fluoride membranes for water treatment. J Colloid Interface Sci, 2018. 531: p. 493-501.

67. Deng, L., et al., Effects of hydraulic retention time and bioflocculant addition on membrane fouling in a sponge-submerged membrane bioreactor. Bioresour Technol, 2016. 210: p. 11-7.

68. Skouteris, G., et al., The effect of activated carbon addition on membrane bioreactor processes for wastewater treatment and reclamation - A critical review. Bioresour Technol, 2015. 185: p. 399-410.

69. Zhang, Q., S. Singh, and D.C. Stuckey, Fouling reduction using adsorbents/flocculants in a submerged anaerobic membrane bioreactor. Bioresour Technol, 2017. 239: p. 226-235.

70. Jawaid, M., et al., Application of Nano PAC on Mitigating Membrane Fouling by Surface Properties Optimization. MATEC Web of Conferences, 2016. 67.

71. Lee, K., et al., Quorum sensing and quenching in membrane bioreactors: Opportunities and challenges for biofouling control. Bioresour Technol, 2018. 270: p. 656-668.

72. Bani-Melhem, K. and M. Elektorowicz, Performance of the submerged membrane electro-bioreactor (SMEBR) with iron electrodes for wastewater treatment and fouling reduction. Journal of Membrane Science, 2011. 379(1-2): p. 434-439.

73. Ibeid, S., M. Elektorowicz, and J.A. Oleszkiewicz, Novel electrokinetic approach reduces membrane fouling. Water Res, 2013. 47(16): p. 6358-66.

74. Jiang, B., et al., Enhanced treatment performance of coking wastewater and reduced membrane fouling using a novel EMBR. Bioresour Technol, 2017. 229: p. 39-45. 
75. Liu, L., et al., Minute electric field reduced membrane fouling and improved performance of membrane bioreactor. Separation and Purification Technology, 2012. 86: p. 106-112.

76. Hou, B., et al., Enhanced performance and hindered membrane fouling for the treatment of coal chemical industry wastewater using a novel membrane electrobioreactor with intermittent direct current. Bioresour Technol, 2019. 271: p. 332339.

77. Kose, B., et al., Performance evaluation of a submerged membrane bioreactor for the treatment of brackish oil and natural gas field produced water. Desalination, 2012. 285: p. 295-300.

78. Hai, F.I., K. Yamamoto, and C.-H. Lee, Membrane biological reactors. 2013: Iwa Publishing.

79. Judd, S., The MBR book: principles and applications of membrane bioreactors for water and wastewater treatment. 2010: Elsevier.

80. Lu, R., et al., Effect of virus influent concentration on its removal by microfiltration: The case of human adenovirus 2. Journal of Membrane Science, 2016. 497: p. 120-127.

81. Cho, J., K.-G. Song, and K.-H. Ahn, The activated sludge and microbial substances influences on membrane fouling in submerged membrane bioreactor: unstirred batch cell test. Desalination, 2005. 183(1-3): p. 425-429.

82. Qin, L., et al., Advanced membrane bioreactors systems: new materials and hybrid process design. Bioresource Technology, 2018.

83. Brepols, C., H. Schafer, and N. Engelhardt, Considerations on the design and financial feasibility of full-scale membrane bioreactors for municipal applications. Water Sci Technol, 2010. 61(10): p. 2461-8.

84. Barillon, B., et al., Energy efficiency in membrane bioreactors. Water Science and Technology, 2013. 67(12): p. 2685-2691.

85. Fenu, A., et al., Energy audit of a full scale MBR system. Desalination, 2010. 262(1-3): p. 121-128.

86. Sun, J., et al., Reducing aeration energy consumption in a large-scale membrane bioreactor: Process simulation and engineering application. Water research, 2016. 93: p. 205-213. 
87. Xiao, K., et al., Engineering application of membrane bioreactor for wastewater treatment in China: current state and future prospect. Frontiers of Environmental Science \& Engineering, 2014. 8(6): p. 805-819.

88. Krzeminski, P., et al., The optimal MBR configuration: Hybrid versus standalone - Comparison between three full-scale MBRs treating municipal wastewater. Desalination, 2012. 284: p. 341-348.

89. Tao, G., et al., Membrane bioreactors for water reclamation. Water Science and Technology, 2005. 51(6-7): p. 431-440.

90. Gabarrón, S., et al., Assessment of energy-saving strategies and operational costs in full-scale membrane bioreactors. Journal of environmental management, 2014. 134: p. 8-14.

91. Xiong, J., et al., Recovery of NH3-N from mature leachate via negative pressure steam-stripping pretreatment and its benefits on MBR systems: A pilot scale study. Journal of Cleaner Production, 2018. 203: p. 918-925.

92. Ho, J., S. Smith, and H.K. Roh, Alternative energy efficient membrane bioreactor using reciprocating submerged membrane. Water Sci Technol, 2014. 70(12): p. 1998-2003.

93. Krzeminski, P., J.H. van der Graaf, and J.B. van Lier, Specific energy consumption of membrane bioreactor $(M B R)$ for sewage treatment. Water Sci Technol, 2012. 65(2): p. 380-92.

94. Tao, G., et al., Energy reduction and optimisation in membrane bioreactor systems. Water Practice and Technology, 2010. 5(4).

95. Xing, C.-H., et al., Physical and biological characteristics of a tangential-flow MBR for municipal wastewater treatment. 2001. 191(1-2): p. 31-42.

96. Stubblefield, A.P., et al., Use of turbidometry to characterize suspended sediment and phosphorus fluxes in the Lake Tahoe basin, California, USA. Hydrological Processes: An International Journal, 2007. 21(3): p. 281-291.

97. Shrestha, S. and F. Kazama, Assessment of surface water quality using multivariate statistical techniques: A case study of the Fuji river basin, Japan. Environmental Modelling \& Software, 2007. 22(4): p. 464-475.

98. Wang, F. and V.V. Tarabara, Pore blocking mechanisms during early stages of membrane fouling by colloids. Journal of colloid and interface science, 2008. 328(2): p. 464-469. 
99. Iritani, E. and N. Katagiri, Developments of blocking filtration model in membrane filtration. KONA Powder and Particle Journal, 2016. 33: p. 179-202.

100. Ryu, D.H., et al., Deposition of titania nanoparticles on spherical silica. 2003. 26(1-3): p. 489-493.

101. Salgin, S., U. Salgin, and N.J.I.J.E.S. Soyer, Streaming potential measurements of polyethersulfone ultrafiltration membranes to determine salt effects on membrane zeta potential. 2013. 8(2013): p. 4073-4084.

102. Sim, S., et al., Colloidal metastability and membrane fouling-Effects of crossflow velocity, flux, salinity and colloid concentration. 2014. 469: p. 174-187.

103. Han, R., et al., Desalination of dye utilizing copoly (phthalazinone biphenyl ether sulfone) ultrafiltration membrane with low molecular weight cut-off. Journal of Membrane Science, 2010. 358(1-2): p. 1-6.

104. Gauß, C.F., Besprechung Des buchs von la seeber: Untersuchungen uber die eigenschaften der positiven ternaren quadratischen formen usw. Gottingensche Gelehrte Anzeigen, 1876. 2: p. 188-196.

105. Song, C., P. Wang, and H.A. Makse, A phase diagram for jammed matter. Nature, 2008. 453(7195): p. 629.

106. Anikeenko, A., et al., Observation of fivefold symmetry structures in computer models of dense packing of hard spheres. Journal of Non-Crystalline Solids, 2007. 353(32-40): p. 3545-3549.

107. Schaep, J., et al., Modelling the retention of ionic components for different nanofiltration membranes. Separation and purification Technology, 2001. 22: p. 169-179.

108. Wilkinson, K.J. and J.R. Lead, Environmental colloids and particles: behaviour, separation and characterisation. Vol. 10. 2007: John Wiley \& Sons.

\section{Other References}

https://www.epa.gov/ Last accessed December 2019

https://www.pub.gov.sg/ Last accessed December 2019

https://www.saginaw-

mi.com/departments/wastewaterandwatertreatmentservices/watertreatment/watertreat mentprocess.php Last accessed December 2019 
https://city.milwaukee.gov/ImageLibrary/Groups/WaterWorks/ConsumerConfidence-Reports/2018ConsumerConfidenceReport.pdf Last accessed December 2019 


\section{A Appendix A: Supporting Figures}

\section{A.1 Absorbance-Concentration Calibration Report I}

Page 1 of 2 5/20/2019 1:13:52 PM

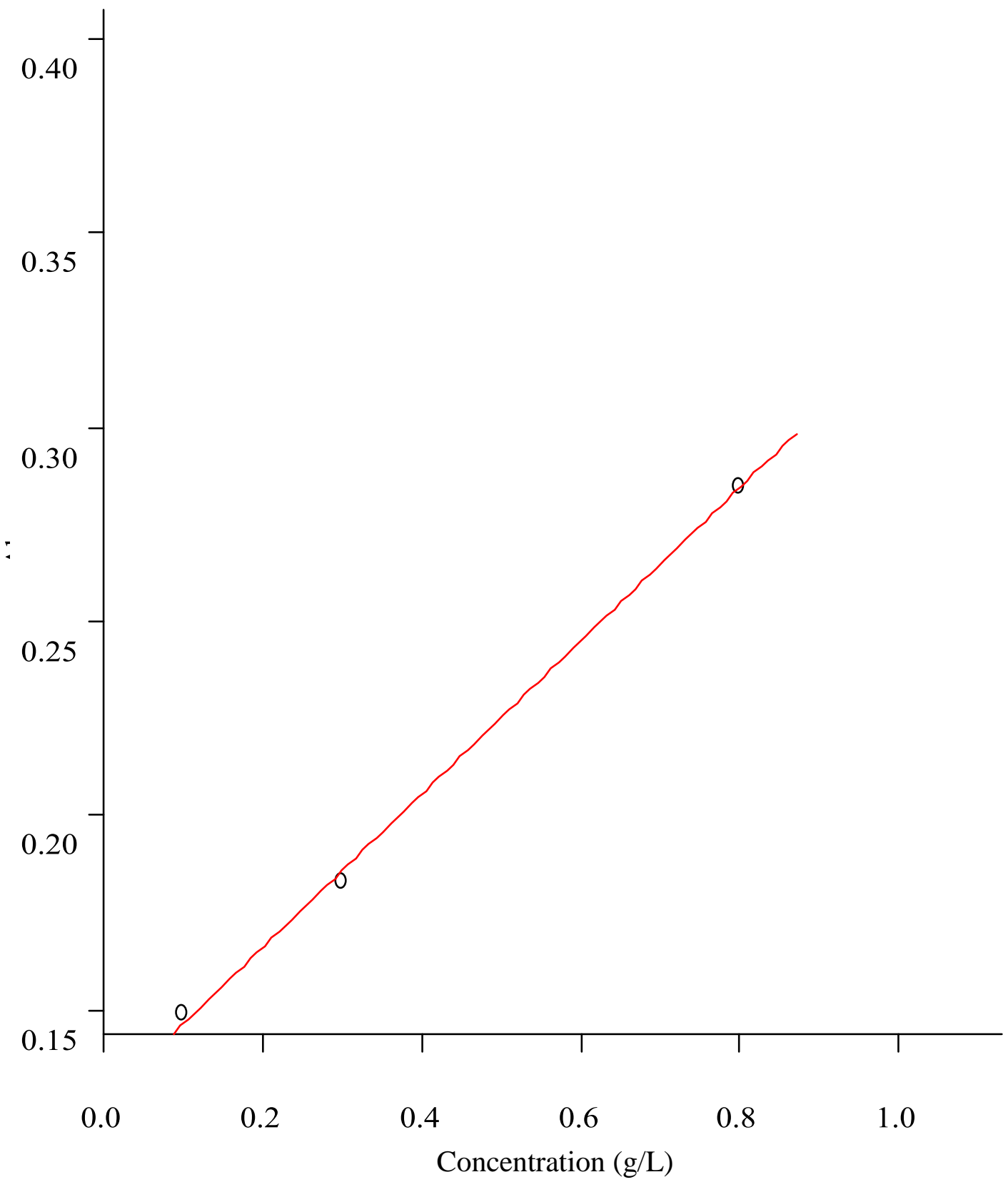

Appendix A 1:Absorbance-Concentration Calibration Report for Summer 2019 
Concentration Analysis Report

Report time 5/20/2019 1:03:24 PM

Method

Batch name

C:IUsers $\backslash$ Dr. $\quad$ Da

CostalDocuments \Cal_Curve_CS_L.BCN

Application

Concentration 5.0.0.999

Operator

Instrument Settings

Instrument

Cary 60

Instrument version no.

2.00

Wavelength (nm)

235.0

Ordinate Mode

Abs

Ave Time (sec)

0.1000

Replicates

1

Standard/Sample averaging $\quad$ OFF

Weight and volume OFF corrections

Fit type Linear

$\begin{array}{ll}\text { Min } \mathrm{R}^{2} & 0.95000\end{array}$

Concentration units $\quad \mathrm{g} / \mathrm{L}$

Calibration

Collection time 5/20/2019 1:03:30 PM

Page 2 of 2 
5/20/2019 1:13:52 PM

$\begin{array}{lll}\begin{array}{l}\text { Standard } \\ \text { F g/L }\end{array} & \text { Concentration } & \text { Readings } \\ \text { Std 1 } & 0.00 & 0.1227 \\ \text { Std 2 } & 0.05 & 0.1401 \\ \text { Std 3 } & 0.10 & 0.1490 \\ \text { Std 4 } & 0.30 & 0.1833 \\ \text { Std 5 } & 0.80 & 0.2849 \\ \text { Calibration eqn } & \text { Abs }=0.19724 * \text { Conc }+0.12669 \\ \text { Correlation Coefficient } & 0.99750 \\ \text { Calibration } & \text { time 5/20/2019 } & \\ \text { 1:10:48 PM } & & \end{array}$

Analysis

Collection time $\quad$ 5/20/2019 1:10:48 PM

Read sequence cancelled

Results Flags Legend

$\mathrm{U}=$ Uncalibrated $\quad \mathrm{O}=$ Overrange

$\mathrm{N}=$ Not used in calibration $\quad \mathrm{R}=$ Repeat reading 


\section{A.2 Absorbance-Concentration Calibration Report II}

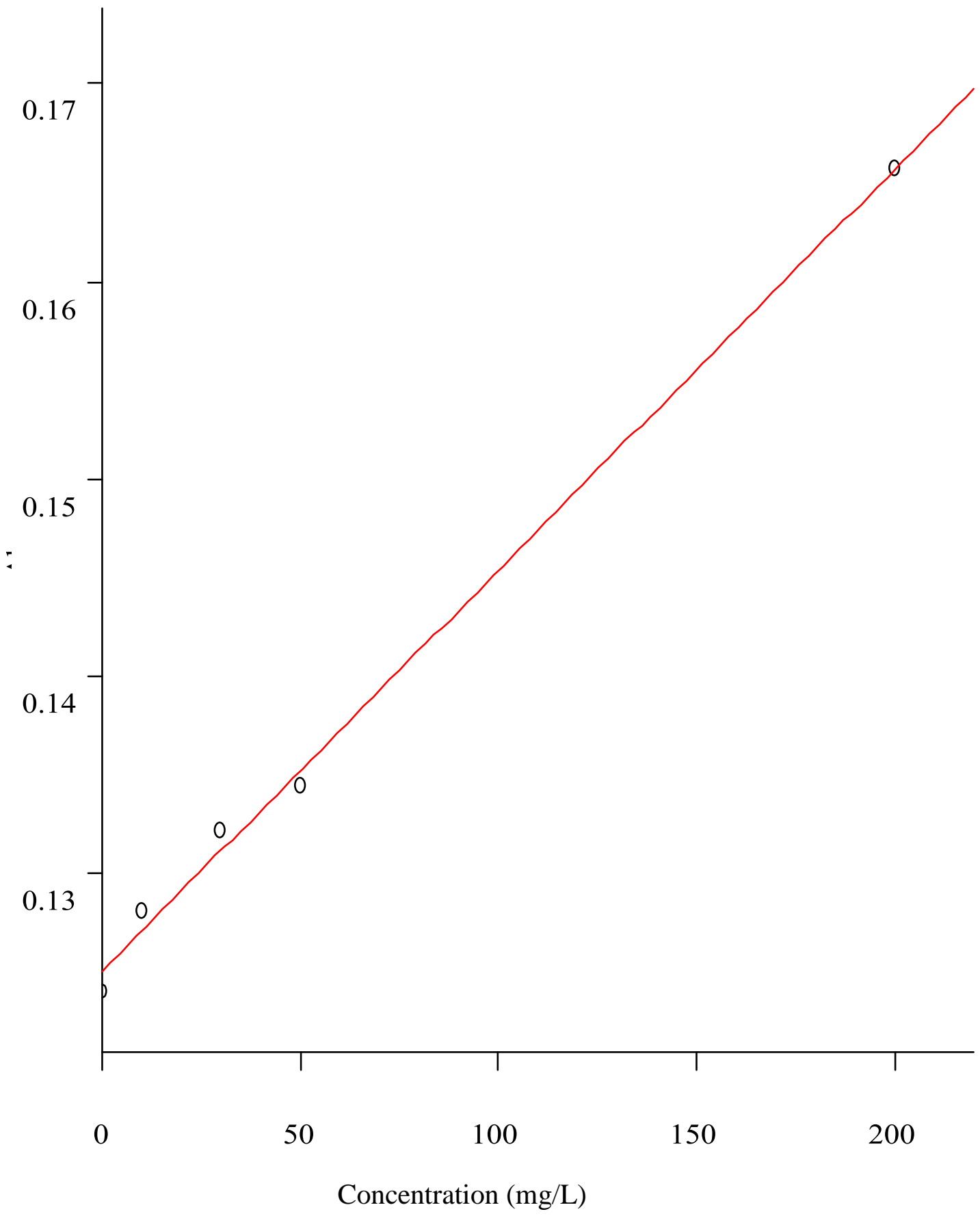

Appendix A 2:Absorbance-Concentration Calibration Report for Fall 2019 


\section{Concentration Analysis Report}

Report time

9/26/2019 3:50:08 PM

Method

Batch name

C:IUsers\Dr.

Da

Costa\Desktop\Henry\9.26.2019

(CS

Calibration)

Application

Concentration 5.0.0.999

Operator

Instrument Settings

Instrument

Cary 60

Instrument version no.

2.00

Wavelength (nm)

235.0

Ordinate Mode

Abs

Ave Time (sec)

0.1000

Replicates

1

Standard/Sample averaging $\quad$ OFF

Weight and volume $\mathrm{OFF}$ corrections

Fit type

\section{Linear}

$\operatorname{Min} \mathrm{R}^{2}$

0.95000

Concentration units

$\mathrm{mg} / \mathrm{L}$

Calibration

Collection time 


\section{Concentration Analysis Report}

Report time

9/26/2019 3:50:58 PM

Method

Batch name

C:IUsers\Dr.

Da

Costa\Desktop〈Henry\9.26.2019

(CS

Calibration)

Application

Concentration 5.0.0.999

Operator

Instrument Settings

Instrument

Cary 60

Instrument version no.

2.00

Wavelength (nm)

235.0

Ordinate Mode

Abs

Ave Time (sec)

0.1000

Replicates

1

Standard/Sample averaging $\quad \mathrm{OFF}$

Weight and volume $\mathrm{OFF}$ corrections

Fit type

Linear

$\operatorname{Min} \mathrm{R}^{2}$

0.95000

Concentration units

$\mathrm{mg} / \mathrm{L}$

Calibration

Collection time 9/26/2019

3:56:36 PM 


$\begin{array}{lcl}\begin{array}{l}\text { Standard } \\ \text { F mg/L }\end{array} & \text { Concentration } & \text { Readings } \\ \text { Std 1 } & 0.0 & 0.1240 \\ \text { Std 2 } & 10.0 & 0.1280 \\ \text { Std 3 } & 30.0 & 0.1321 \\ \text { Std 4 } & 50.0 & 0.1344 \\ \text { Std 5 } & 200.0 & 0.1657 \\ \text { Calibration eqn } & \text { Abs }=0.00020 * \text { Conc }+0.12506 \\ \text { Correlation Coefficient } & 0.99682 \\ \text { Calibration } & \text { time } 9 / 26 / 2019 & \\ \text { 4:04:21 PM } & & \end{array}$

Results Flags Legend

$\mathrm{U}=$ Uncalibrated $\quad \mathrm{O}=$ Overrange

$\mathrm{N}=$ Not used in calibration $\quad \mathrm{R}=$ Repeat reading 


\section{A.3 Conductivity-Salinity Calibration Curve}

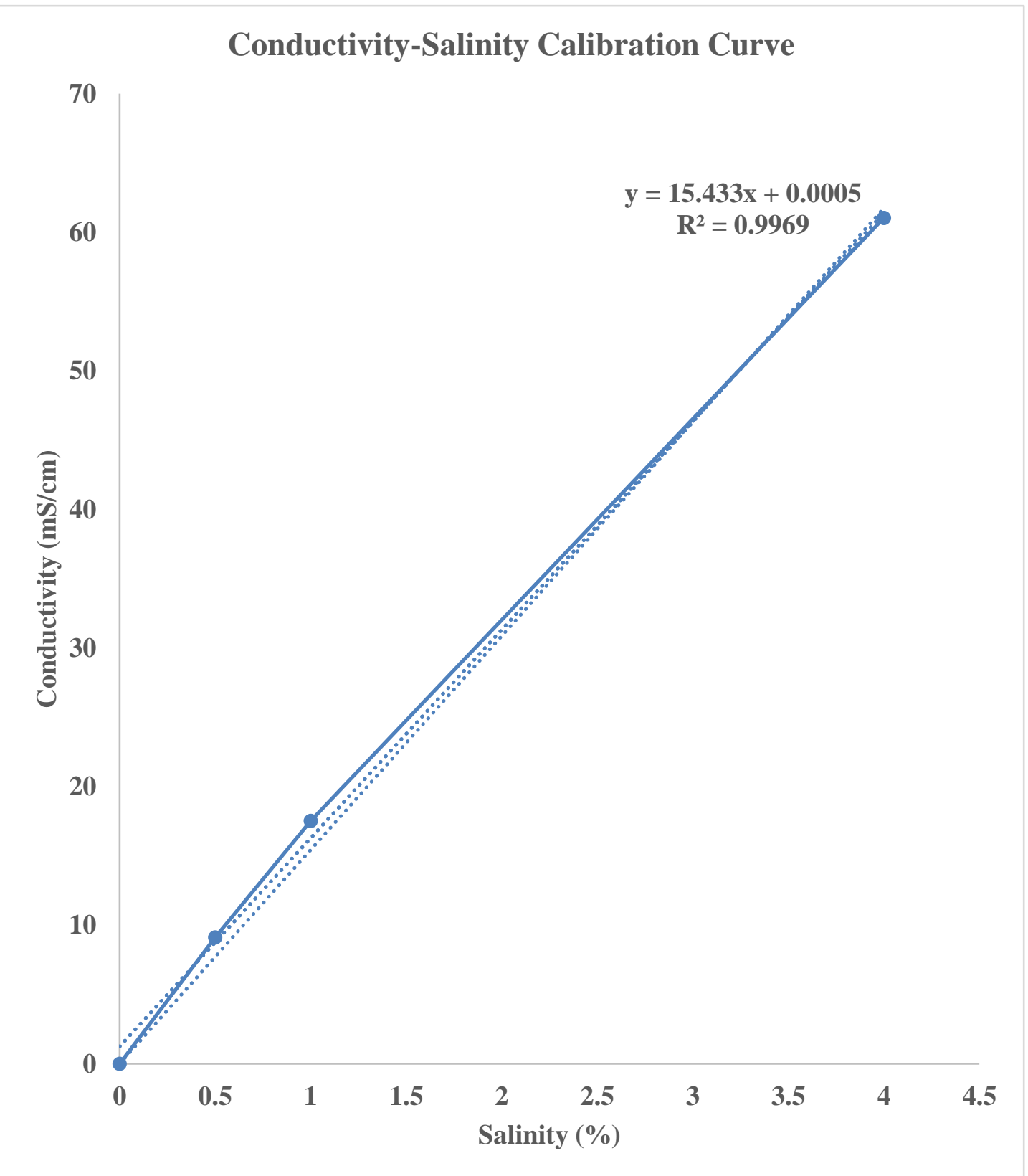

Appendix A 3: Conductivity-Salinity Calibration Curve 


\section{A.4 Data Description by Blocking Laws: Effect of Nanoparticle Concentration at 20psi}

\section{A.4.1 Standard Blocking}

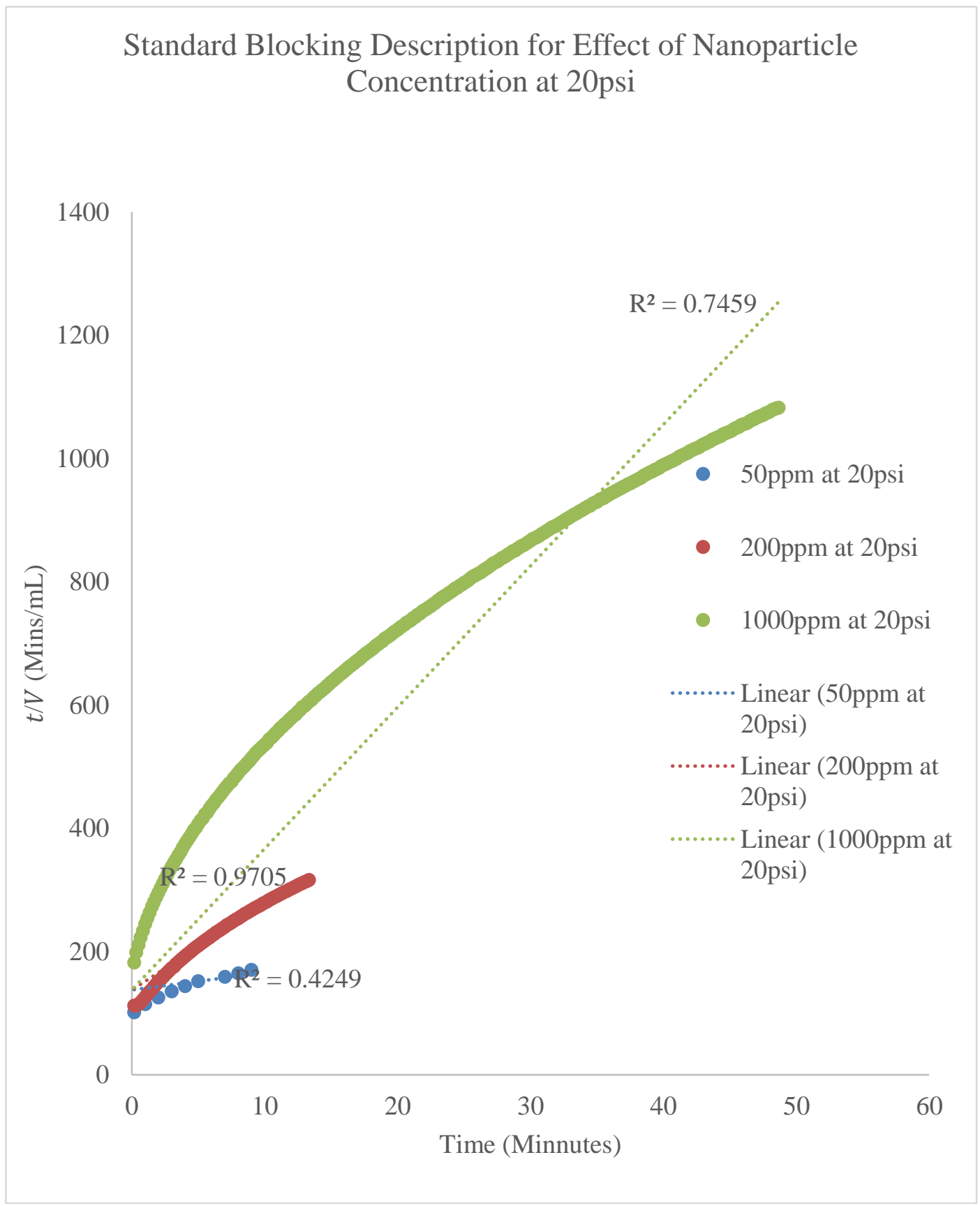

Appendix A 4 1: Standard Blocking Description for Effect of Nanoparticle Concentration at 20psi 


\section{A.4.2 Cake Filtration}

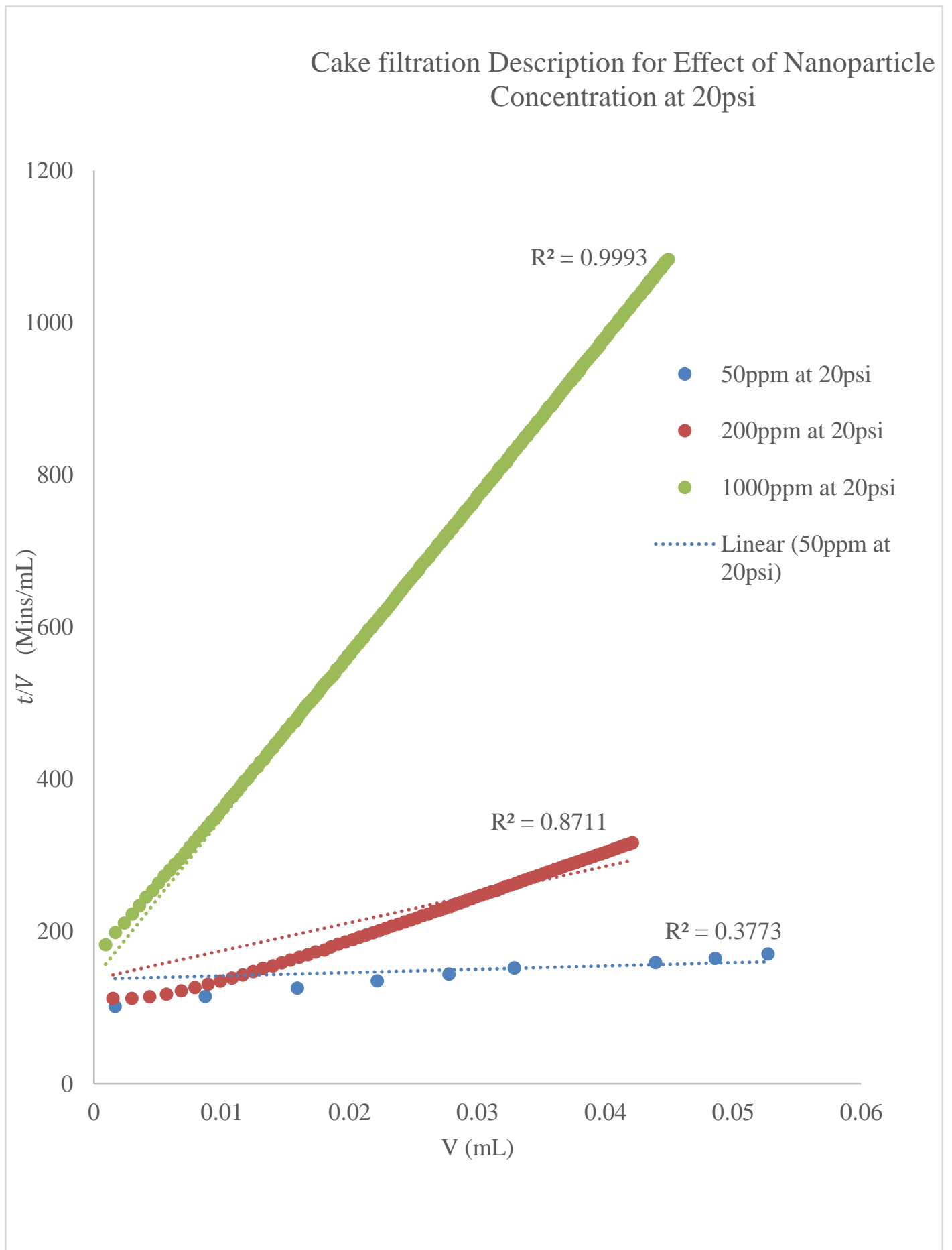

Appendix A 4 2:Cake Filtration Description for Effect of Nanoparticle Concentration at 20psi 


\section{A.4.3 Intermediate Blocking}

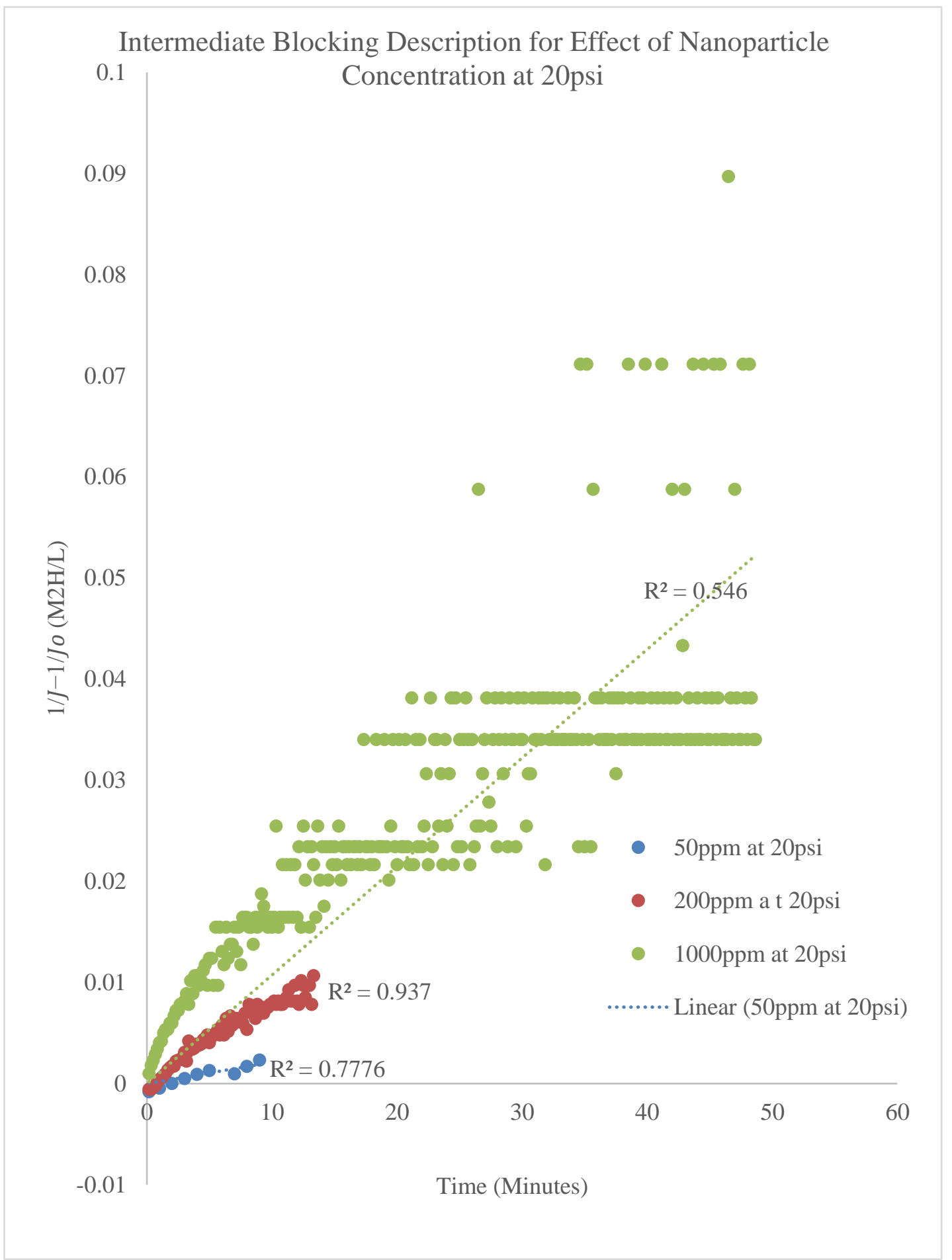

Appendix A 4 3: Intermediate Blocking Description for Effect of Nanoparticle Concentration at 20psi 


\section{A.4.4 Complete Blocking}

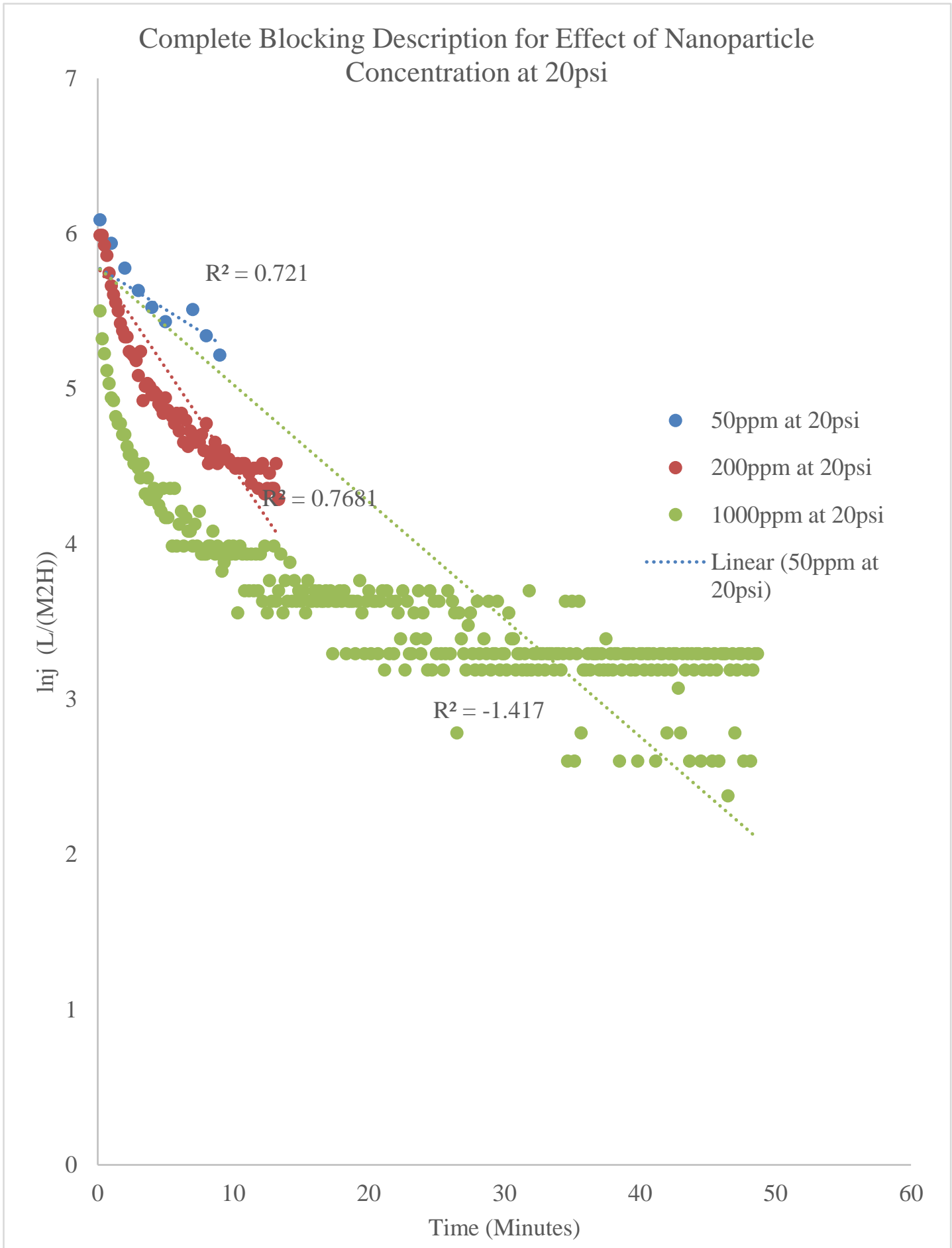

Appendix A 4 4:Complete Blocking Description for Effect of Nanoparticle Concentration at 20psi 


\section{A.5 Data Description by Blocking Law: Effect of Nanoparticle Concentration at 50psi}

\section{A.5.1 Standard Blocking}

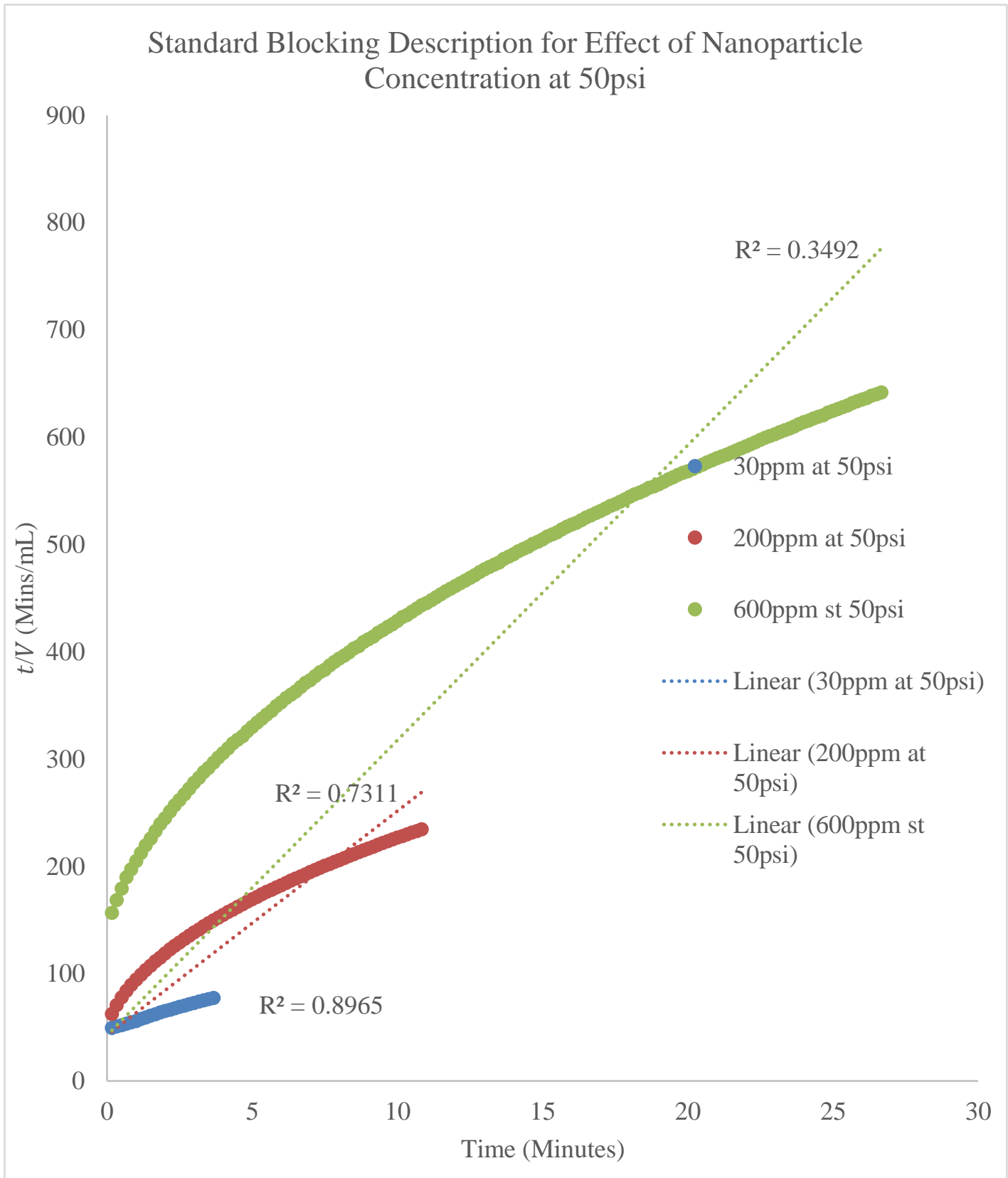

Appendix A 5 1:Standard Blocking Description for Effect of Nanoparticle Concentration at 50psi

\section{Cake Filtration}




\section{A.5.2 Cake Filtration}

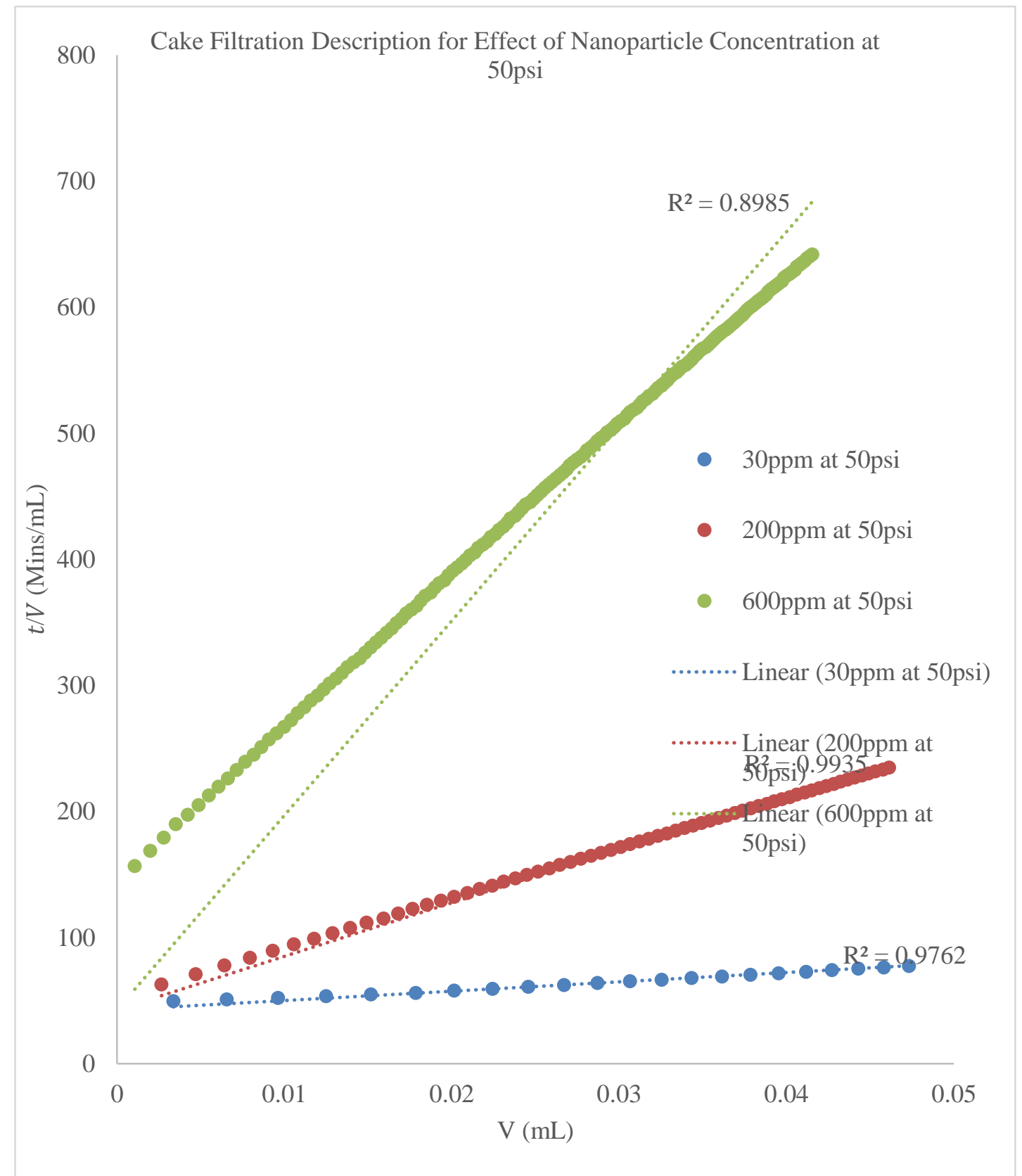

Appendix A 5 2:Cake Filtration Description for Effect of Nanoparticle Concentration at $50 \mathrm{psi}$ 


\section{A.5.3 Intermediate Blocking}

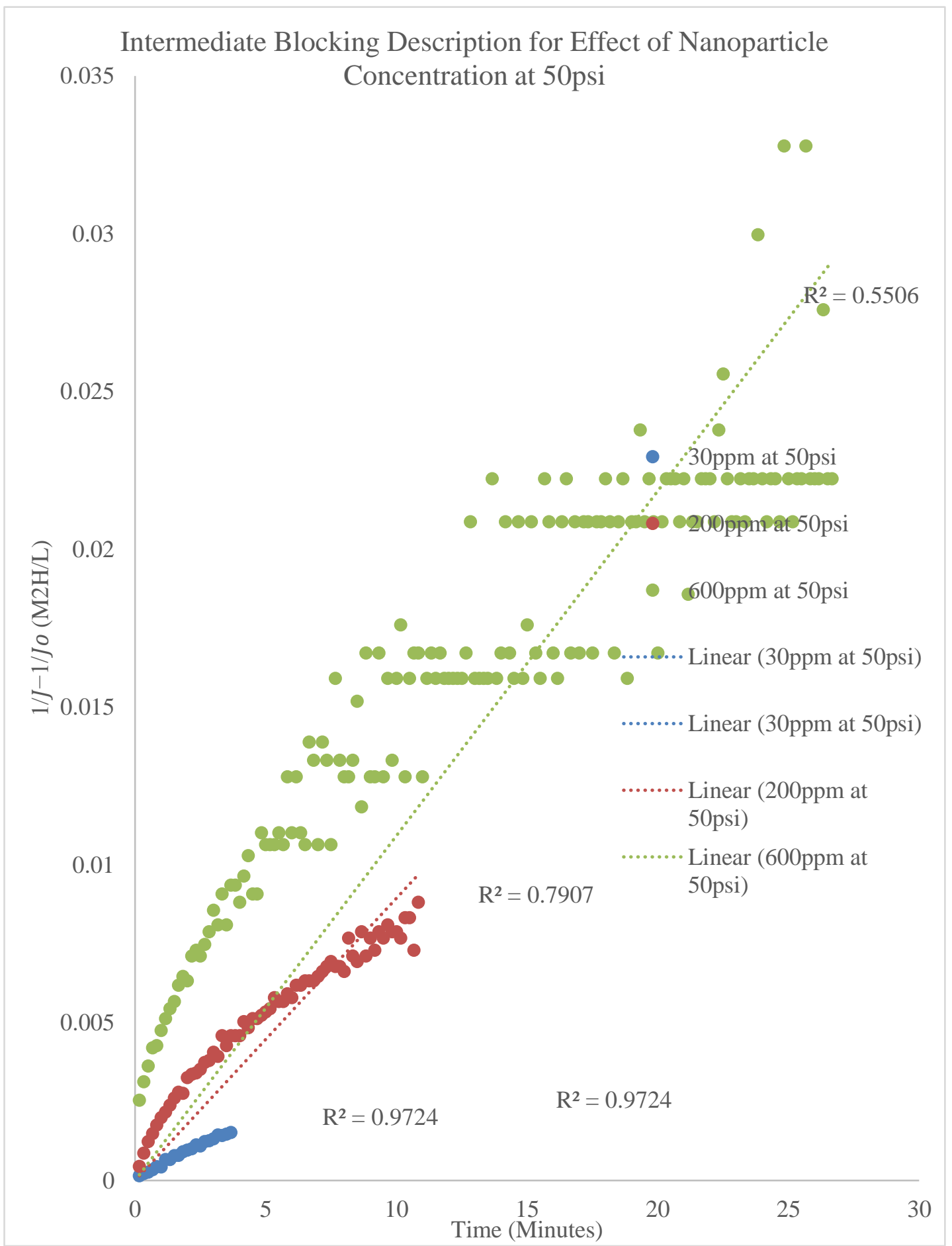

Appendix A 5 3:Intermediate Blocking Description for Effect of Nanoparticle Concentration at 50psi 


\section{A.5.4 Complete Blocking}

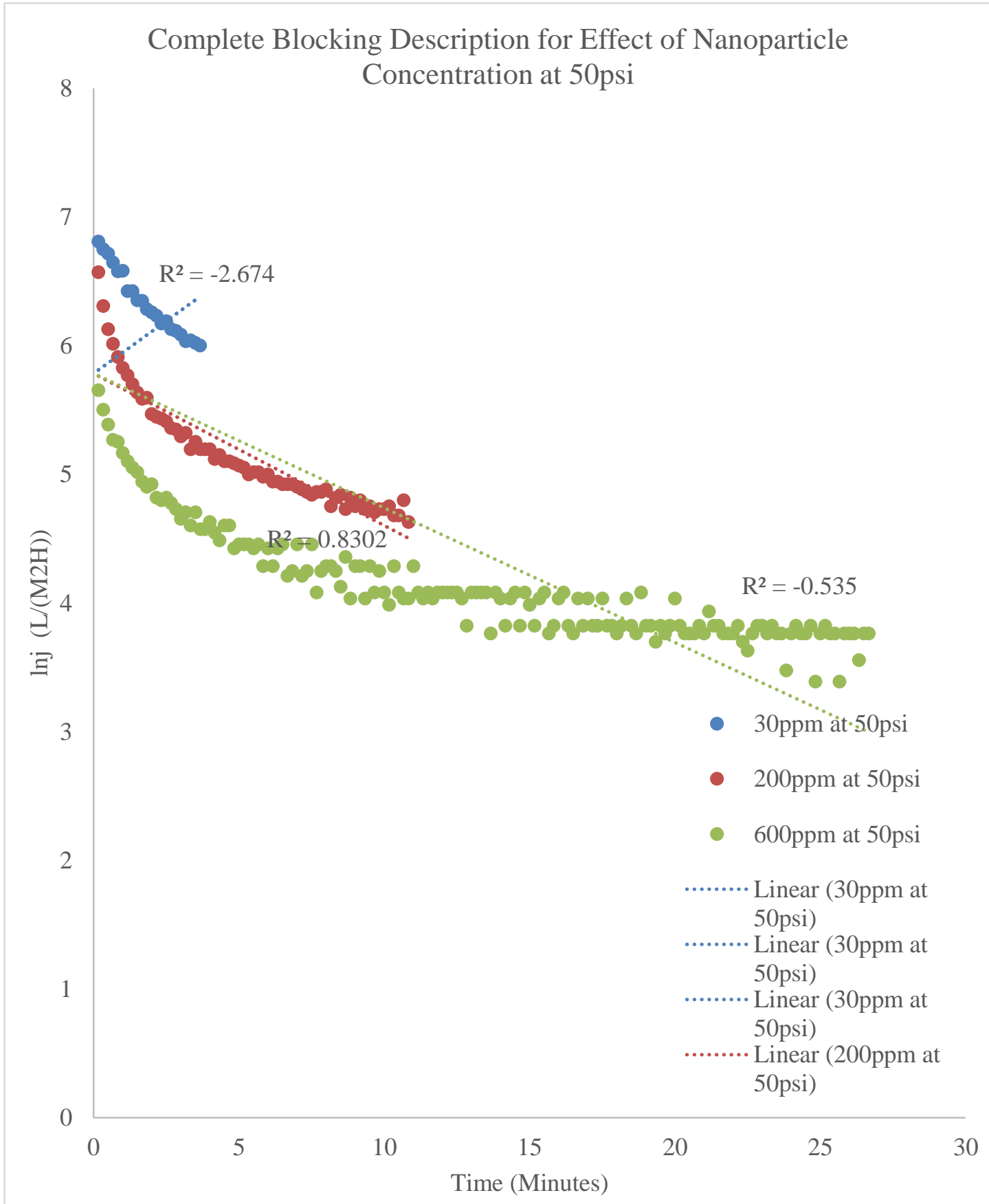

Appendix A 5 4:Complete Blocking Description for Effect of Nanoparticle Concentration at 50psi 


\section{B Sample Calculations}

\section{B.1 Calculation used for feed sample preparation by dilution.}

Using the dilution formula:

$$
C_{1} V_{1}=C_{2} V_{2}
$$

Where $C_{1}$ and $C_{2}$ are silica nanoparticle concentration in the stock solution and prepared feed sample, respectively. $V_{1}$ is the volume of the stock solution needed to prepare a desired volume of the feed sample $\left(\mathrm{V}_{2}\right)$.

Stock solution used is $50 \%$ CS concentration. CS: colloidal silica

To prepare $200 \mathrm{~mL}$ of $1 \%$ CS concentration using the $50 \%$ CS stock solution:

Here, $\mathrm{C}_{1}=50 \%, \mathrm{C}_{2}=1 \%$ and $\mathrm{V}_{2}=200 \mathrm{~mL}$, the volume of stock solution needed $\left(\mathrm{V}_{1}\right)$ is obtained as shown below:

$\mathrm{V} 1=\frac{C_{2} V_{2}}{C_{1}}=\frac{1 \% \times 200 \mathrm{~mL}}{50 \%}=4 \mathrm{~mL}$

Therefore, $4 \mathrm{~mL}$ of the stock solution will be made up with $196 \mathrm{~mL}$ of distilled water to obtain $200 \mathrm{~mL}$ of $1 \%$ CS feed sample.

\section{B.2 Calculation used for description by blocking laws: effect of nanoparticle concentration}

Experimental results obtained for effect of nanoparticle concentration using $10 \mathrm{KDa}$ membranes were fitted with following blocking laws:

Cake filtration [98]: $\frac{t}{V}=\frac{K_{c}}{2} V+\frac{1}{Q_{o}}$

Standard blocking [98]: $\frac{t}{V}=\frac{K_{s}}{2} t+\frac{1}{Q_{o}}$

Intermediate blocking [99]: $\frac{1}{J}-\frac{1}{J_{o}}=K_{i} t$

complete blocking [99]: $\ln (\mathrm{J})=\ln \left(J_{o}\right)-K_{b} t$

where $\mathrm{t}$ is time, $\mathrm{V}$ is the cumulative permeate volume at any time $\mathrm{t}$ during the filtration (represented hereafter as sum_v), $\mathrm{J}$ is permeate flux at any time $\mathrm{t}$ and $J_{o}$ is diwater flux 
on pristine membrane, $Q_{o}\left(=\frac{J_{o}}{\text { membrane surface area }}\right)$ is the diwater flowrate on pristine membrane and $K_{c}, K_{s}, K_{i}$ and $K_{b}$ are the blocking constants corresponding to the four filtration laws.

Variables plotted and the calculation for intercept used in each case are outlined below:

\section{- Data Fitting with Standard Blocking Law}

Plot t/sum_v vs t,

Where intercept $\frac{1}{q_{o}}=\frac{60}{J_{o} \times A} \quad J_{o}$ is the distilled water flux at a given pressure and $\mathrm{A}$ is the effective surface area of the membrane used. 60 in the numerator converts the filtration time from hour to minutes.

For example for 10KDa GE Osmonics ${ }^{\mathrm{TM}}$ membrane at 50psi, $J_{o}=1050$ and $\mathrm{A}=0.00134$ $\mathrm{m}^{2}$, the intercept of the plot of Plot t/sum_v vs t should be set at $\frac{1}{q_{o}}=42.64$

\section{- Data Fitting with Model for Cake Filtration}

Plot t/sum_v vs sum_v,

Where intercept $\frac{1}{q_{o}}=\frac{60}{J_{o} \times A} \quad J_{o}$ is the distilled water flux at a given pressure and A is the effective surface area of the membrane used. 60 in the numerator converts the filtration time from hour to minutes.

For example, for $10 \mathrm{KDa} \mathrm{GE}$ Osmonics ${ }^{\mathrm{TM}}$ membrane at 50psi, $J_{o}=1050$ and $\mathrm{A}=$ $0.00134 \mathrm{~m}^{2}$, the intercept of the plot of Plot t/sum_v vs t should be set at $\frac{1}{q_{o}}=42.64$

\section{- Data Fitting with Intermediate Blocking Law}

Plot $\frac{1}{J}-\frac{1}{J_{o}}$ vs t, with no intercept; set the intercept to pass through the origin.

\section{- Calculation used for Data Fitting with Complete Blocking Law}

Plot lnj vs t, Where intercept $=\ln J_{o}$ For example, for 10KDa GE Osmonics ${ }^{\mathrm{TM}}$ membrane at 50psi, $J_{o}=1050, \ln J_{o}=5.7838$, the intercept of the plot of lnj vs t should be set at 5.7838 


\section{Equipment Images and Experimental Setup}

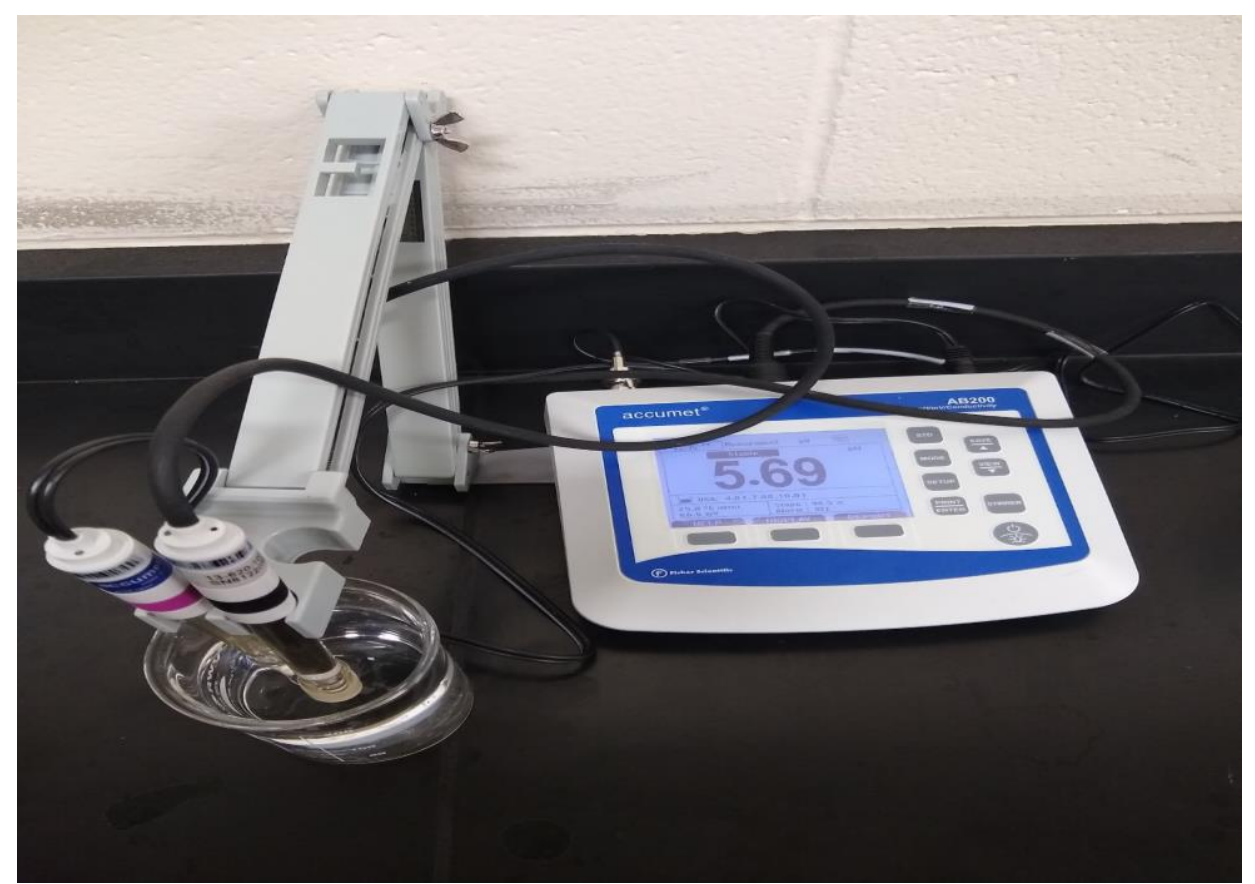

Appendix C 1:Accumet $\mathrm{pH}$ meter

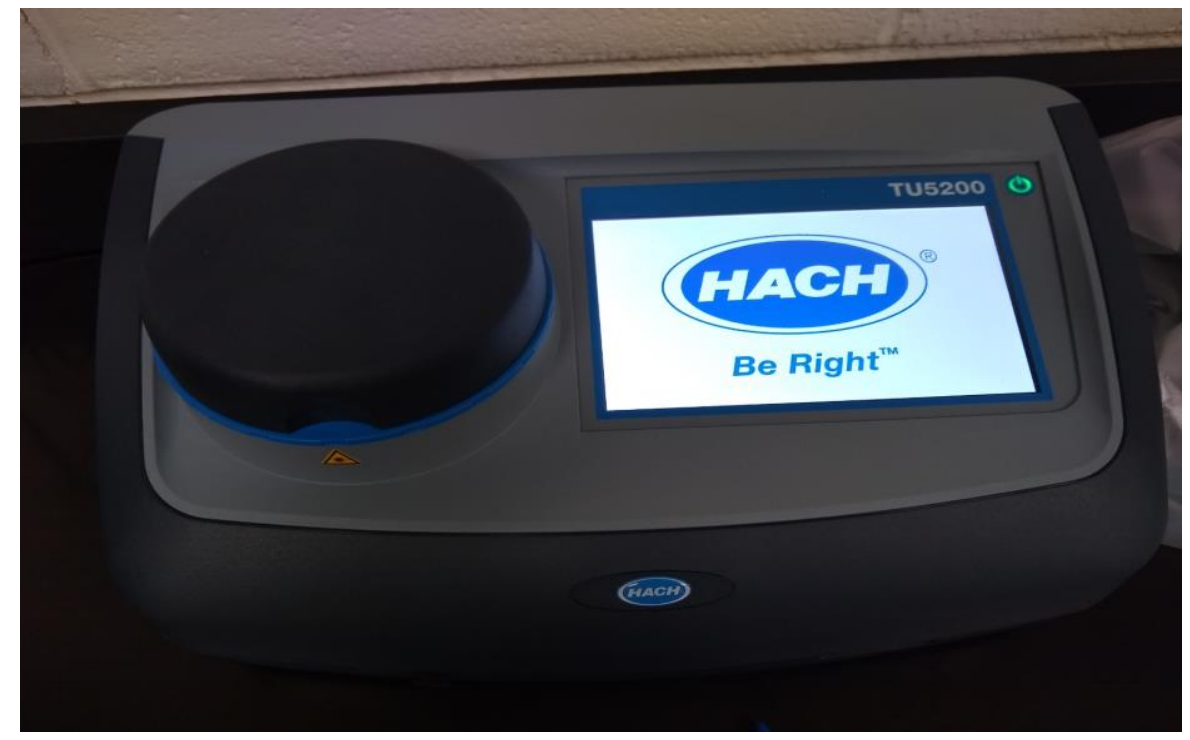

Appendix C 2:Digital Hach Turbidimeter 


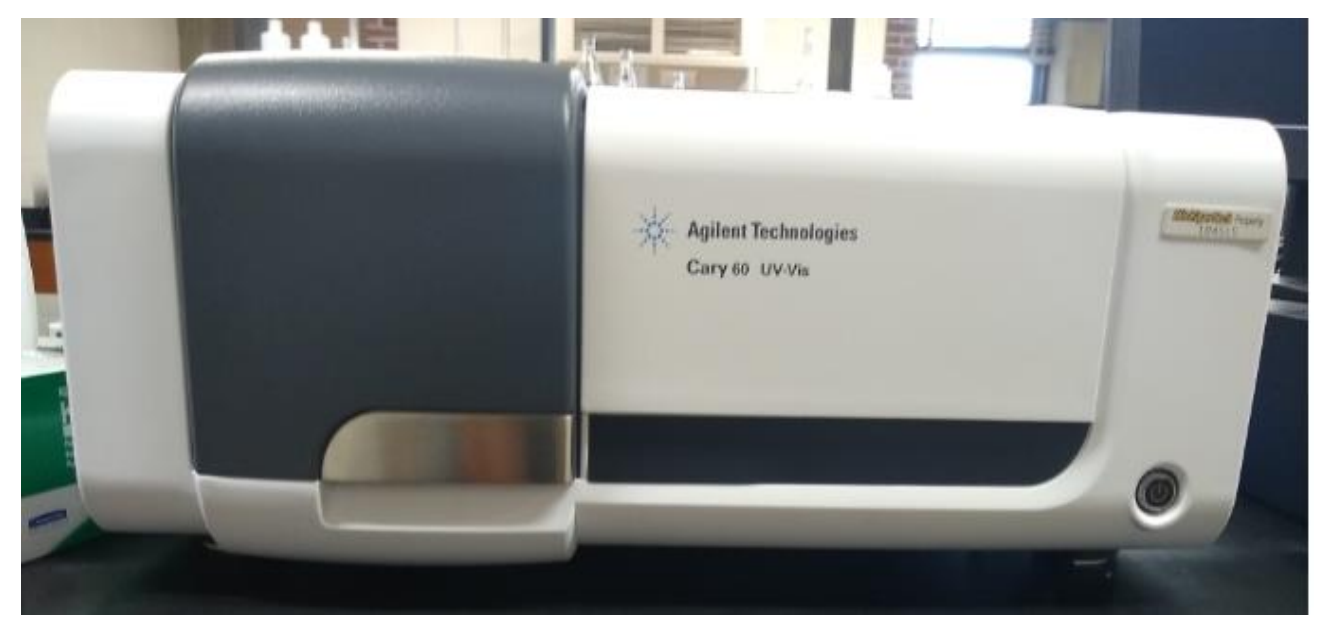

Appendix C 3:Cary 60 UV-vis Spectrophotometer for Concentration

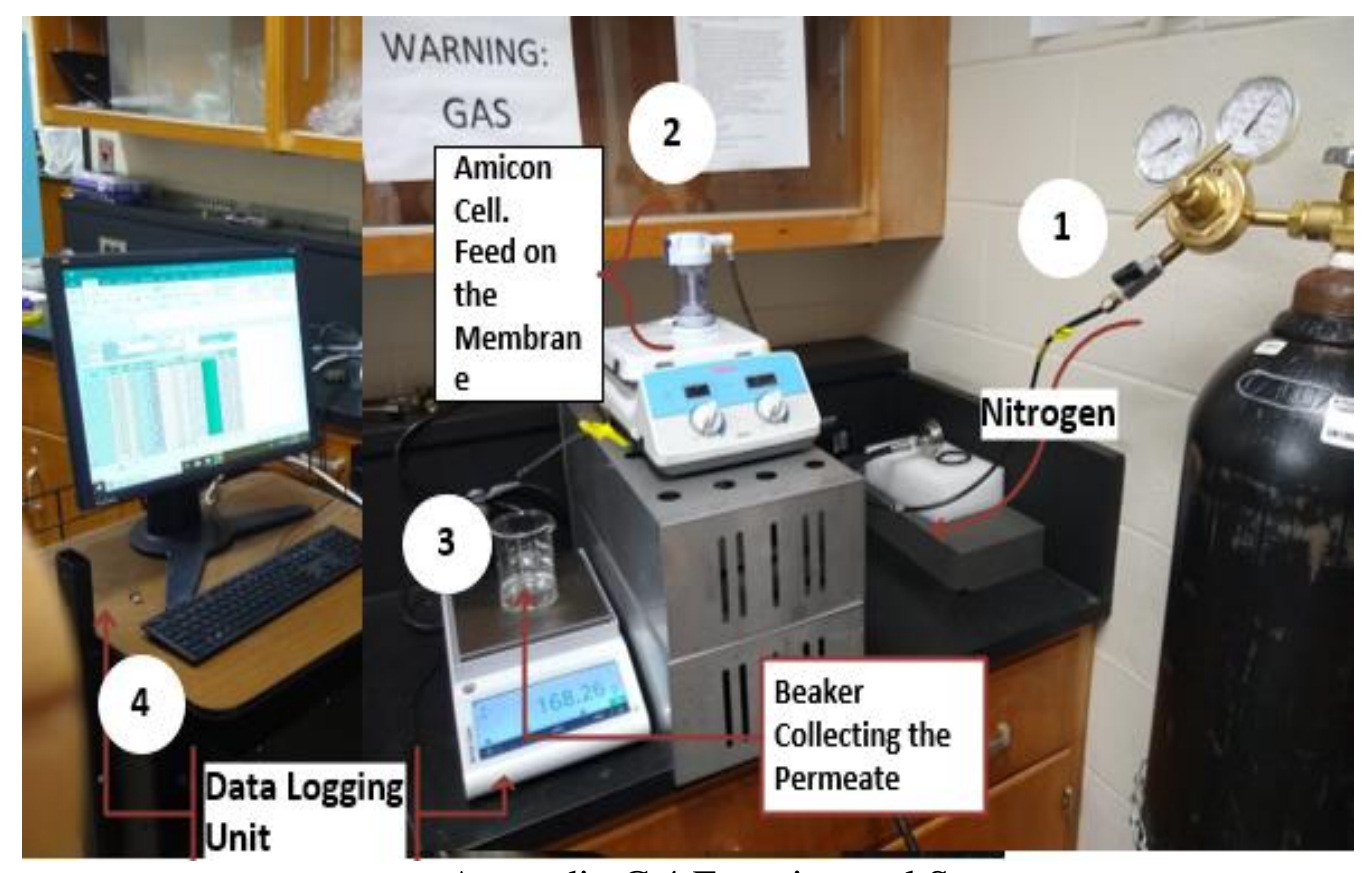

Appendix C 4:Experimental Set-up 


\section{Copyright documentation}

Figure 3.1: "Conventional Municipal Water Treatment Scheme I" by Milwaukee Water Works. Consumer Confidence Report Licensed under Public Domainhttps://city.milwaukee.gov/ImageLibrary/Groups/WaterWorks/ConsumerConfidence-Reports/2018ConsumerConfidenceReport.pdf. Last accessed November 2019

Figure 3.2: "Conventional Municipal Water Treatment Scheme II" by City of Saginaw. Licensed under Public Domain - https://www.saginawmi.com/departments/wastewaterandwatertreatmentservices/watertreatment/watertreat mentprocess.php. Last accessed November 2019. 